\title{
The millipede genus Tylopus Jeekel, 1968 (Diplopoda, Polydesmida, Paradoxosomatidae), with a key and descriptions of eight new species from Indochina
}

\author{
Natdanai LIKHITRAKARN ${ }^{1}$, Sergei I. GOLOVATCH ${ }^{2, *}$ \& Somsak PANHA 3 ,** \\ ${ }^{1}$ Division of Plant Protection, Faculty of Agricultural Production, \\ Maejo University, Chiang Mai 50290, Thailand. \\ ${ }^{2}$ Institute for Problems of Ecology and Evolution, Russian Academy of Sciences, \\ Leninsky pr. 33, Moscow 119071, Russia. \\ ${ }^{3}$ Animal Systematics Research Unit, Department of Biology, Faculty of Science, \\ Chulalongkorn University, Bangkok 10330, Thailand. \\ 1Email: kongerrrr@hotmail.com \\ 2,*Corresponding author: sgolovatch@yandex.ru \\ 3,*Corresponding author: somsak.pan@ chula.ac.th \\ ${ }^{1}$ urn:1sid:zoobank.org:author:442E2E6E-1CB3-47B2-9896-1A922CE509E1 \\ ${ }^{2}$ urn:lsid:zoobank.org:author:71532F45-BDD5-415D-BC54-86256E5D5D4A \\ ${ }^{3}$ urn:1sid:zoobank.org:author:AC935098-D901-4F35-A414-4B0D4FE44E79
}

\begin{abstract}
The Indochinese to southern Chinese millipede genus Tylopus currently comprises 62 species, including eight new ones: T. flavolineatus sp. nov., T. hongkhraiensis sp. nov. from central and northern Thailand, respectively, T. moniliformis sp. nov., T. retusus sp. nov., T. acuminatus sp. nov., T. dorsalis sp. nov., T. thunghaihin sp. nov., all from Laos, and T. punctus sp. nov. from northern Myanmar. A new record of T. baenzigeri Golovatch \& Enghoff, 1993, from northern Thailand is given. All these species are richly illustrated, and a modified key to all known species of the genus is also provided.
\end{abstract}

Keywords. Myriapoda, Taxonomy, Thailand, Laos, Myanmar.

Likhitrakarn N., Golovatch S.I. \& Panha S. 2016. The millipede genus Tylopus Jeekel, 1968 (Diplopoda, Polydesmida, Paradoxosomatidae), with a key and descriptions of eight new species from Indochina. European Journal of Taxonomy 195: 1-47. http://dx.doi.org/10.5852/ejt.2016.195

\section{Introduction}

Tylopus Jeekel, 1968, has long been recognized as one of the largest and widespread millipede Oriental genera in the entire family Paradoxosomatidae (Likhitrakarn et al. 2010). This genus has been reviewed and rediagnosed several times, chiefly in the context of adding new species (Jeekel 1965, 1968; Golovatch \& Enghoff 1993; Likhitrakarn et al. 2010). One of the most recent updates considers and keys 41 species (Likhitrakarn et al. 2010), followed by Nguyen (2012) who added five new congeners from Vietnam and provided a key and a distribution map to all 13 Tylopus known to occur in that country. Liu \& Luo 
(2013), and Golovatch $(2013,2014)$ described a few other new Tylopus species from southern China. The latest review of Tylopus in Thailand (Likhitrakarn et al. 2014a) provides a new distribution map and an updated key to all 32 species known to occur in Thailand. As a result, Tylopus is currently recognized as the largest genus of Diplopoda in the Oriental realm, comprising 54 described species ranging from southern China (6) to Myanmar (2), Laos (1), Thailand (32) and Vietnam (18).

Almost all Tylopus species appear to be confined to high montane forest habitats (Likhitrakarn et al. 2014a), usually representing highly local endemics. This genus is readily distinguished from all Sulciferini (Paradoxosomatidae) except Oxidus Cook, 1911, by gonopodal postfemoral lamina I being separated from the femorite by a more or less distinct transverse sulcus, from the oligotypic Oxidus by the number and location of postfemoral outgrowths or processes (Golovatch \& Enghoff 1993). In addition, most of Tylopus species show adenostyles (= ventral outgrowths) at least on some of the male legs. Only very few species, e.g., T. peramatus Hoffman, 1973, which is quite widespread in northern Thailand (Hoffman 1973; Likhitrakarn et al. 2010), demonstrate evident variations in gonopod structure, whereas it is gonopod conformation that provides many of the key characters for species identification.

Numerous Tylopus species are found to occur sympatrically in such larger montane areas as Doi Inthanon (10 species) and Doi Suthep national parks (again 10 species, mostly different) (Likhitrakarn et al. 2010, 2014a) in Thailand, but the adult, identifiable stages of at least some of them seem to represent distinct phenofaunas restricted to rather short time periods which fail to overlap with others.

The present paper puts on record another eight new species of Tylopus, this time from Myanmar, Thailand and Laos, and their distributions are mapped. A new, modified key to all 62 species of the genus is also given.

\section{Material and methods}

New material was collected from northern Thailand and southern Laos from 2008 to 2014 by SP and members of the Animal Systematics Research Unit, Chulalongkorn University. Live animals were photographed in the laboratory. Specimens were preserved in $75 \%$ ethanol, and morphological investigations were carried out in the laboratory using an Olympus stereo microscope. Scanning electron micrographs (SEM) of gonopods coated with gold were taken using a JEOL, JSM-5410 LV microscope, and returned to alcohol after examination to ultimately be stored in the alcohol collection. Digital images of the specimens were taken in the laboratory and assembled using the "Cell of the Olympus Soft Imaging Solution GmbH package. In addition, line drawings of gonopods were also prepared. All holotypes, as well as most of the paratypes, are kept in the Museum of Zoology, Chulalongkorn University (CUMZ), Bangkok, Thailand; some duplicates were also donated to the collections of the Natural History Museum of Denmark, University of Copenhagen, Denmark (ZMUC), the Zoological Museum, State University of Moscow, Russia (ZMUM), and the Naturhistorisches Museum Wien, Austria (NHMW), as indicated in the text. The types of one species from Myanmar were revised using the NHMW collection.

Collecting sites were located by GPS using the WGS84 datum.

The terminology concerning gonopod structure and body characters mostly follows Golovatch \& Enghoff (1993) and Likhitrakarn et al. (2010). 


\title{
Results
}

\section{Taxonomic descriptions}

\author{
Class Diplopoda Blainville-Gervais, 1844 \\ Order Polydesmida Leach, 1814 \\ Family Paradoxosomatidae Daday, 1889 \\ Subfamily Paradoxosomatidae Daday, 1889 \\ Tribe Sulciferini Attems, 1898 \\ Genus Tylopus Jeekel, 1968 \\ Tylopus flavolineatus sp. nov. \\ urn:Isid:zoobank.org:act:4A4DA74B-774B-45F5-A60F-96EB516022D2
}

Figs $1-3,26$

\section{Diagnosis}

Differs in the presence of middle and lateral yellow stripes on the body, by the sterna bearing evident cones caudally near each coxa, and in $\delta$ femur 5 showing a large distovental adenostyle, coupled with the gonopods being rather slender, with a quite large, slightly curved and pointed process $\mathbf{h}$.

\section{Etymology}

To emphasize the middle and lateral yellow stripes on the body; adjective.

\section{Material examined}

\section{Holotype}

THAILAND: ${ }^{\top}$, Wat Tham Santisuk, Nong Muang, Lopburi, 15²12'10" N, 100³9'50" E, 145 m a.s.1., 7 Jun. 2008, leg. C. Sutcharit \& N. Likhitrakarn (CUMZ).

\section{Paratypes}

THAILAND: 2 ふึग, 2 우 (CUMZ), same data as for holotype.

\section{Description}

MEASUREMENTS AND COLOUR. Length 13.8-16.4 $\left({ }^{\Uparrow}\right)$ or $14.2-16.5 \mathrm{~mm}(+$ ) , width of midbody pro- and metazonae $0.83-0.92$ and $1.21-1.33 \mathrm{~mm}\left({ }^{\Uparrow}\right)$ or $1.19-1.28$ and $1.68-1.73 \mathrm{~mm}(+)$, respectively. Coloration of alcohol material after six years of preservation dark brown; a pair of paramedian longitudinal stripes flanking a narrow, sometimes vague, brown, axial line; paraterga and area of pleurosternal carinae contrasting light yellow to yellowish; legs and venter dark brown to dark yellow (Fig. 1).

HeAD. Clypeolabral region densely, vertex sparsely, setose; epicranial suture distinct. Antennae rather short (Fig. 1B), clavate (antennomere 6 highest), extending behind body segment $3\left(\delta^{\Uparrow}\right)$ or $2(+)$ when stretched dorsally. In width, segment $2=3<$ head $<$ collum $<$ segment $4<5-15$; thereafter body gently and gradually tapering. Collum with three transverse rows of very small setigerous tubercles: $6+6$ anterior, $4+4$ intermediate and $5+5$ posterior; with a small lateral denticle at about $1 / 3$ collum length in front of caudal corner; the latter very broadly rounded anteriorly, declined ventrad, caudal corner not surpassing rear tergal margin.

BoDy. Tegument smooth and shining, prozonae and surface below paraterga largely finely shagreened, metaterga rather smooth and leathery, posterior halves faintly rugulose, surface below paraterga finely microgranulate (Fig. 1A-G). Postcollum metaterga with four transverse rows of very small setigerous

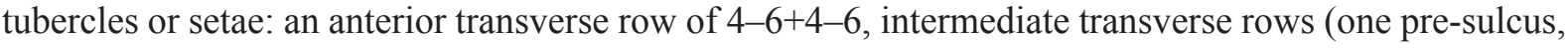


the other post-sulcus) of 3-4+3-4, and a posterior transverse row of 5-7+5-7; tergal setae long, strong, slender, about $2 / 3$ of metatergal length (Fig. 1A, D, F). Axial line visible both on pro- and metazonae. Paraterga well-developed (Fig. 1A, D, F), especially so in ${ }^{\lambda}$, lying rather high (at upper $1 / 3$ of body height), anterior edge rounded and narrowly bordered, fused to callus; caudal corner very narrowly rounded to pointed. Paraterga 2 and 3 each with two evident setigerous incisions at lateral edge (Fig. 1A). Following poreless segments with two evident setigerous incisions; following pore-boring segments often with one incision in front of pore (Fig. 1C-D). Calluses on paraterga delimited by a sulcus both dorsally and ventrally. Ozopores evident, lateral, lying in an ovoid groove at about $1 / 4$ metatergal length in front of posterior edge of metaterga. Transverse sulcus usually distinct (Fig. 1A, D, F), slightly incomplete on segments 4 and 19, complete on segments 5-18, rather wide, line-shaped, rather deep, not reaching bases of paraterga, beaded at bottom. Stricture between pro- and metazonae evident, wide and rather deep, ribbed at bottom down to base of paraterga (Fig. 1A, C-F). Pleurosternal carinae complete crests with a sharp caudal tooth on segments 2 and 3 , thereafter increasingly reduced and broken, remaining as a front bulge and a caudal tooth until segment $10(\widehat{)})$ or $6($ ( ) $)$, on following segments retained as a small caudal tooth until segment $18\left({ }^{\Uparrow}\right)$ or absent starting with segment 7 (ㅇ). Epiproct (Fig. 1E-G) conical, flattened dorsoventrally, with two evident, small, rounded apical papillae; tip subtruncate; pre-apical
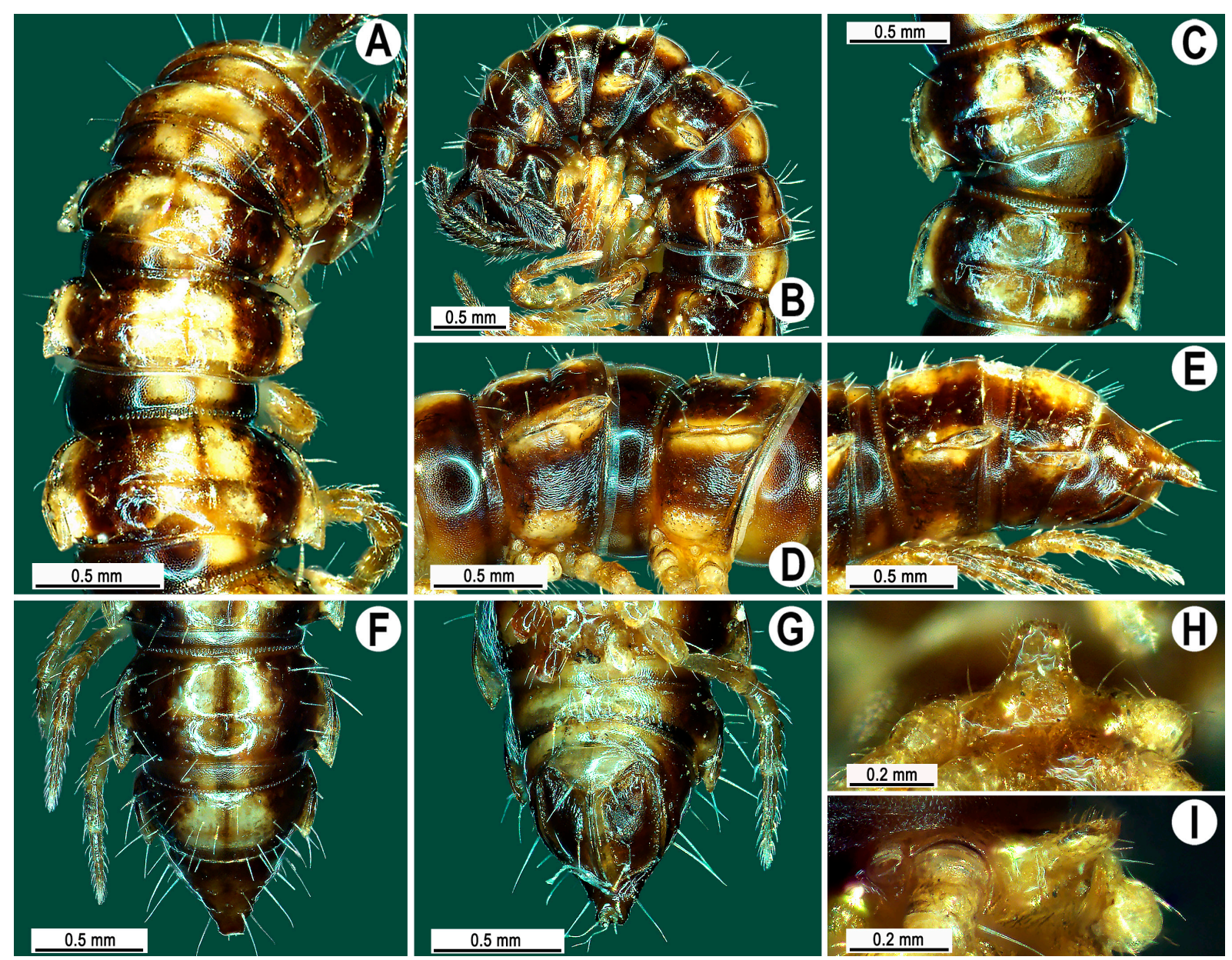

Fig. 1. Tylopus flavolineatus sp. nov., holotype, $\widehat{\partial}$ (A, C-I), paratype, $\widehat{\partial}(\mathbf{B})$. A-B. Anterior part of body, dorsal and lateral views, respectively. C-D. Segments 10 and 11, dorsal and lateral views, respectively. E-G. Posterior part of body, lateral, dorsal and subventral views, respectively. H-I. Sternal cones between coxae 4 , caudal and sublateral views, respectively. 
lateral papillae evident, lying close to tip. Hypoproct roundly subtriangular, setigerous knobs at caudal edge small and well-separated (Fig. 1G).

Sterna. Densely setose, with a small, but evident cone caudally near each coxa, rear cones being a little larger than fore ones (Fig. 2E); an entire, large, tongue-shaped sternal lobe between $\widehat{\partial}$ coxae 4 (Fig. 1H, I). Legs rather long and slender, midbody ones ca 1.2-1.3 (ठ) or 0.9-1.0 (ㅇ) as long as body

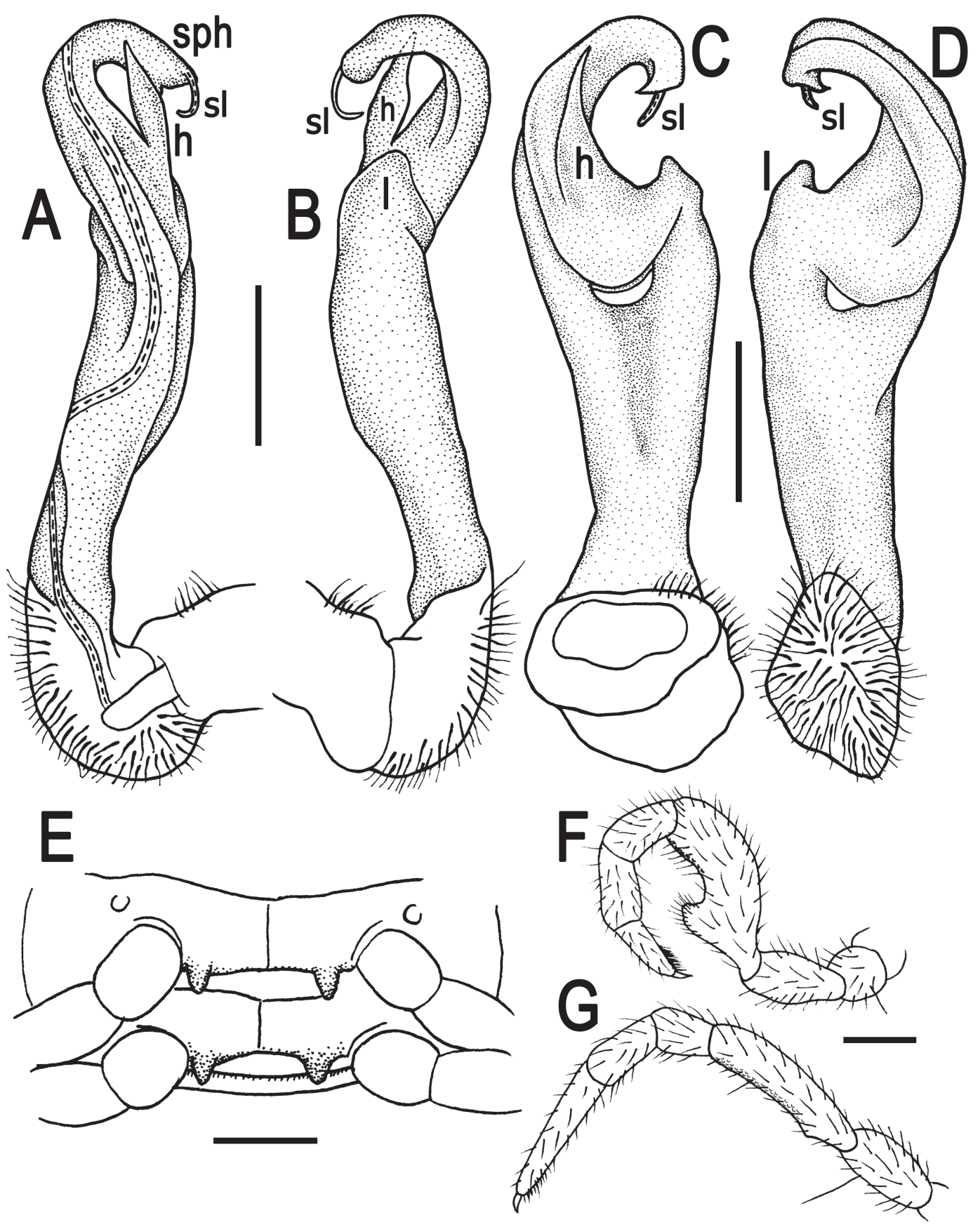

Fig. 2. Tylopus flavolineatus sp. nov., holotype, $\widehat{\partial}$, left gonopod. A-D. Mesal, lateral, caudal and suboral views, respectively. E. Sterna of segment 10. F. Leg 6. G. Leg 10. Scale bars $=0.5 \mathrm{~mm}$. Abbreviations are explained in the text. 
height (Fig. 2G); $\partial^{\lambda}$ femora 5 (Fig. 2F) each with a very strong, distovental, densely pilose adenostyle in distal $1 / 3$, ô prefemora 10-12 each with a small parabasal adenostyle (Fig. 2G); ô prefemora 2 until segment 12 each with microgranulations; tarsal brushes present until $\partial$ leg 6 .

GoNOPOD. Rather simple (Figs 2A-D, 3); coxa slightly curved caudad, sparsely setose distoventrally. Prefemur as usual, densely setose, about $1 / 3$ as long as femorite + postfemoral part. Femorite slightly curved and rather slender, with an evident mesal groove and a strong distolateral sulcus demarcating a postfemoral part; lobe $\mathbf{I}$ rather small, rounded apically, process $\mathbf{h}$ large, slightly curved and pointed; solenophore ( $\mathbf{s p h}$ ) clearly curved mesad, long, vaguely bifid, lamina medialis supporting a long flagelliform solenomere (sl).

\section{Remark}

In the normal condition, the solenomere is sheathed by the solenophore (Fig. 2A-D), broken off in Fig. 3.

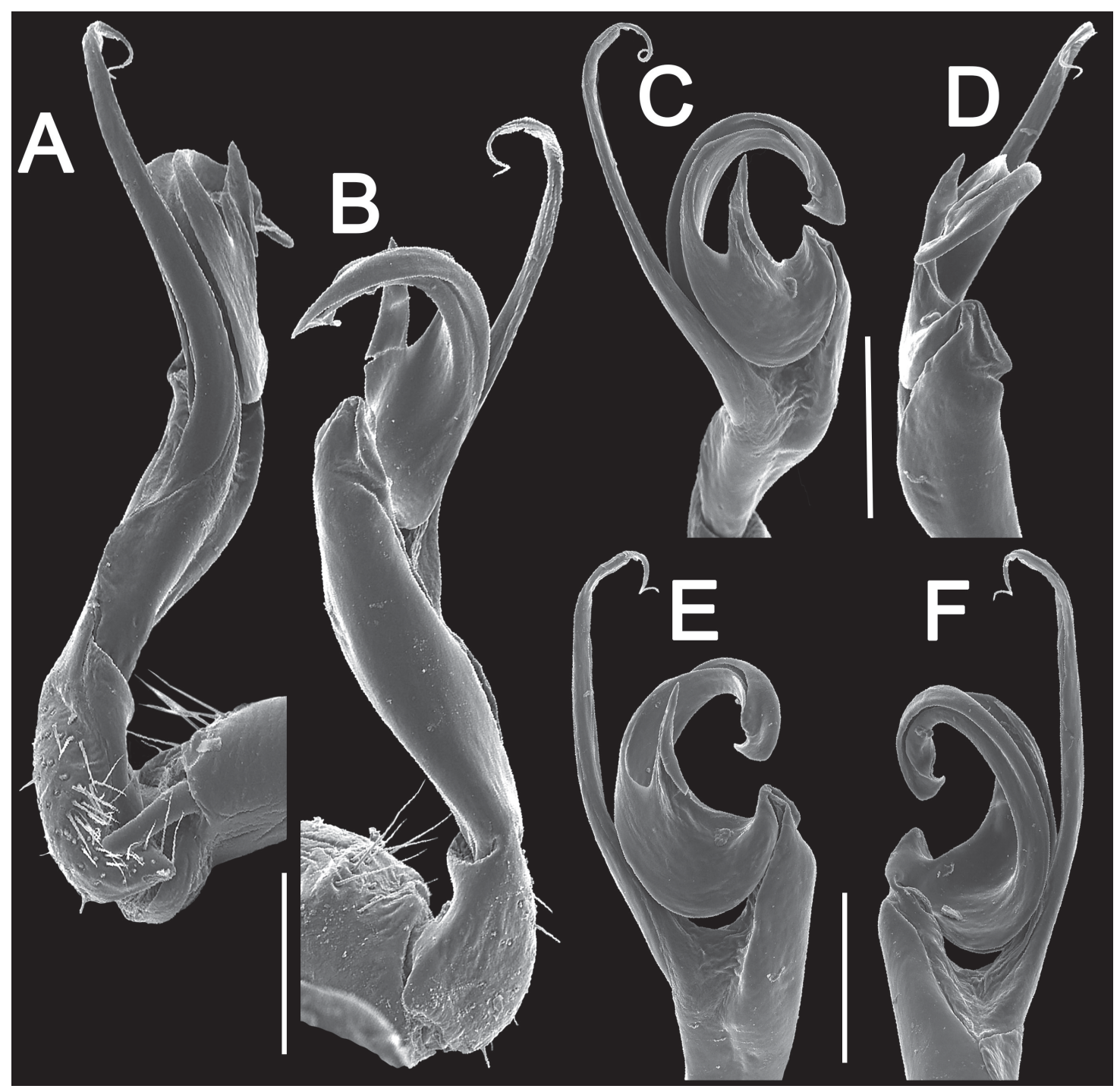

Fig. 3. Tylopus flavolineatus sp. nov., holotype, ô, right gonopod. A-B. Mesal and lateral views, respectively. C-F. Distal part, subcaudal, subcaudal, suboral and sublateral views, respectively. Scale bars $=0.2 \mathrm{~mm}$. 
Tylopus hongkhraiensis sp. nov.

urn:1sid:zoobank.org:act:E217CF1E-83D8-4EFD-875B-7C3845D01580

Figs 4-6, 26

\section{Diagnosis}

Differs from all known congeners in the almost missing paraterga, coupled with the gonopod being especially similar to that of T. magicus Golovatch, 1984, but differs in process $\mathbf{h}$ being strong and

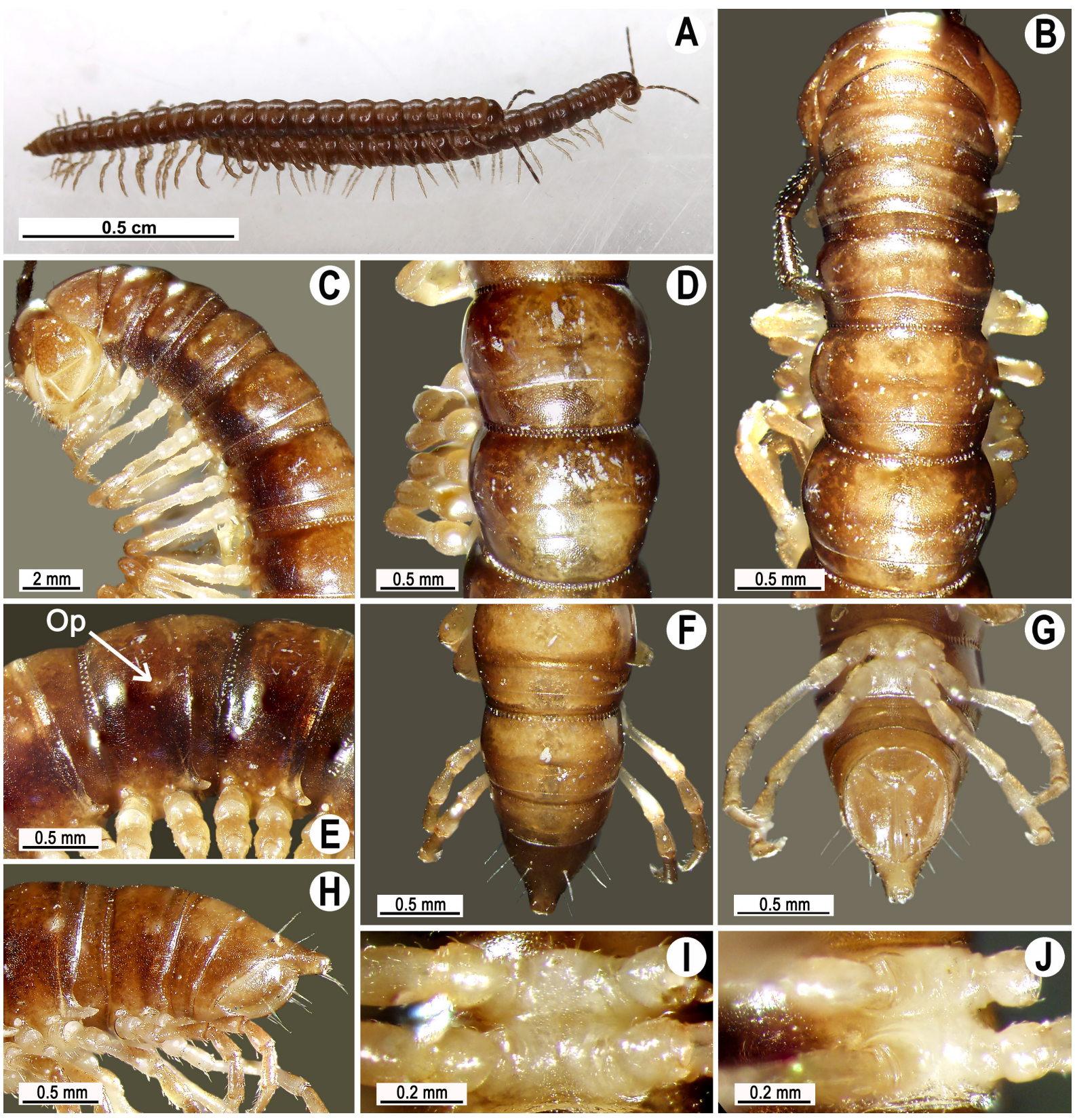

Fig. 4. Tylopus hongkhraiensis sp. nov., holotype, $\hat{\sigma}(\mathbf{B}-\mathbf{J})$, paratypes, $\hat{\jmath}, q(\mathbf{A}) . \mathbf{A}$. Habitus, live coloration. B-C. Anterior part of body, dorsal and lateral views, respectively. D-E. Segments 10 and 11, dorsal and lateral views, respectively. $\mathbf{F}-\mathbf{H}$. Posterior part of body, dorsal, ventral and lateral views, respectively I-J. Sternal cones between coxae 4, subcaudal and sublateral views, respectively. Abbreviations are explained in the text. 
pointed, while process $\mathbf{z}$ long, slender and pointed.

\section{Etymology}

The species is named to emphasize the type locality; adjective.

\section{Material examined}

\section{Holotype}

THAILAND: $\widehat{\jmath}$, Huai Hong Khrai Royal Development Study Centre, Doi Saket, Chiang Mai, $18^{\circ} 52^{\prime} 45^{\prime \prime}$ N, 99¹2'40" E, ca 420 m a.s.1., 29 Jul. 2015, leg. N. Likhitrakarn (CUMZ).

\section{Paratypes}

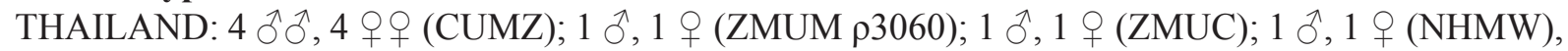
all same data as for holotype.

\section{Description}

MEASUREMENTS AND COLOUR. Length 11.2-12.8 ( $\overbrace{}^{\Uparrow})$ or $11.5-12.6 \mathrm{~mm}(+$ ), width of midbody pro- and metazonae $0.85-0.96$ and $1.04-1.2 \mathrm{~mm}\left({ }^{\Uparrow}\right)$ or $0.85-1.05$ and $1.05-1.32 \mathrm{~mm}(+$ ) $)$, respectively. Coloration of live animals dark brown (Fig. 4A); legs light brown, venter and a few basal podomeres light brown to yellow-brown. Coloration in alcohol after three months of preservation faded to light brown; antennae and epiproct light brown to pallid, venter and a few basal podomeres light brown to pallid (Fig. 4B-J).

HEAD. Clypeolabral region and vertex sparsely setose, epicranial suture distinct. Antennae rather short (Fig. 4A), surpassing body segment $2(0$,, ) when stretched dorsally. In width, segment $3<2<$ collum $<$ segment $4<5<6<7<$ head $<8-17\left({ }^{\Uparrow}\right)$ or segment $2<3<$ collum $<$ segment $4<5=6<7<$ head $<$
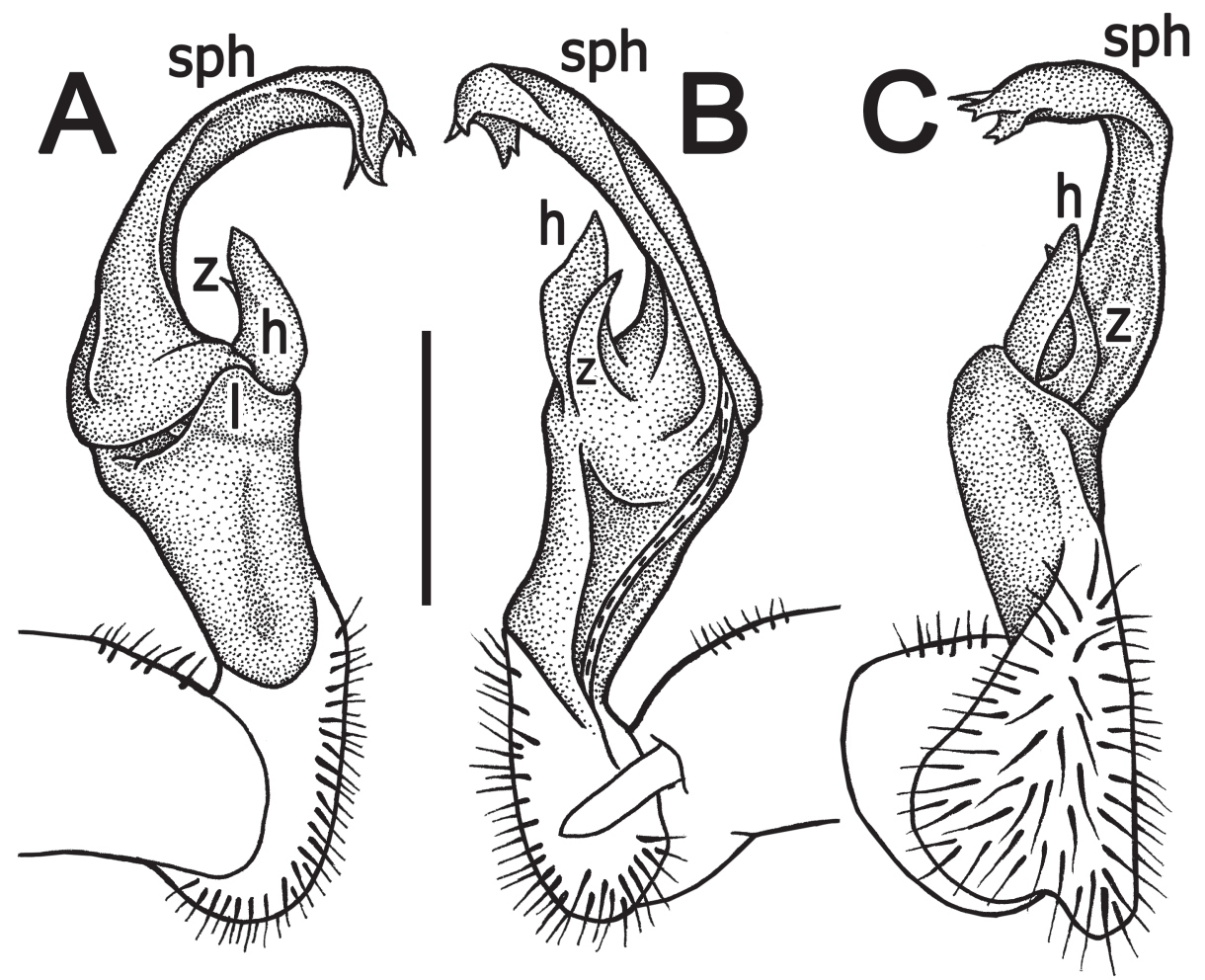

Fig. 5. Tylopus hongkhraiensis sp. nov., holotype, ổ, right gonopod. A-C. Lateral, mesal and suboral views, respectively. Scale bar $=0.2 \mathrm{~mm}$. Abbreviations are explained in the text. 
8-17 (P); thereafter body gently and gradually tapering. Collum with three transverse rows of setae: $3+3$ anterior, $2+2$ intermediate and $3+3$ posterior; caudal corner very narrowly rounded, not surpassing rear tergal margin (Fig. 4B-C).

BoDy. Tegument smooth and shining, prozonae very finely shagreened, metaterga nearly smooth, faintly rugulose and leathery (Fig. 4B-F, H). Postcollum metaterga with two transverse rows of setae: $2+2$ anterior and $2+2$ posterior, traceable at least as insertion points when setae broken off. Tergal setae simple, slender, rather short, about $1 / 5$ of metatergal length. Axial line visible, traceable only on metazonae. Postcollum paraterga virtually missing, in pore-bearing segments lateral bulges with ozopores set at about half of midbody height. Ozopores (Op) evident (Fig. 4E), lateral, located at about $1 / 3$ of metatergal

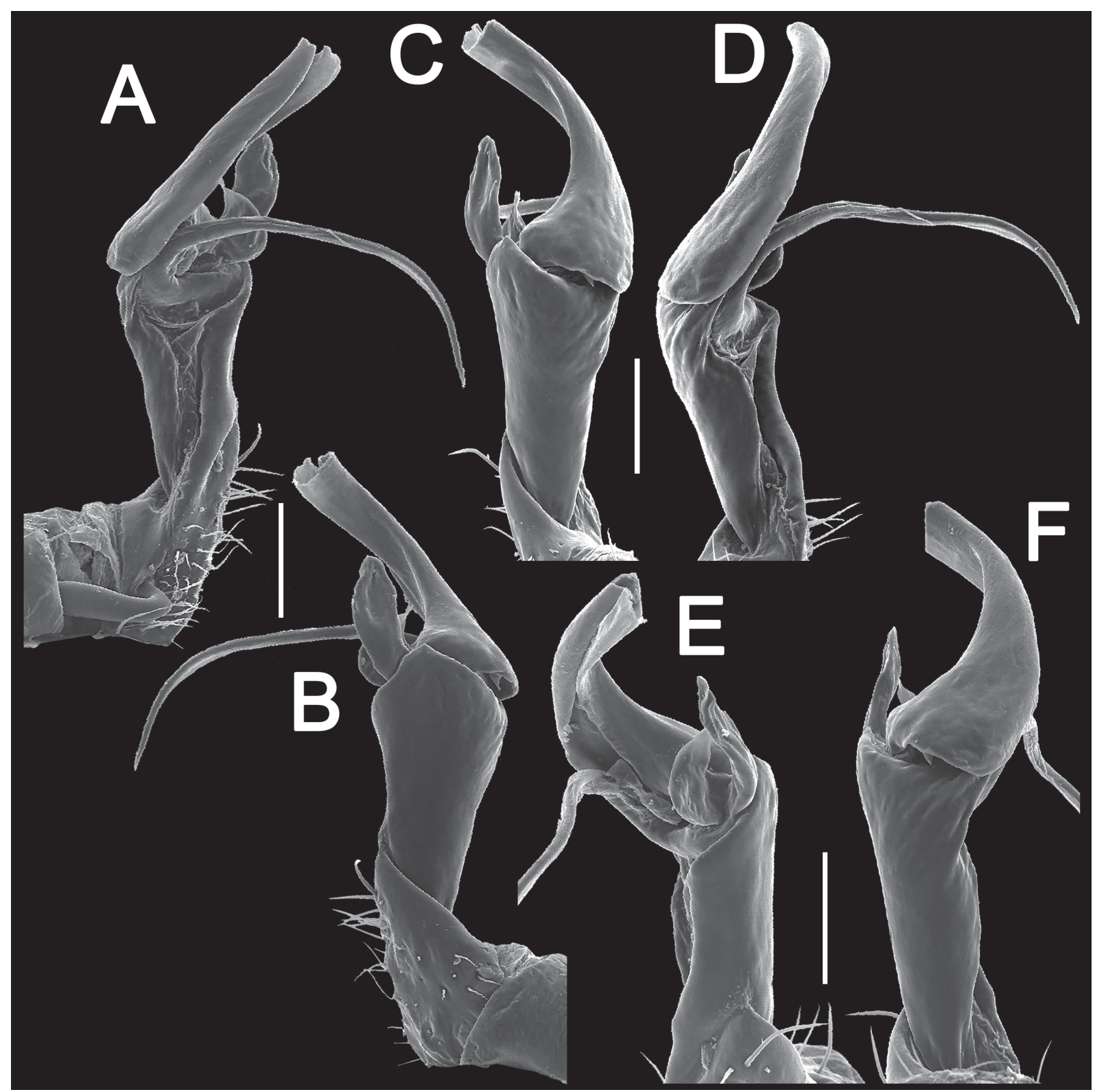

Fig. 6. Tylopus hongkhraiensis sp. nov., holotype, $\widehat{\jmath}$, left gonopod. A-B. Mesal and lateral views, respectively. C-F. Distal part, sublateral, submesal, suboral and subcaudal views, respectively. Scale bars $=0.1 \mathrm{~mm}$. 
length in front of posterior edge of metaterga. Transverse sulcus complete on segments 6-16, incomplete on segments 7 and 18 ( $\hat{\partial}$,, ), very narrow, shallow, not reaching bases of paraterga (Fig. 4B-F, H). Stricture between pro- and metazonae wide, deep, evidently ribbed at bottom down to base of paraterga (Fig. 4B-F, H). Pleurosternal carinae complete crests with a very sharp median tooth on segment 2, increasingly reduced to a rounded caudal crest bulged on segments 2 and $3(\hat{O},+$ ), retained only as an evident, sharp, caudal tooth on segments 5 and 6, thereafter increasingly reduced in size until segment 17, remaining as a small caudal tooth on segment 18 ( $)$ (Fig. 4C, E, H), or increasingly reduced to caudally roughly granulated bulges on segments 5 and 6, thereafter missing ( $(+)$. Epiproct (Fig. 4F-H) conical, flattened dorsoventrally, with two small, but evident, rounded apical papillae; tip subtruncate; lateral pre-apical papillae very small, lying close to tip. Hypoproct roundly subtrapeziform, setigerous knobs at caudal edge small and well-separated (Fig. 4G).

STERNA. Sparsely setose, without modifications; a small, rounded, densely setose sternal cone between $\checkmark$ coxae 4 (Fig. 4I, J). A paramedian pair of small tubercles in front of gonopod aperture. Legs rather rather short, slightly incrassate in $\hat{\partial}^{\lambda}$, midbody ones ca 1.1-1.3 (ठ) or 0.8-0.9 times (ㅇ) as long as body height, prefemora without modifications, $\partial$ tarsal brushes absent.

GonOPOD. Simple (Figs 5, 6); fermorite faintly curved, stout, slightly expanded distad, showing a strong mesal groove; process $\mathbf{h}$ prominent, slightly curved, pointed; process $\mathbf{z}$ long and rather slender, evident, likewise curved and pointed; solenophore (sph) expanded distally and flattened, typically coiled, clearly bifid, with a pair of small spines.

\section{Remarks}

The millipedes were found mating on bamboo logs on the soil surface during rain. The male was observed walking along the female's back and stimulating her with rhythmic pulses of his legs. The tips of the solenophore and solenomere in Fig. 6 are broken off.

\section{Tylopus moniliformis sp. nov. \\ urn:lsid:zoobank.org:act:A510843C-08CC-4818-A45F-E35AFDE80E71}

Figs 7-9, 26

\section{Diagnosis}

Differs from all known congeners by the almost missing paraterga, much like in T. hongkhraiensis sp. nov., coupled with the gonopod structure being similar to that of T. reductus Golovatch, 2013, but it differs in the solenophore being more strongly twisted and thicker.

\section{Etymology}

To emphasize the body being strongly bead-shaped, or moniliform; adjective.

\section{Material examined}

\section{Holotype}

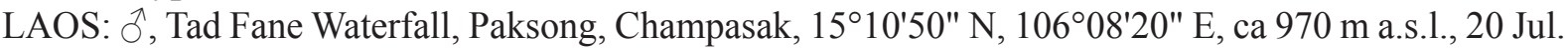
2013, leg. S. Panha, C. Sutcharit, W. Siriwut (CUMZ).

\section{Paratypes}

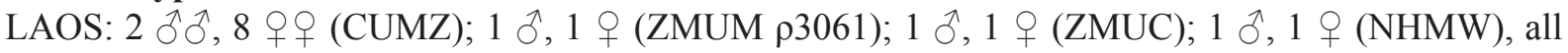
same data as for holotype. 


\section{Description}

MEASUREMENTS AND COLOUR. Length 14-16 (ð) or 16-18 mm (P), width of midbody pro- and metazonae $0.6-0.9$ and $0.9-1.1 \mathrm{~mm}\left({ }^{\Uparrow}\right)$ or $0.9-1.2$ and $1.2-1.3 \mathrm{~mm}(+)$, respectively. Coloration of live animals dark castaneous brown (Fig. 7A); legs light brown, venter and a few basal podomeres light brown to yellow-brown. Coloration of alcohol material after three months of preservation faded to light brown; antennae and epiproct light brown to pallid, venter and a few basal podomeres light brown to pallid (Fig. 7B-J).

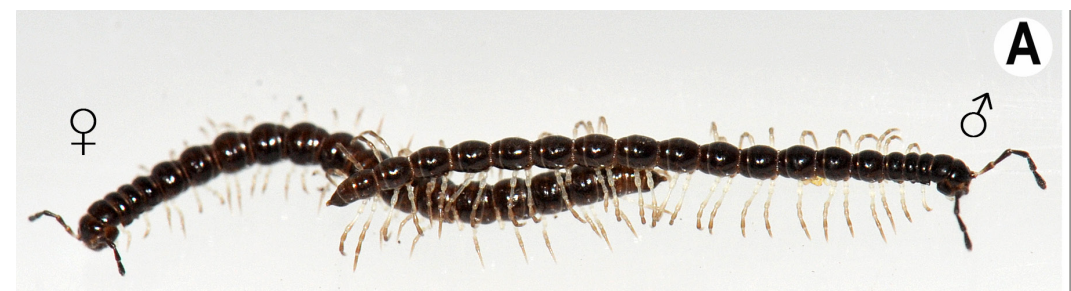

$0.5 \mathrm{~cm}$
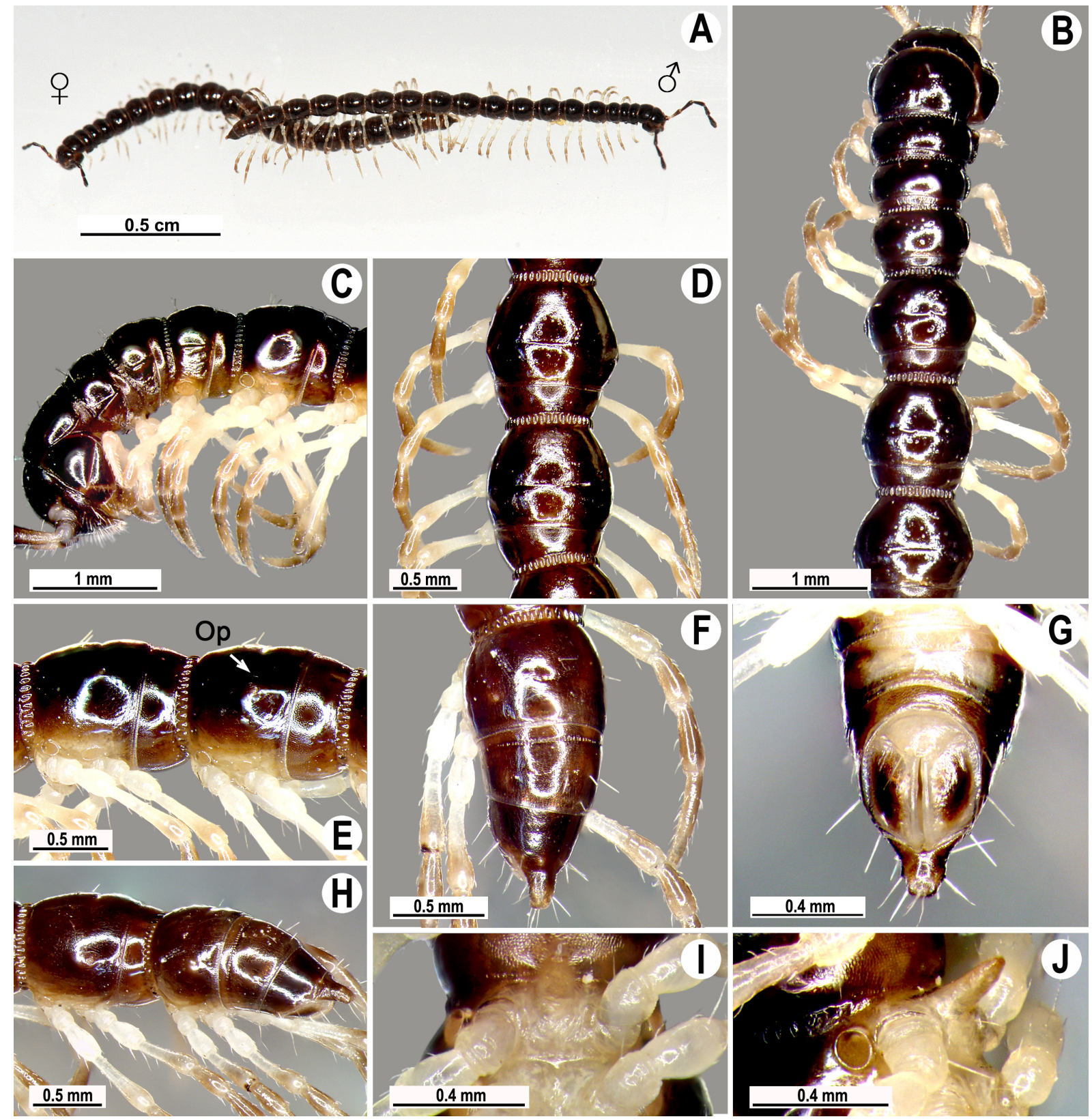

Fig. 7. Tylopus moniliformis sp. nov., holotype, $\widehat{\partial}(\mathbf{B}-\mathbf{J})$, paratypes, $\hat{\jmath}$, $q$ (A). A. Habitus, live coloration. B-C. Anterior part of body, dorsal and lateral views, respectively. D-E. Segments 10 and 11, dorsal and lateral views, respectively. F-H. Posterior part of body, subdorsal, ventral and sublateral views, respectively. I-J. Sternal cones between coxae 4, subcaudal and sublateral views, respectively. Abbreviations are explained in the text. 
HEAD. Clypeolabral region and vertex sparsely setose, epicranial suture distinct. Antennae moderately long (Fig. 7A), surpassing body segment 5 ( ${ }^{\text {( ) }}$ or reaching body segment 4 ( + ) when stretched dorsally. In width, head $<$ segment $4<2=3<$ collum $<$ segment $5<6-17(\hat{0}$, ) $)$; thereafter body gently and gradually tapering. Collum with three transverse rows of setae: $5+5$ anterior, $2+2$ intermediate and $1+1$ posterior; a very faint marginal incision laterally in posterior $1 / 3$; caudal corner very narrowly rounded, not surpassing rear tergal margin (Fig. 7B-C).

BoDy. Tegument smooth and shining, prozonae very finely shagreened, metaterga almost smooth, delicately rugulose, leathery (Fig. 7B-F, H). Postcollum metaterga with two transverse rows of setae: $2+2$ anterior, always abraded, and $1+1$ posterior row, setae traceable at least as insertion points. Tergal setae simple, strong, slender, about $1 / 3$ of metatergal length. Axial line visible, but barely traceable on

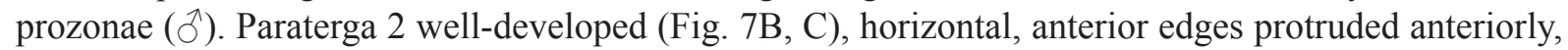
fore corner bent ventrad, pointed; lateral edge with two minute incisions in anterior half; caudal corner very narrowly rounded. Paraterga 3 and 4 rounded, expanded laterally, with two minute incisions only in segment 3. Following paraterga virtually missing $\left({ }^{\Uparrow}\right)$ or traceable as small, rounded, laterally expanded bulges (P), in pore-bearing segments with ozopores set at about half of midbody height. Ozopores (Op) evident (Fig. 7E), lateral, lying in an ovoid groove at about $1 / 3$ of metatergal length in front of posterior edge of metaterga. Transverse sulcus usually distinct (Fig. 7B-F, H), slightly incomplete on segment 3, complete on segments 4-18 (ठ) or complete on segments 5-18 (ㅇ), always incomplete on segment $19(\hat{0}, \uparrow)$, narrow, not reaching bases of paraterga, at most faintly beaded at bottom. Stricture between pro- and metazonae wide, evidently ribbed at bottom down to base of paraterga (Fig. 7B-

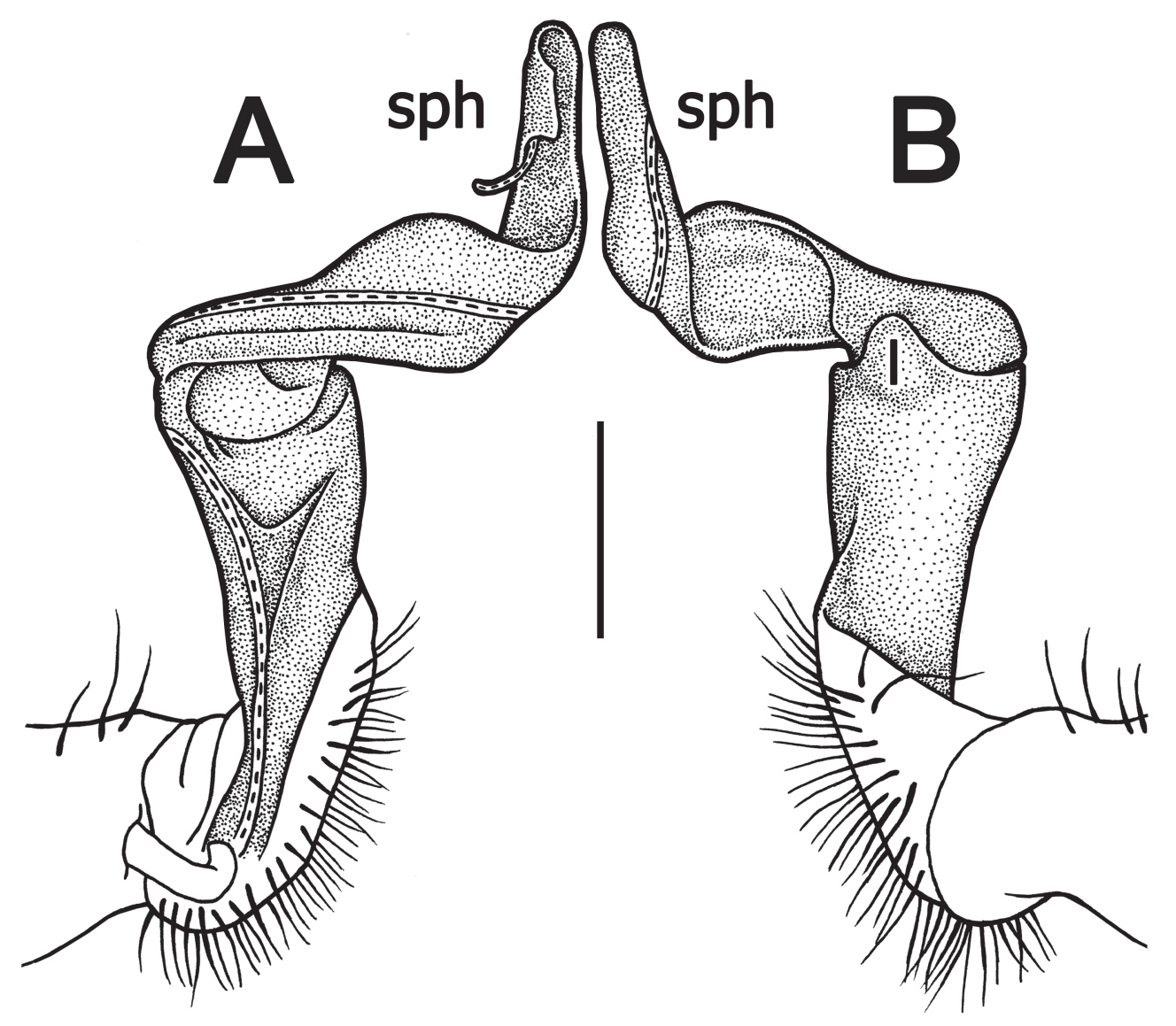

Fig. 8. Tylopus moniliformis sp. nov., paratype, $\hat{\partial}$, left gonopod. A-B. Mesal and lateral views, respectively. Scale bar $=0.2 \mathrm{~mm}$. Abbreviations are explained in the text. 
F, H). Pleurosternal carinae complete crests with a sharp caudal tooth on segments 2 and 3, reduced and remaining a sharp caudal tooth on segment 4, thereafter missing ( 3 ) (Fig. 7C), or thereafter increasingly reduced and remaining a front bulge until segment 18 (क). Epiproct (Fig. 7F-H) rather short, flattened dorsoventrally, tip subtruncate, subapical lateral papillae small, but visible, lying close to tip. Hypoproct roundly subtriangular, setigerous knobs at caudal edge well-separated and evident.

Sterna. Moderately setose, without modifications; an entire, high, inverted funnel-shaped, sternal lobe each between $\widehat{\delta}$ coxae 3 and 4 (Fig. 7I-J), lobe being larger between coxae 4. A paramedian pair of evident tubercles in front of gonopod aperture. Legs very long and slender, slightly incrassate

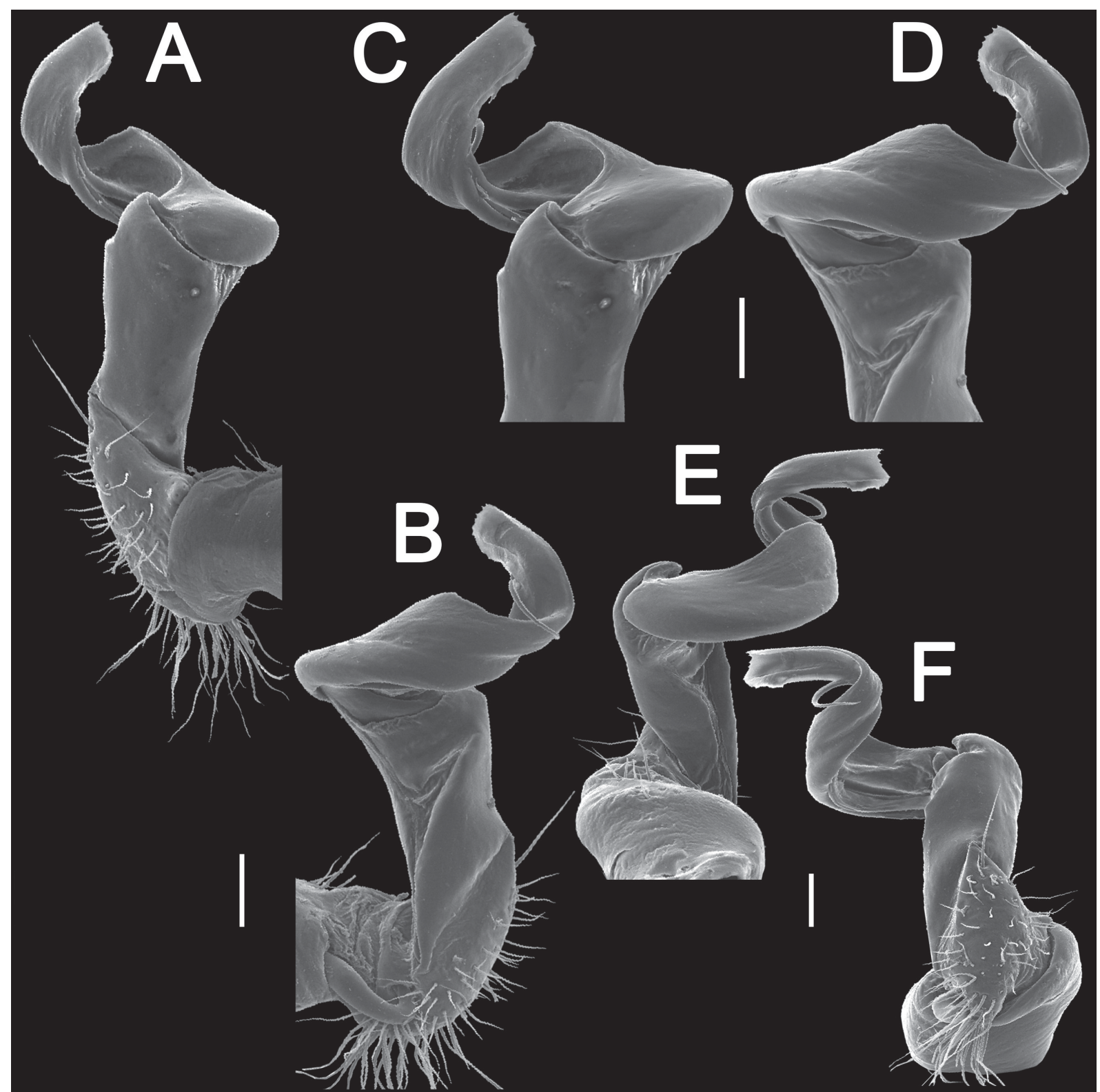

Fig. 9. Tylopus moniliformis sp. nov., holotype, ô, left gonopod. A-B. Lateral and mesal views, respectively. C-F. Distal part, lateral, mesal, subcaudal and suboral views, respectively. Scale bars = $0.1 \mathrm{~mm}$. 
in $\widehat{\jmath}$, midbody ones ca 1.5-1.8 (ठ) or 1.1-1.4 times (†) as long as body height, prefemora without modifications, $\hat{o}$ tarsal brushes absent.

GONOPOD. Very simple (Figs 8, 9); fermorite straight and rather stout, slightly expanded distad, showing a distinct mesal groove, without outgrowths except for a low, sometimes poorly delimited lobe $\mathbf{I}$; solenophore (sph) expanded and flattened, typically coiled, suberect distally, devoid of processes.

\section{Remarks}

This species shows the gonopod with lobe $\mathbf{l}$ separated from the femorite by a rather indistinct sulcus, the presence of the latter lobe being one of the main characteristics of Tylopus. Since this locality also yielded the holotype of Desmoxytes rhinoceros Likhitrakarn, Golovatch \& Panha, 2014 (cf. Likhitrakarn et al. 2014b), Tad Fane Waterfall becomes a site quite important for nature conservation, being the type locality of these two millipede species.

\section{Tylopus retusus sp. nov. urn:lsid:zoobank.org:act:40D74A7C-61D7-442B-B388-3868C47102C5}

Figs $10-11,26$

\section{Diagnosis}

Distinguished by its relatively small body with four transverse rows of setae forming no regular pattern of setation; in gonopod structure it is similar to T. haplorugosus Golovatch \& Enghoff, 1993, but differs in process $\mathbf{h}$ being rather short, slightly flattened, blunt, coupled with the solenophore being strongly coiled.

\section{Etymology}

To emphasize the blunt tip of process $\mathbf{h}$; adjective.

\section{Material examined}

\section{Holotype}

LAOS: ${ }^{\lambda}$, Muang Xay City, Xay, Oudomxai, 2041'00" N, 10159'05" E, ca 640 m a.s.1., mango garden, 14 Oct. 2014, leg. C. Sutcharit \& R. Srisonchai (CUMZ).

\section{Paratype}

LAOS: 1 9, Khoua, Phongsaly, ca 835 m a.s.1., $21^{\circ} 11^{\prime} 55^{\prime \prime} \mathrm{N}, 102^{\circ} 06^{\prime} 40^{\prime \prime} \mathrm{E}$, forest near road, 15 Oct. 2014, leg. C. Sutcharit \& R. Srisonchai (CUMZ).

\section{Description}

MEASUREMENTS AND COLOUR. Length 16.3 ( ${ }^{\Uparrow}$ ) or $20.4 \mathrm{~mm}$ ( $(+)$, width of midbody pro- and metazonae 1.12 and $2.07 \mathrm{~mm}\left({ }^{\Uparrow}\right)$ or 2.7 and $3.7 \mathrm{~mm}$ ( $($ ), respectively. Live coloration light brown (Fig. 10A); prozonae dark brown; paraterga, antennae, head and legs light brown to yellow-brown. Coloration of alcohol material after one year of preservation faded to light brown to yellow-brown; paraterga, antennae, head, legs and venter light brown to light yellow (Fig. 10B-J).

HEAD. Clypeolabral region and vertex sparsely setose, epicranial suture distinct. Antennae (Fig. 10A, B) rather short and stout, antennomeres $2-6$ subequal in length, reaching body segment $3(\hat{\partial}$,, $)$ when stretched dorsally. In width, head $<$ segment $3<4<$ collum $<$ segments $5-15$; thereafter body gently and gradually tapering. Collum with three transverse rows of setae: $6+6$ anterior, $4+4$ intermediate and $6+6$ posterior; a small lateral incision at about midway; caudal corner very broadly rounded, paraterga declined ventrad, slightly produced behind rear tergal margin. 
Body. Tegument smooth and shining, prozonae finely shagreened, metaterga leathery, finely rugulose (Fig. 10B, D, F); surface below paraterga roughly microgranulate (Fig. 10C, E, H). Postcollum metaterga with four transverse rows of setae forming no regulated pattern of setation, anterior row with the most dense setae growing increasingly dense towards segment 19 (Fig. 10B, D, F). Tergal setae long and slender, about $2 / 3$ as long as metaterga. Axial line well visible on metazonae, traceable also on prozonae. Paraterga strongly developed (Fig. 10B-H), especially so in $\widehat{O}^{\lambda}$, set rather high (at upper $1 / 3$ of body height), slightly upturned, but lying below dorsum; anterior edge broadly rounded and narrowly bordered, fused to callus; caudal corner very narrowly rounded, starting with segment 16 extending
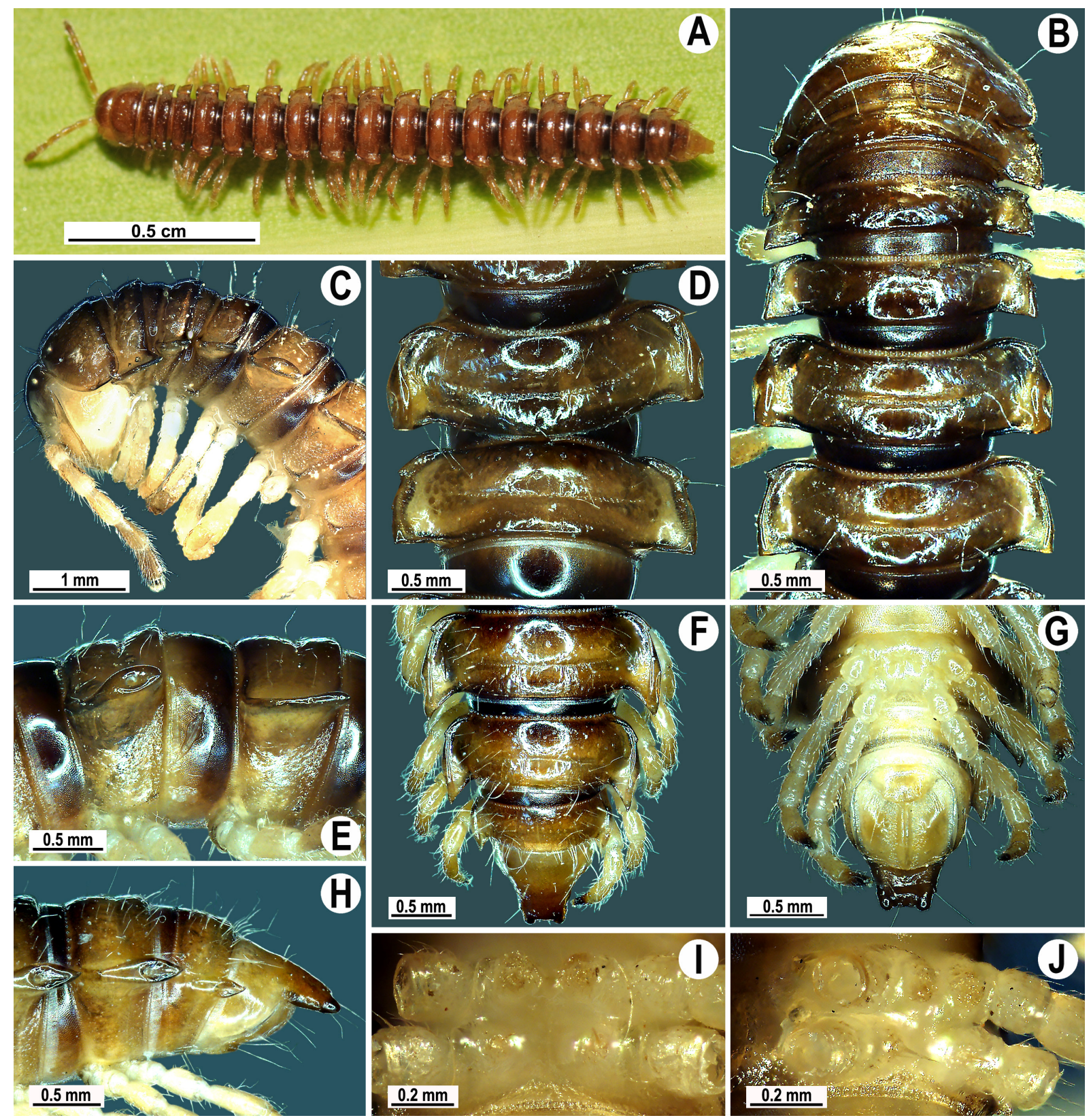

Fig. 10. Tylopus retusus sp. nov., holotype, ô. A. Habitus, live coloration. B-C. Anterior part of body, dorsal and lateral views, respectively. D-E. Segments 10 and 11, dorsal and lateral views, respectively. F-H. Posterior part of body, dorsal, ventral and lateral views, respectively. I-J. Sternal cones between coxae 4 , caudal and sublateral views, respectively. 
increasingly behind rear tergal margin (Fig. 10F, H). Paraterga 2 and 3 with two evident incisions at lateral edge (Fig. 10B). Following poreless segments with two similar incisions; pore-boring segments with one, often setigerous incision lying in front of pore (Fig. 10D, E). Calluses of paraterga delimited

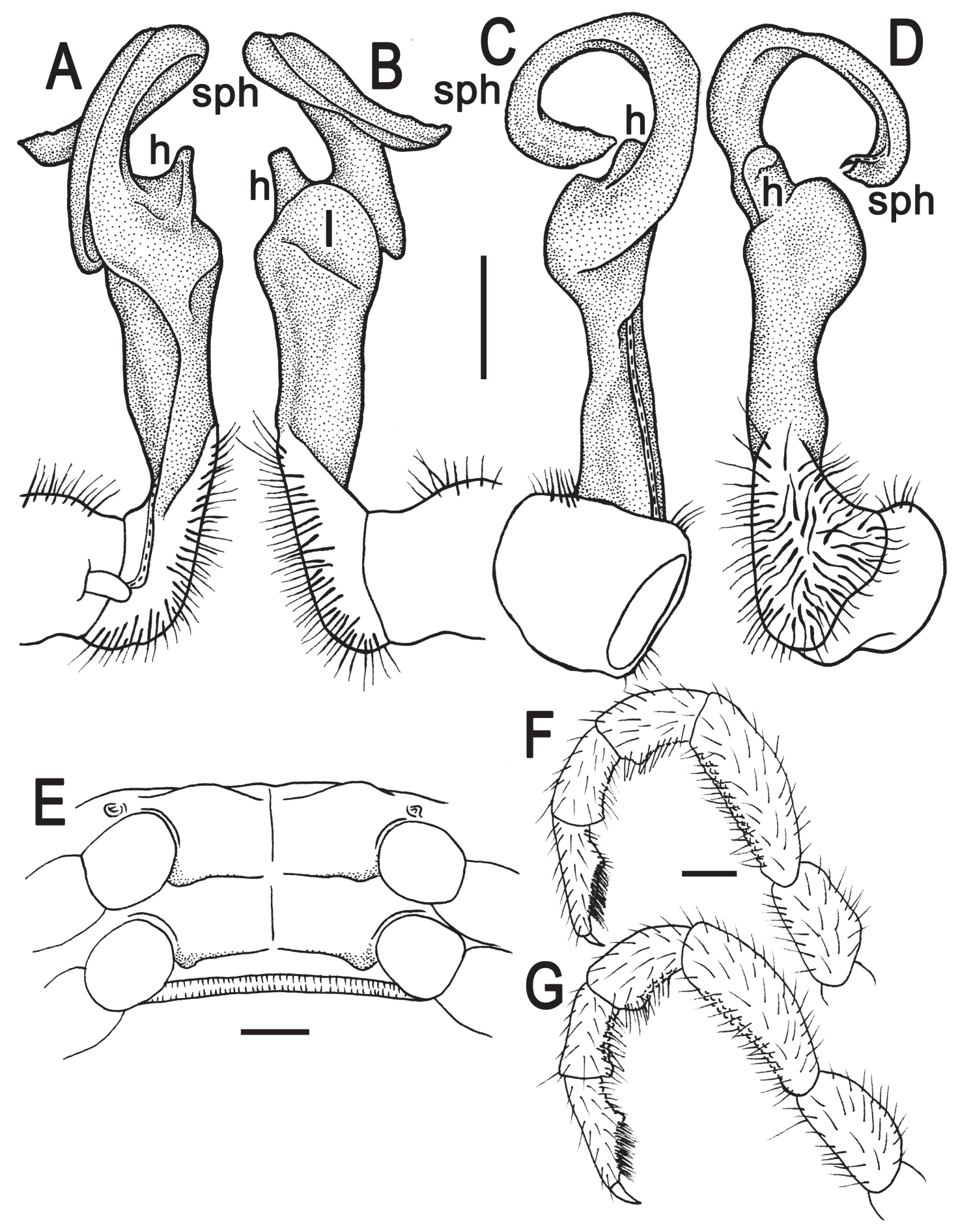

Fig. 11. Tylopus retusus sp. nov., holotype, $\partial$, left gonopod. A-D. Mesal, lateral, subcaudal and suboral views, respectively. E. Sterna of segment 10. F. Leg 6. G. Leg 10. Scale bars $=0.2 \mathrm{~mm}$. Abbreviations are explained in the text. 
by a sulcus both dorsally and ventrally. Ozopores evident, lateral, lying in an ovoid groove at about $1 / 3$ of metatergal length in front of posterior edge of metaterga. Transverse sulcus usually distinct (Fig. 10B, $\mathrm{D}, \mathrm{F}$ ), slightly incomplete on segment 19 , complete on segments 5-18, narrow, undulate, shallow, not reaching bases of paraterga, beaded at bottom. Stricture between pro- and metazonae evident, wide and deep, beaded at bottom down to base of paraterga (Fig. 10B, D-F). Pleurosternal carinae complete crests with a sharp caudal tooth on segments $2-7(\overbrace{}^{\lambda})$ or 2-4 (ㅇ), thereafter increasingly reduced to a small tooth until segment $15\left({ }^{\Uparrow}\right)$ or 13 (\$), missing more caudally. Epiproct (Fig. 10F-H) conical, flattened dorsoventrally, with two evident, large, rounded apical papillae; tip subtruncate; lateral preapical papillae small, lying close to tip. Hypoproct (Fig. 10G) roundly subtrapeziform, setigerous knobs at caudal edge small and well-separated.

STERNA. Densely setose, with a small cone caudally near each coxa, rear cones being a little larger than fore ones (Fig. 11E); two small, rough, fully separated, setose cones between $\widehat{\delta}$ coxae 4 (Fig. 10I, J). Legs rather long and slender, midbody ones ca 1.2-1.3 (ð) or 0.9-1.0 (†) as long as body height; all male legs until segment 16 with tarsal brushes, prefemora not swollen; prefemora, femora and tibiae with ventral microgranulations; femora, tibiae and tarsi each with an evident adenostyle (tubercle) medially (Fig. 11F-G).

GoNOPOD. Rather simple (Fig. 11A-D); coxa a little curved caudad, sparsely setose distoventrally. Femorite slightly curved and stout, with an evident mesal groove and a clear distolateral sulcus demarcating a postfemoral part; lobe $\mathbf{I}$ evident, rounded, with process $\mathbf{h}$ rather short, slightly flattened, blunt; solenophore (sph) strongly coiled, devoid of processes, pointed.

\section{Remark}

This species was found in a mango plantation in Muang Xay City.

Tylopus acuminatus sp. nov. urn:1sid:zoobank.org:act:C0DB482F-EE58-4385-9733-7D2E724DEFED

Figs $12-15,26$

\section{Diagnosis}

Very similar to T. jeekeli Golovatch \& Enghoff, 1993 and T. parajeekeli Likhitrakarn, Golovatch, Prateepasen \& Panha, 2010, especially in its gonopod conformation, but differs in process $\mathbf{h}$ being higher and more strongly flattened, pointed, while the sternal lobe between $\hat{\delta}$ coxae 4 linguiform and larger.

\section{Etymology}

To emphasize the acuminate processes $\mathbf{h}$ on the gonopod; adjective.

\section{Material examined}

\section{Holotype}

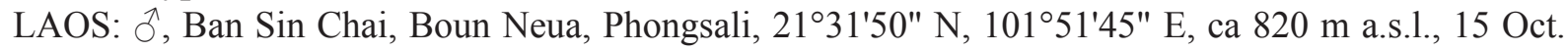
2014, leg. C. Sutcharit \& R. Srisonchai (CUMZ).

\section{Paratypes}

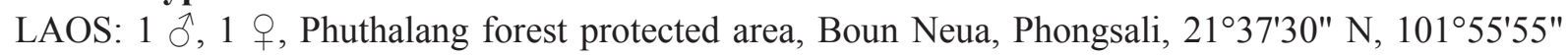
E, ca 1125 m a.s.1., 16 Oct. 2014 (CUMZ); 1 ô, 2 우, Phufa, Boun Neua, Phongsali, $21^{\circ} 41^{\prime} 05^{\prime \prime}$ N, $102^{\circ} 06^{\prime} 35^{\prime \prime}$ E, ca 1470 m a.s.1, 16 Oct. 2014 (CUMZ); 1 , , near Ban Borkhun, Boun Neua, Phongsali, $21^{\circ} 27^{\prime} 57^{\prime \prime} \mathrm{N}, 101^{\circ} 47^{\prime 2} 20^{\prime \prime}$ E, ca 880 m a.s.1., 18 Oct. 2014 (CUMZ); 1 \&, Khoua, Phongsali, $21^{\circ} 11^{\prime} 55^{\prime \prime}$ N,

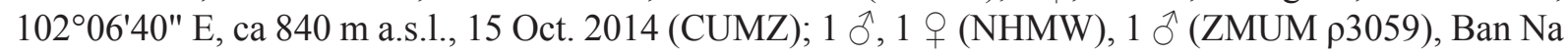




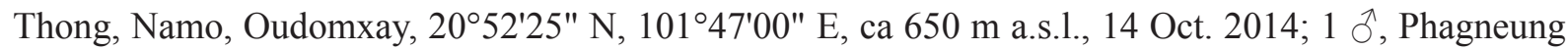
Phoukulom Waterfall, Sing, Luang Namtha, $21^{\circ} 07^{\prime} 15^{\prime \prime} \mathrm{N}, 101^{\circ} 14^{\prime} 40^{\prime \prime}$ E, ca 900 m a.s.1., 13 Oct. 2014, all leg. C. Sutcharit \& R. Srisonchai (ZMUC).

\section{Description}

MEASUREMENTS AND COLOUR. Length 24.5-31.6 ( $\left.\AA^{-}\right)$or $24.3-31.5 \mathrm{~mm}(+9)$, width of midbody pro- and metazonae 1.98-2.6 and 2.95-3.6 $\mathrm{mm}\left({ }^{3}\right)$ or 2.7-2.9 and 3.1-4.2 $\mathrm{mm}(9)$, respectively. Live coloration dark brown (Fig. 12A); antennae and epiproct light brown; legs yellow-brown. Coloration of alcohol

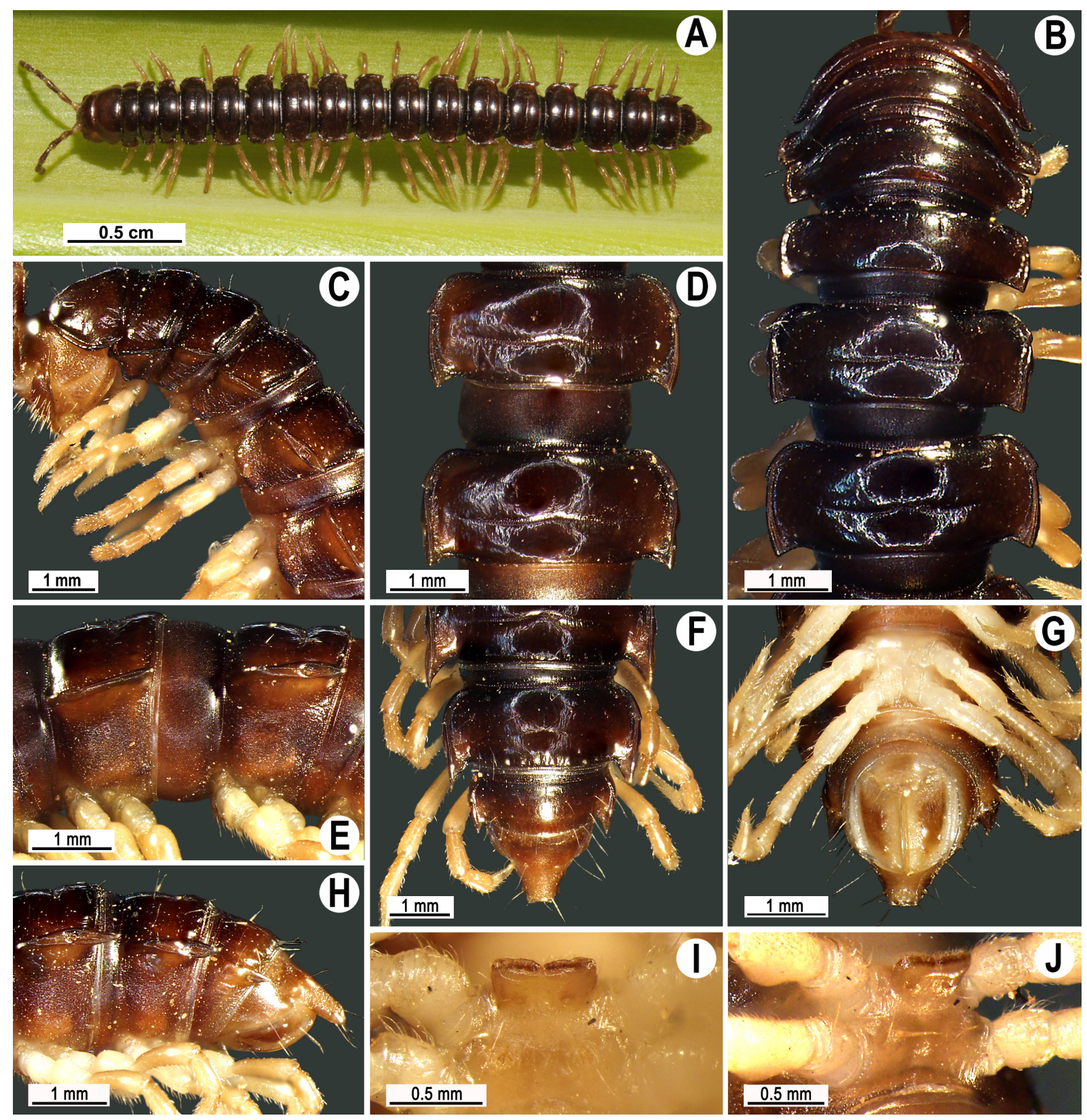

Fig. 12. Tylopus acuminatus sp. nov., holotype, $\widehat{\partial}$. A. Habitus, live coloration. B-C. Anterior part of body, dorsal and lateral views, respectively. D-E. Segments 10 and 11, dorsal and lateral views, respectively. $\mathbf{F}-\mathbf{H}$. Posterior part of body, dorsal, ventral and lateral views, respectively. I-J. Sternal cones between coxae 4, caudal and sublateral views, respectively. 
material after one year of preservation faded to brown to yellow-brown; head, antennae, epiproct light brown to yellow-brown, legs and venter yellow-brown to light yellow (Fig. 12B-J).

HeAd. Clypeolabral region densely, vertex sparsely, setose; epicranial suture distinct. Antennae (Fig. 12A) short, surpassing body segment $2(\hat{0}$,,+$)$ when stretched dorsally. In width, head $<$ segment $3<$ collum $<$ segment $4<2<5-16(\widehat{\bigcirc})$, or head $<$ segment $3<4<$ collum $<$ segment $2<5-16$ ( $($ ) ; thereafter body gently and gradually tapering. Collum with three transverse rows of setae: $4+4$ anterior, $1+1$ intermediate and $2+2$ posterior paraterga declined ventrad, with a small lateral incision at about midway; caudal corner very broadly rounded, not surpassing rear tergal margin (Fig. 12C).

BoDy. Tegument smooth and shining, prozonae finely shagreened, metaterga smooth and leathery (Fig. 12B, D, F); surface below paraterga microgranulate (Fig. 12C, E, H). Postcollum metaterga with an anterior transverse row of $2+2$, mostly abraded setae; posterior row barely traceable as $4+4$ insertion points, these being better visible on segments 17-19 (Fig. 12F). Tergal setae simple and slender, about $2 / 3$ as long as metaterga. Axial line traceable on prozonae and anterior halves of metazonae. Paraterga well-developed (Fig. 12B-F, H), especially so in $\mathrm{O}^{\lambda}$, set rather high (at upper $1 / 3$ of body height), slightly upturned, but lying below dorsum; anterior edge broadly rounded and narrowly bordered, fused to callus; caudal corner very narrowly rounded, drawn behind tergal margin, increasingly protruding and pointed starting with segment 16 (Fig. 12F, H). Paraterga 2 with two evident incisions at lateral edge in anterior $1 / 3$. Paraterga 3 and 4 each with two similar incisions at lateral edge, one in anterior $1 / 3$, the other about the middle. Following paraterga each with one evident lateral incision in anterior $1 / 3$ and, in pore-bearing segments, a very small denticle in the middle (Fig. 12B, D, F). Calluses on paraterga delimited by a sulcus both dorsally and ventrally. Ozopores evident, lateral, lying in an ovoid groove

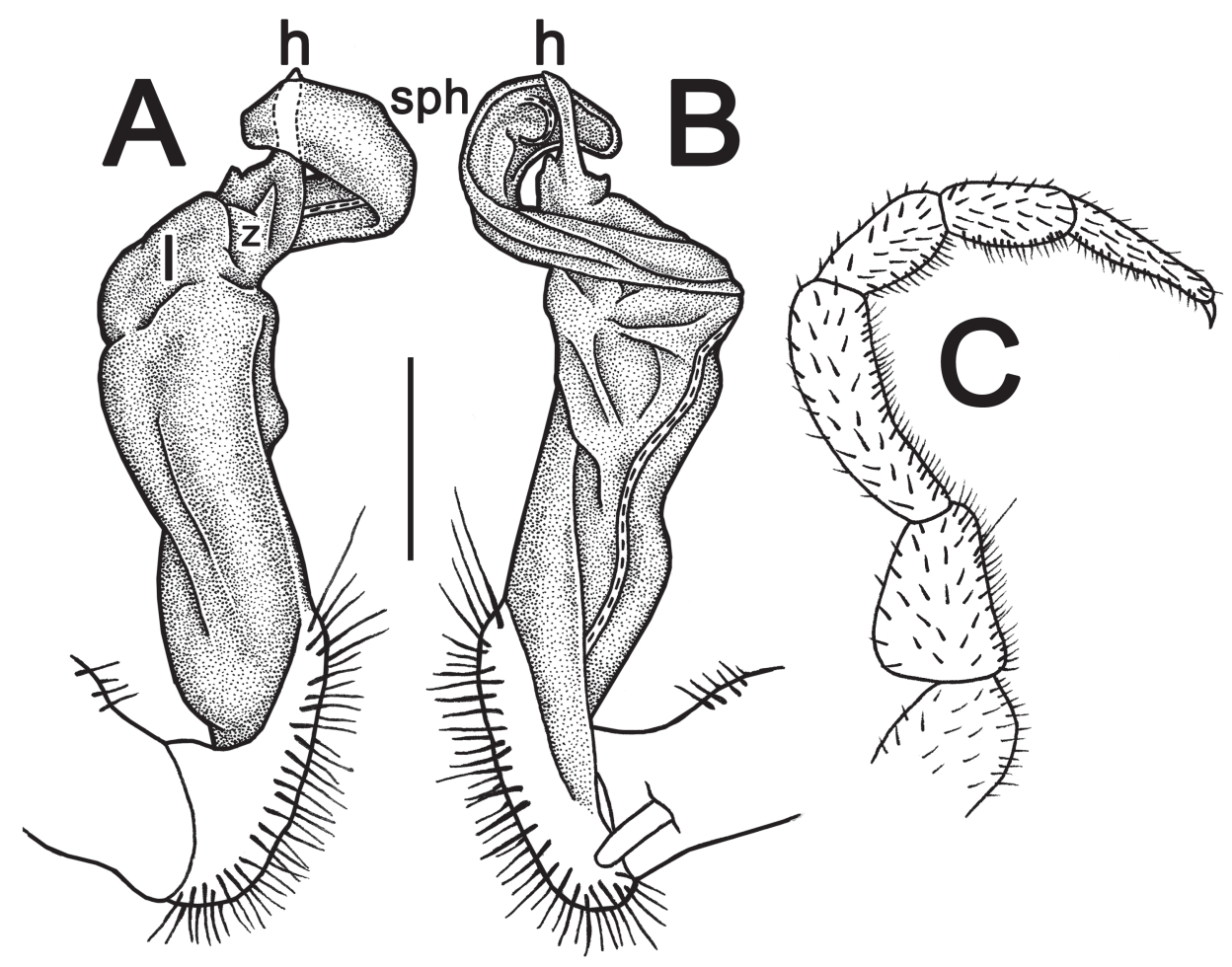

Fig. 13. Tylopus acuminatus sp. nov., holotype, $\widehat{\jmath}$, right gonopod. A-B. Lateral and mesal views, respectively. C. Leg 13. Scale bar: A-B. $0.5 \mathrm{~mm} ; \mathrm{C}=$ no scale bar. Abbreviations are explained in the text. 
at about $1 / 3$ of metatergal length in front of posterior edge of metaterga. Transverse sulcus evident on metaterga 5-17, incomplete on metaterga 18, narrow, line-shaped, rather deep, ribbed at bottom, not reaching bases of paraterga (Fig. 12B, D, F). Stricture between pro- and metazonae evident, wide and deep, ribbed at bottom down to base of paraterga (Fig. 12B, D-F). Pleurosternal carinae complete crests with a sharp caudal tooth on segments 2 and $3(\hat{0},+$, ), increasingly reduced and remaining a strong, sharp, caudal tooth on segments 4-8, retained as a small sharp tooth on segments $9-16$, a minute tooth on segment $17\left({ }^{\Uparrow}\right)$, or an evident, sharp, caudal tooth on segments 4-15, then remaining a small rounded tooth on segment 16, thereafter missing (P) (Fig. 12C, E, H). Epiproct (Fig. 12F-H) conical, flattened dorsoventrally, with two evident, rounded, apical papillae; tip subtruncate; lateral pre-apical papillae

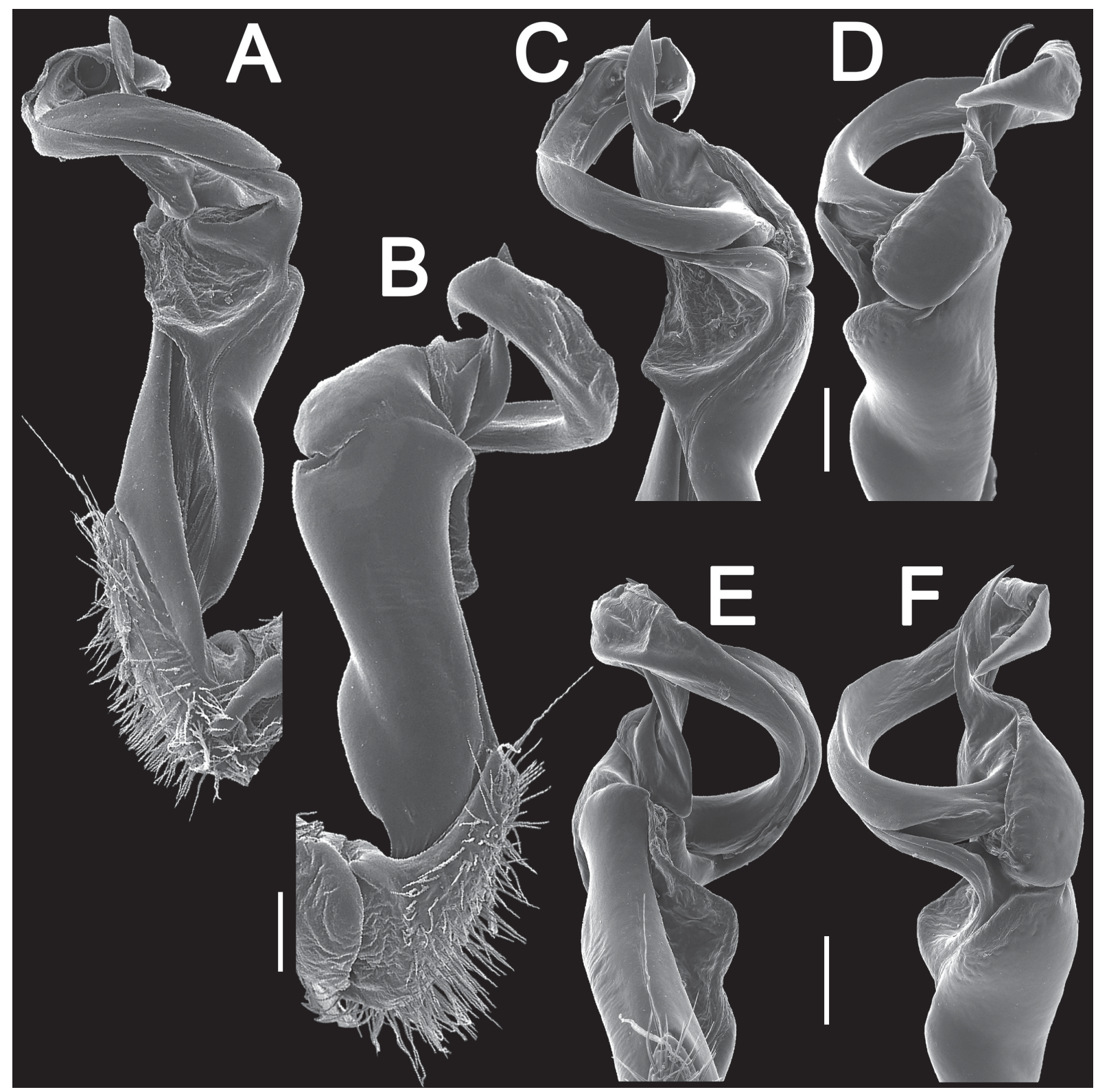

Fig. 14. Tylopus acuminatus sp. nov., holotype, ô, right gonopod. A-B. Mesal and lateral views, respectively. C-F. Distal part, sublateral, submesal, subcaudal and suboral views, respectively. Scale bars $=0.2 \mathrm{~mm}$. 
evident, lying close to tip. Hypoproct (Fig. 12G) roundly subtrapeziform, setigerous knobs at caudal edge small and well-separated.

STERnA. Moderately setose and densely microtuberculate; cross-impressing shallow; an entire, linguiform, sternal lobe between $\widehat{\partial}$ coxae 4 (Fig. 12I-J). A paramedian pair of conspicuous ridges in front of gonopod aperture. Legs rather long and slender, midbody ones ca 1.2-1.3 (ठ) or 1.0-1.1 () as long as body height; $\widehat{\partial}$ legs with prefemora distinctly swollen laterally, acropodites with particularly dense setae ventrally (Fig. 13C), but tarsal brushes absent.

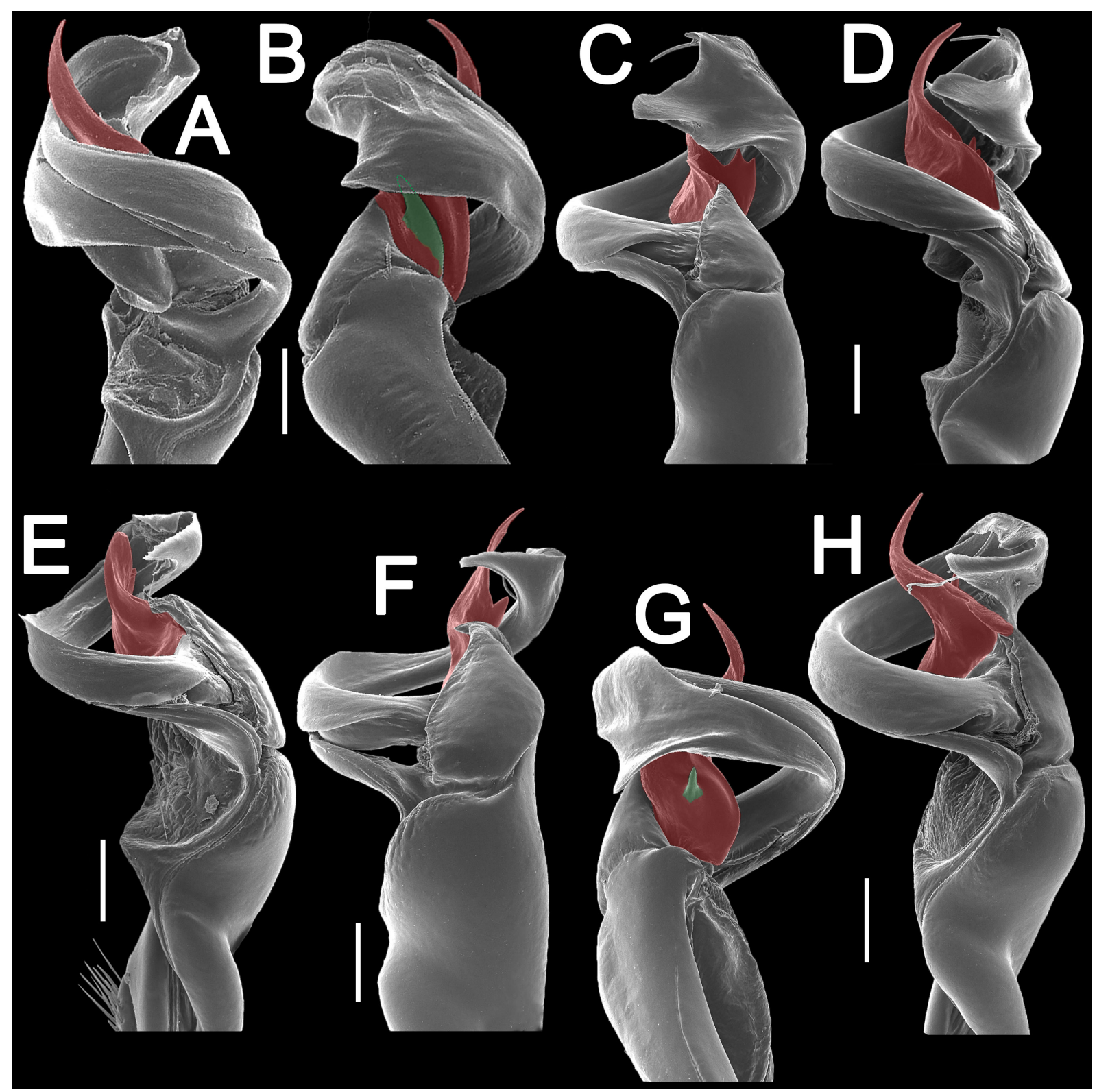

Fig. 15. Tylopus acuminatus sp. nov., paratype, $\widehat{\jmath}$, from Phufa (A-B), paratype, $\hat{\jmath}$, from Phuthalang forest protected area $(\mathbf{C}-\mathbf{D})$, paratype, $\hat{\partial}$, from forest near road (E), paratype, $\hat{\partial}$, from Ban Na Thong (F), paratype, $\hat{\jmath}$, from Phagneung Phoukulom waterfall $(\mathbf{G}-\mathbf{H})$. A-H. Distal part, sublateral, submesal, dorsal, subdorsal, dorsal, subdorsal, ventral and dorsal views, respectively. Scale bars $=0.2 \mathrm{~mm}$. Red colour shows process $\mathbf{h}$. Green colour shows spine $\mathbf{z}$. 
GoNopoD. Rather simple (Figs 13A-B, 14-15); coxa slightly curved caudad, sparsely setose distoventrally. Femorite slightly curved and stout, with an evident mesal groove and a clear distolateral sulcus demarcating a postfemoral part; process $\mathbf{h}$ prominent, evidently curved, pointed, with a small, but evident dorsal tooth and sometimes with a small ventral denticle (Fig. 13A-B); spine $\mathbf{z}$ pointed, sometimes small (Fig. 15G); solenophore (sph) large, expanded, flattened and typically coiled.

\section{Remark}

This species shows slight variations in gonopod structure, process $\mathbf{h}$ often being rather narrow to slightly broader, while spine $\mathbf{z}$ small to slightly broader (Fig. 15).

\section{Tylopus dorsalis sp. nov. urn:1sid:zoobank.org:act:EDC8D353-BE43-4D79-8BA4-E23D0FD57CE7}

Figs $16-17,26$

\section{Diagnosis}

The live coloration is similar to that of T. trigonum, but the new species differs in the head and collum being light brown (versus blackish), and the pattern not contrasting (versus contrasting); the gonopod structure is similar to that of $T$. crassipes Golovatch, 1984, but the new species differs in process $\mathbf{x}$ being longer and its tip rounded dorsally.

\section{Etymology}

To emphasize process $\mathbf{x}$ on the solenophore arising dorsally; adjective.

\section{Material examined}

\section{Holotype}

LAOS: ${ }^{\lambda}$, Phuthalang forest protected area, Boun Neua, Phongsali, $21^{\circ} 37^{\prime} 30^{\prime \prime} \mathrm{N}, 101^{\circ} 55^{\prime} 55^{\prime \prime}$ E, ca 1125 m a.s.1., 16 Oct. 2014, leg. C. Sutcharit \& R. Srisonchai (CUMZ).

\section{Paratype}

LAOS: 1 , same data as for holotype (CUMZ).

\section{Description}

MEASUREMENTS AND COLOUR. Length 22.1 ( $\overbrace{}^{3})$ or $22.3 \mathrm{~mm}($ ( $)$, width of midbody pro- and metazonae 2.5 and $3.6 \mathrm{~mm}\left({ }^{\Uparrow}\right)$ or 1.97 and $2.55 \mathrm{~mm}(+)$, respectively. Live coloration light brown (Fig. 16A); paraterga, legs and epiproct light yellow-brown, head and collum light brown, antennomere 7 blackish, collum and following terga each with a light brown triangle and a dark brown collar covering both proand metazonae. Coloration of alcohol material faded after one year of preservation to light brown, with a pattern of a dark brown band in pre-sulcus area on metazonae and a pair of paramedian, longitudinal, brown stripes dorsally both on pro- and metaterga; paraterga light red-brown, head brown, antennae, legs, venter and epiproct light yellow-brown (Fig. 16B-J).

HeAD. Clypeolabral region densely, vertex sparsely, setose; epicranial suture distinct. Antennae rather short (Fig. 16A), extending behind body segment $3($ ( ) or 2 (ㅇ) when stretched dorsally. In width, head $<$ segment $3<2=4<$ collum $<$ segments $5-17(\hat{0},+$ ) $)$; thereafter body gently and gradually tapering. Collum with three transverse rows of setae: $3+3$ anterior, $1+1$ intermediate and $2+2$ posterior; a small lateral denticle at about anterior $1 / 3$ (Fig. 16B, D); caudal corner of paraterga very broadly rounded, declined ventrad, not surpassing rear tergal margin. 
BoDy. Tegument smooth and shining, prozonae finely shagreened, metaterga smooth and leathery, posterior halves rugulose, surface below paraterga microgranulate (Fig. 16B-F, H). Postcollum metaterga with two transverse rows of setae: $2+2$ in anterior (pre-sulcus) row, also $2+2$ in posterior (post-sulcus) one. Tergal setae long, strong, slender, about $2 / 3$ of metatergal length. Axial line traceable both on pro- and metazonae. Paraterga well-developed (Fig. 16B, D, F), especially so in $\delta^{\lambda}$, set rather high (at upper 1/3 of body height), anterior edge rounded and narrowly bordered, fused to callus; caudal corner very narrowly rounded, extending increasingly behind rear tergal margin, posterior edge slightly oblique. Calluses on paraterga delimited by a sulcus only dorsally. Paratega 2 broad, anterior edge angular, lateral edge with

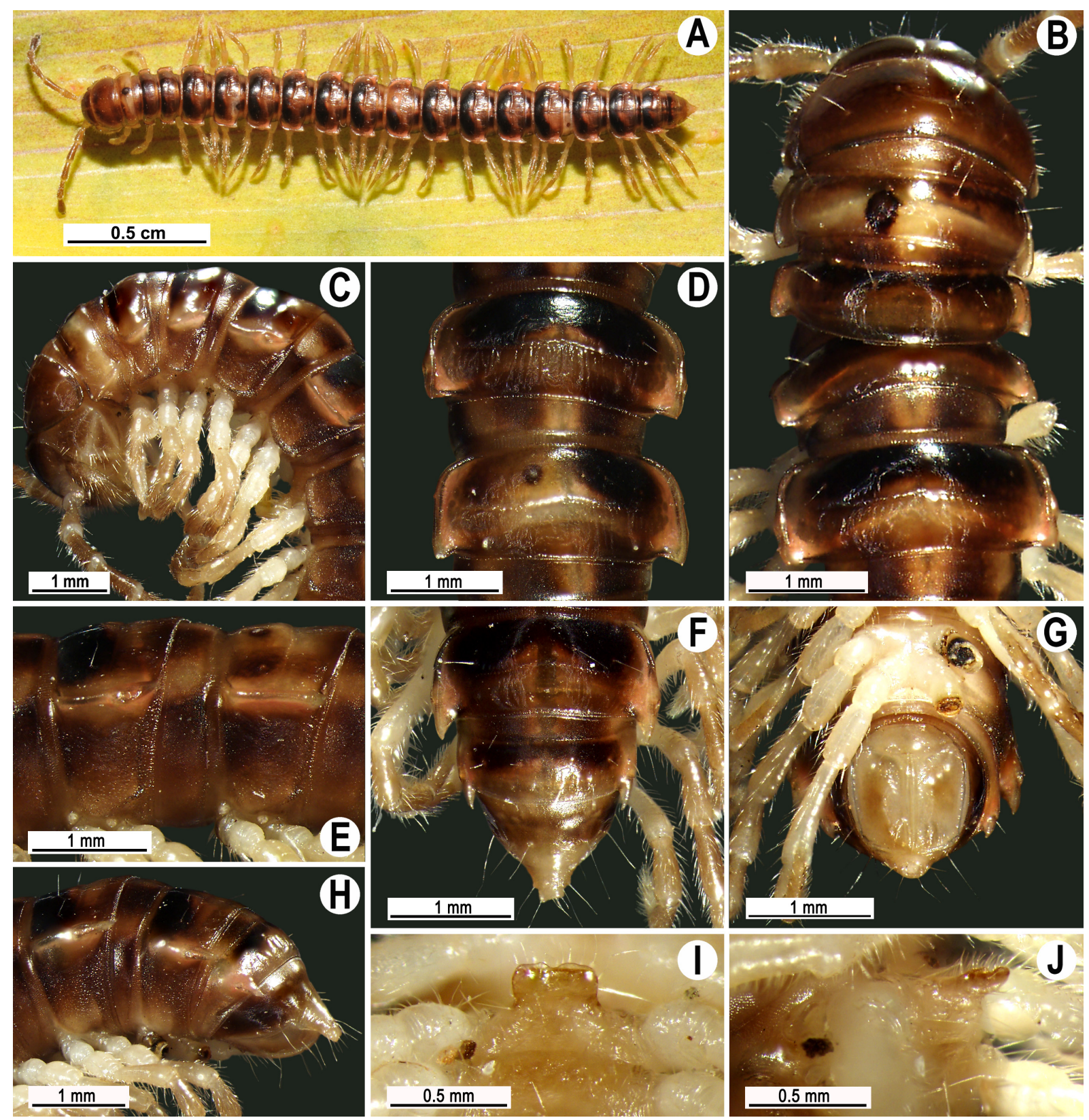

Fig. 16. Tylopus dorsalis sp. nov., holotype, Ô. A. Habitus, live coloration. B-C. Anterior part of body, dorsal and lateral views, respectively. D-E. Segments 10 and 11, dorsal and lateral views, respectively. F-H. Posterior part of body, dorsal, ventral and lateral views, respectively. I-J. Sternal cones between coxae 4, caudal and sublateral views, respectively. 
three evident incisions. Lateral edge of following paraterga with a clear incision in anterior $1 / 3$ (Fig. 16B, D). Paraterga 14-19 with caudal corner extending increasingly behind, with tip evidently curved mesad (Fig. 16F). Ozopores distinct, lateral, lying in an ovoid groove at about $1 / 3$ of metatergal length in front of posterior edge of metaterga. Transverse sulcus usually distinct (Fig. 16B, D, F), slightly incomplete on segment 3, complete on segments 4-18, narrow, line-shaped, deep, not reaching bases of paraterga, beaded at bottom. Stricture between pro- and metazona evident, wide, rather deep, clearly ribbed at bottom down to base of paraterga (Fig. 16B, D-G). Pleurosternal carinae complete crests with a sharp

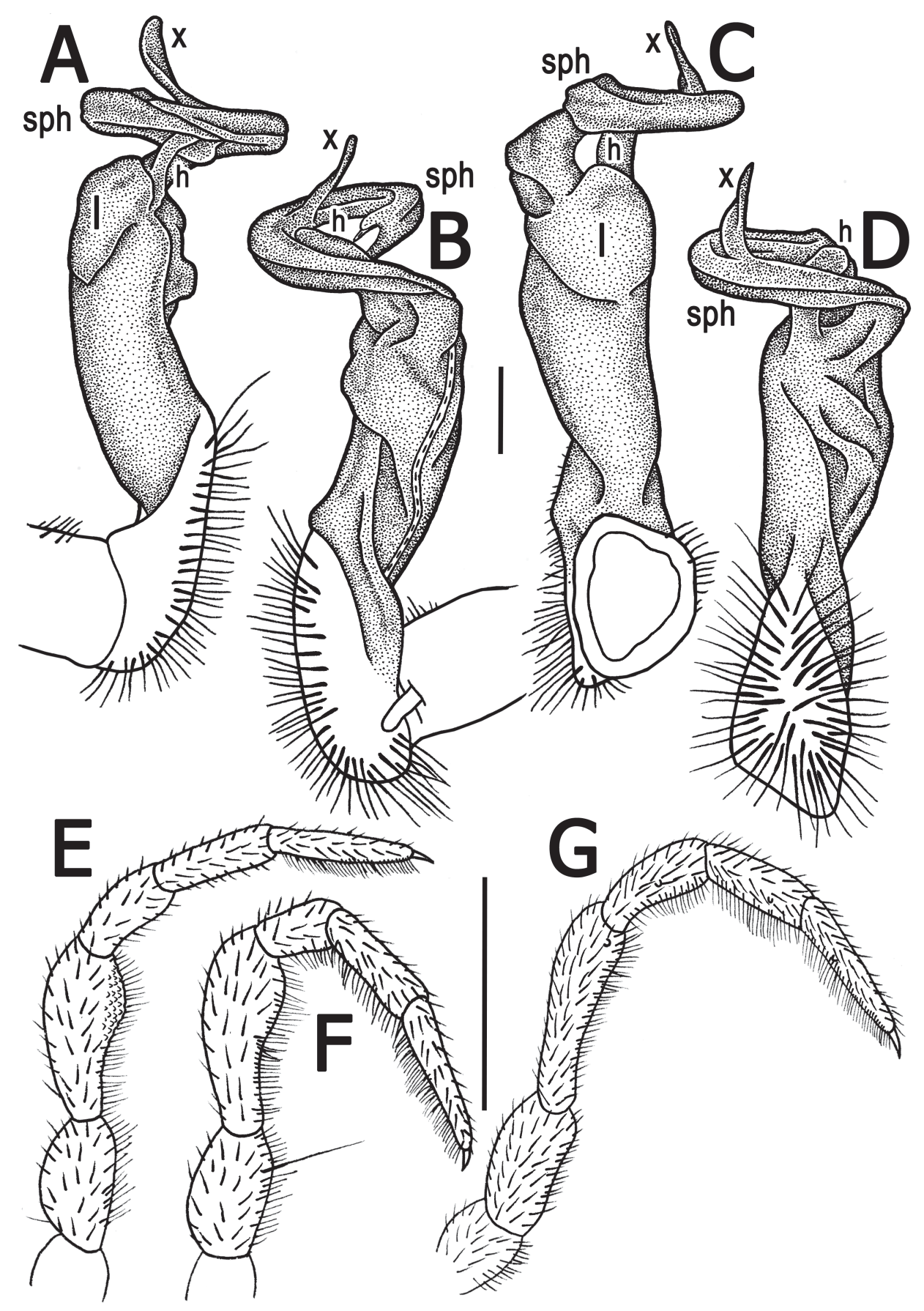

Fig. 17. Tylopus dorsalis sp. nov., holotype, $\widehat{\partial}$. A-D. Right gonopod, lateral, mesal, caudal and oral views, respectively. Scale bars $=0.2 \mathrm{~mm}$. Abbreviations are explained in the text. 
caudal tooth on segments $2-7$, reduced and remaining only a sharp caudal tooth on segment 8 , reduced to a small, delicately denticulate, caudal crest on segments $9-15$, retained as a minute tooth on segment 16 , thereafter missing $(\widehat{\circlearrowleft})$, or with complete crests and a sharp caudal tooth on segments $2-4$, remaining only an evident caudal tooth on segments $5-12$, a rounded caudal crest on segments $13-17$, thereafter missing (ㅇ) (Fig. 16C, E, H). Epiproct (Fig. 16E-G) conical, flattened dorsoventrally, with two evident, rounded, apical papillae; tip subtruncate; lateral pre-apical papillae evident, lying close to tip. Hypoproct roundly subtriangular, setigerous knobs at caudal edge small and well-separated (Fig. 16G).

Sterna. Separsely setose, without modifications; cross-impressions shallow; an entire, linguiform, sternal lobe between $\delta^{\lambda}$ coxae 4 (Fig. 16I-J). Legs long and slender, midbody ones ca 1.3-1.4 ( $\overbrace{}^{\lambda})$ or $0.9-1.1$ (ㅇ) as long as body height; $\widehat{\partial}$ femora 6 bulged and microtuberculate ventrally (Fig. 17E); $\lambda$ femora 7 also bulged ventrally (Fig. 17F), but following femora not swollen; legs of segments 7-16 each with femur, postfemur, tibia and tarsus carrying a small adenostyle (tubercle) medially (Fig. 17G), telopodites particularly densely setose ventrally (Fig. 17G), tarsal brushes present until $\widehat{\delta}$ segment 6 .

GonOPOD. Rather simple (Fig. 17A-D); coxa slightly curved caudad, sparsely setose distoventrally. Femorite slightly curved and stout, with an evident mesal groove and a clear distolateral sulcus demarcating a postfemoral part; process $\mathbf{h}$ rather high, directed anterodorsally, flattened, tip rounded; solenophore (sph) rather slender, strongly coiled, flattened and evidently bifid, with process $\mathbf{x}$ being slim and directed dorsally.

Tylopus thunghaihin sp. nov. urn:1sid:zoobank.org:act:D8C75297-3063-4B15-ADA6-D86AD5796B96

Figs 18-20, 26

\section{Diagnosis}

The new species seems to be especially similar to T. nodulipes (Attems, 1953), but differs in the body tegument being dull, coupled with gonopodal process $\mathbf{m}$ smaller, process $\mathbf{z}$ high and rounded, and process $\mathbf{x}$ pointed.

\section{Etymology}

To emphasize the type locality, in Lao "Thung Hai Hin", commonly translated as the famous Plain of Jars, a noun in apposition.

\section{Material examined}

Holotype

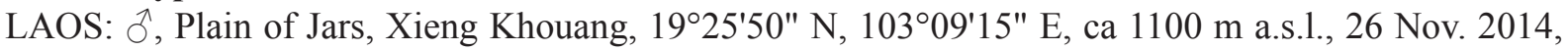
leg. S.I. Golovatch, C. Sutcharit, N. Likhitrakarn (CUMZ).

\section{Paratype}

LAOS: 1 , same data as for holotype (CUMZ).

\section{Description}

MEASUREMENTS AND COLOUR. Length 26.1 (§) or $26.2 \mathrm{~mm}$ ( $(+)$, width of midbody pro- and metazonae 2.02 and $3.02 \mathrm{~mm}\left({ }^{\lambda}\right)$ or 2.04 and $3.04 \mathrm{~mm}$ (\$), respectively. Live coloration brown black (Fig. 18A); antennae, paraterga and legs dark brown. Coloration in alcohol after one year of preservation blackish, paraterga dark brown; venter and a few basal podomeres light brown to yellow-brown, legs increasingly darker brown distally (Fig. 18B-J). 
HEAD. Clypeolabral region and vertex sparsely setose, epicranial suture distinct. Antennae rather short (Fig. 18A), extending behind body segment $3\left({ }^{\Uparrow}\right)$ or $2($ ) $)$ when stretched dorsally. In width, head $<$ segment $3<4<5<$ collum $<$ segment $2<6-16(\hat{0}$,,+ ); thereafter body gently and gradually tapering. Collum with three transverse rows of setae: $4+4$ anterior, $1+1$ intermediate and $3+3$ posterior; with a small lateral incision near midway (Fig. 18B, D); caudal corner of paraterga very broadly rounded, declined ventrad, not surpassing rear tergal margin.

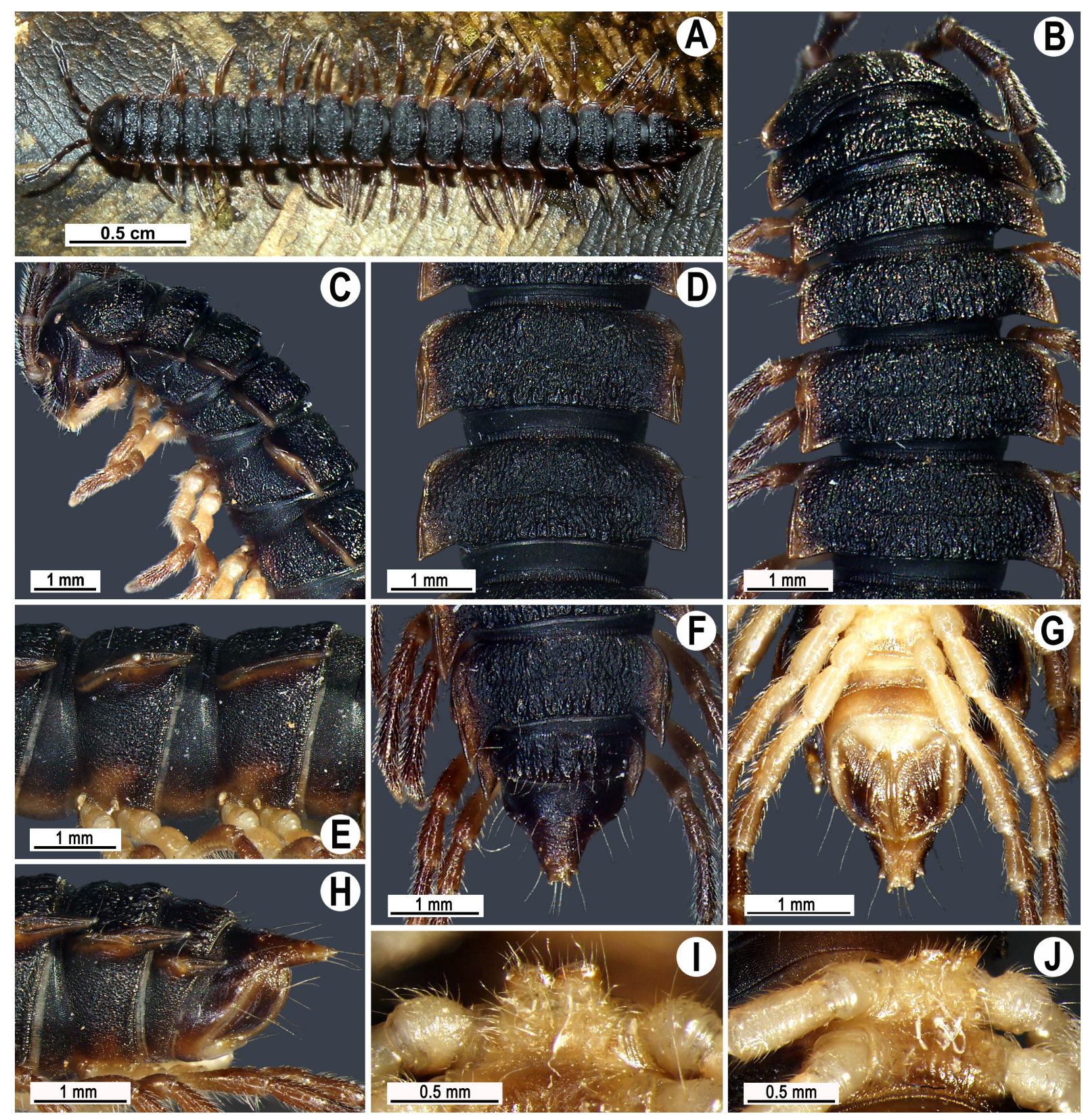

Fig. 18. Tylopus thunghaihin sp. nov., holotype, $\widehat{\jmath}$. A. Habitus, live coloration B-C. Anterior part of body, dorsal and lateral views, respectively. D-E. Segments 10 and 11, dorsal and lateral views, respectively. F-H. Posterior part of body, dorsal, ventral and lateral views, respectively. I-J. Sternal cones between coxae 4, caudal and sublateral views, respectively. 
BoDy. Tegument dull, shining, prozonae finely shagreened; metaterga often roughly microgranulate and rugulose, leathery; surface below paraterga more delicately, but still sufficiently clearly microgranulate and rugulose (Fig. 18A-F, H). Metaterga with two transverse rows of small setigerous cones: $2+2$ in anterior (pre-sulcus) row and $3+3$ setae usually borne on low, oblong, rounded tubercles in posterior (post-sulcus) row, except for metaterga 17-19, these latter bearing 3(2)+3(2) setae in anterior row and $4+4$ in posterior row. Tergal setae simple, slender, often abraded, about as long as $1 / 3$ of metazonite. Axial line visible both on pro- and metazonae. Paraterga strongly developed (Fig. 18B, D, F), especially so in $\widehat{0}$, set high (at upper $1 / 4$ of body height), anterior edge rounded and narrowly bordered, fused to callus; caudal corner very narrowly rounded, extending increasingly behind rear tergal margin, posterior edge slightly oblique. Calluses on paraterga delimited by a sulcus only dorsally. Paratega 2 broad, anterior edge angular, lateral edge with three evident incisions. Lateral edge of following paraterga with a clear incision in anterior $1 / 3$ (Fig. 18B, D, F). Paraterga 16-19 with caudal corner extending increasingly caudally, tip clearly curved mesad (Fig. 18F). Ozopores evident, lateral, lying in an ovoid groove at about $1 / 3$ in front of posterior edge of metaterga. Transverse sulcus distinct (Fig. 18B, D, F), slightly incomplete on segments 4 and 18, complete on segments 5-17, narrow, wave-shaped, rather deep, not reaching bases of paraterga, ribbed at bottom. Stricture between pro- and metazonae evident, wide, deep, ribbed at bottom down to base of paraterga (Fig. 18B-G). Pleurosternal carinae complete crests with a sharp caudal tooth on segments $2-4(\hat{O}$,,+$)$, increasingly reduced to a front bulge and a caudal tooth until segment 7 , retained only as a sharp caudal tooth until segment 16 , thereafter missing $\left({ }^{\lambda}\right)$, or increasingly reduced and remaining only a sharp caudal tooth until segment 15 , thereafter missing (o) (Fig. 18C, E, H). Epiproct (Fig. 18F-H) conical, flattened dorsoventrally, with two evident, rounded,

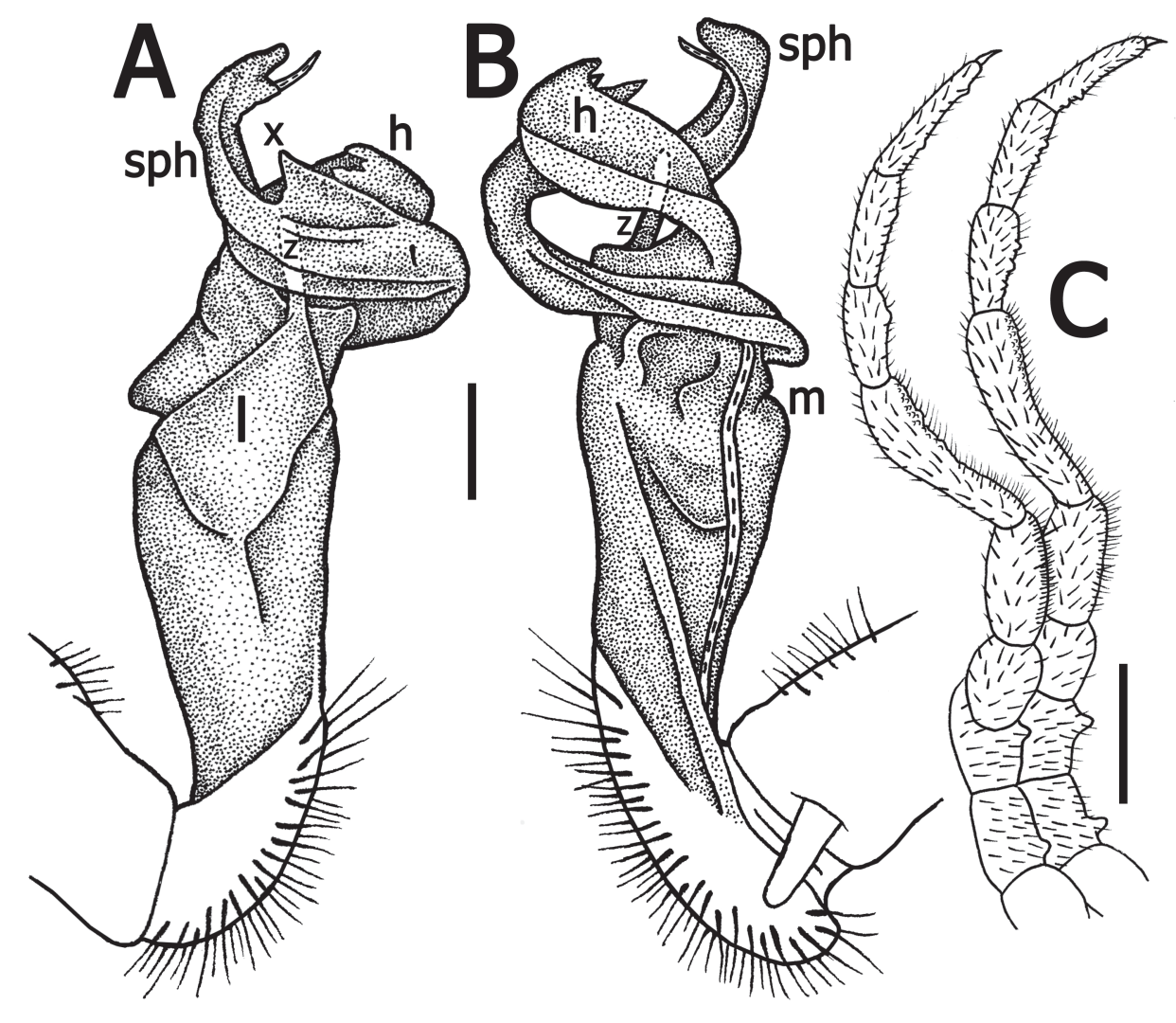

Fig. 19. Tylopus thunghaihin sp. nov., holotype, $\widehat{\partial}$. A-B. Right gonopod, lateral and mesal views, respectively. C. Leg of segment 9. Scale bars: A-B $=0.2 \mathrm{~mm} ; \mathrm{C}=1 \mathrm{~mm}$. Abbreviations are explained in the text. 
apical papillae; tip subtruncate; lateral pre-apical papillae large, lying close to tip. Hypoproct roundly subtriangular, setigerous knobs at caudal edge small and well-separated (Fig. 18G).

Sterna. Sparsely setose, with a small, but evident cone caudally near each coxa, rear cones being a little larger than fore ones (Fig. 19C); cross-impressions shallow; a large, central, slightly bifid, setose lobe between $\delta^{\lambda}$ coxae 4 (Fig. 18I-J). Legs long and slender, midbody ones ca 1.2-1.4 ( ${ }^{\lambda}$ ) or 1.1-1.2 (ㅇ) as long as body height; legs of $\delta$ segments $5-17$ with femur showing a field of ventral microgranulations, while postfemur, tibia and tarsus each with 1-3 minute adenostyles (tubercles), prefemora not swollen (Fig. 19G), ô telopodites with particularly dense short setae ventrally (Fig. 19G), tarsal brushes present until body segment 8 .

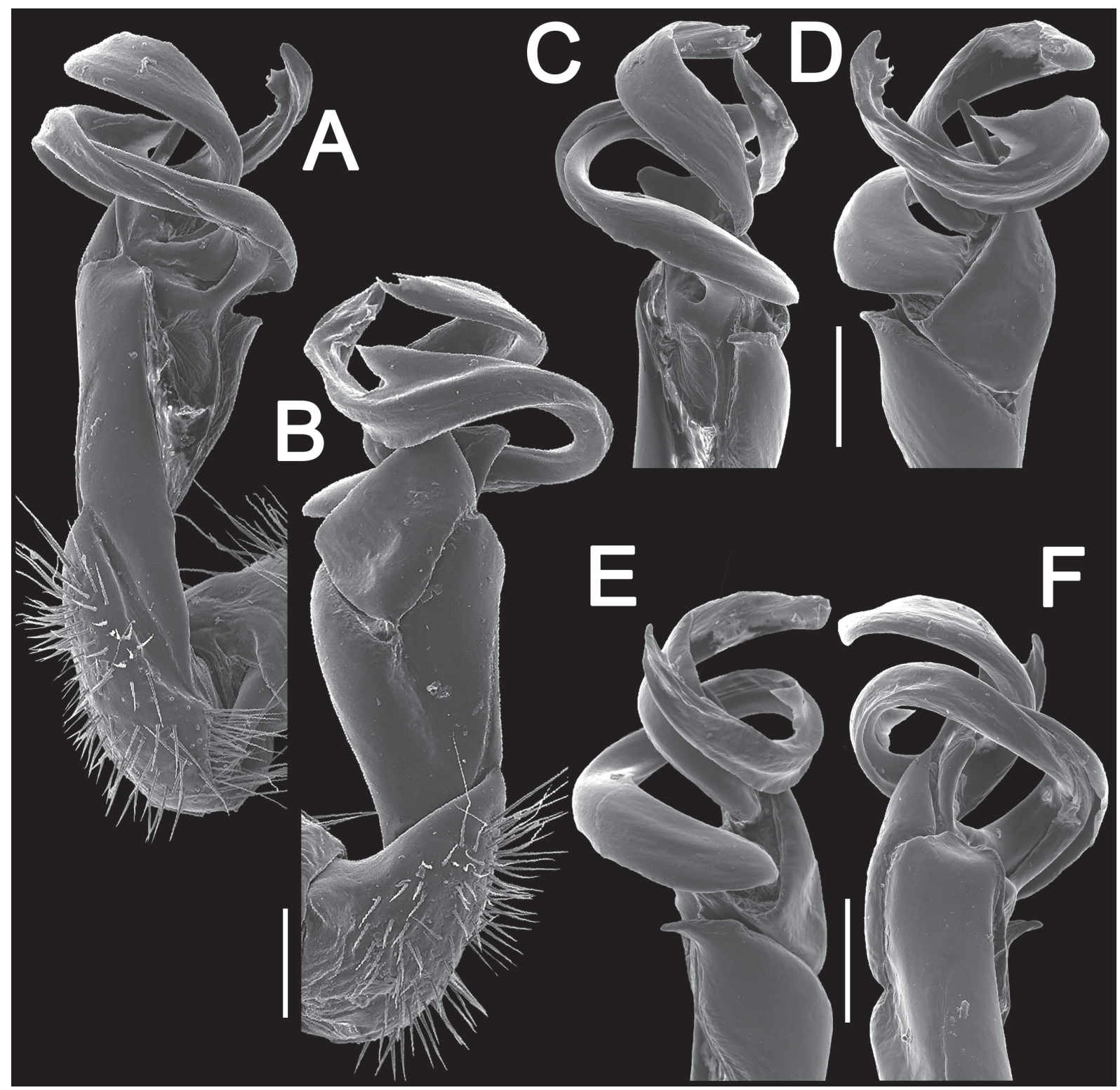

Fig. 20. Tylopus thunghaihin sp. nov., holotype, ठ̊, right gonopod. A-B. Mesal and lateral views, respectively. C-F. Distal part, submesal, sublateral, subcaudal and suboral views, respectively. Scale bars $=0.2 \mathrm{~mm}$. 
GonOPOD. Rather complex (Figs 19A-B, 20); coxa slightly curved caudad, sparsely setose distoventrally. Femorite slightly curved and stout, with an evident mesal groove and a clear distolateral sulcus demarcating a postfemoral part; process $\mathbf{h}$ high, strongly twisted, tip evidently bifid; process $\mathbf{m}$ short; process $\mathbf{z}$ rather long, sausage-shaped; solenophore (sph) large, strongly coiled, expanded distally, flattened and clearly bifid; process $\mathbf{x}$ large, dentiform and pointed dorsally.

\section{Remarks}

This species has been found under stones, each specimen located in its own burrow of ca $30 \mathrm{~cm}$ long under its own stone and forming a kind of small cavern, all in the Plain of Jars, Laos.

Tylopus punctus sp. nov. urn:1sid:zoobank.org:act:35585ACA-8490-49EE-8DA5-73EB3EB04A5C

Figs 21-22, 26

\section{Diagnosis}

Very similar to T. silvestris (Pocock, 1895), but differs in the smaller size, the width of midbody being 2.1-2.5 $\mathrm{mm}$ (versus $3.0 \mathrm{~mm}$ ); the caudal corner of midbody paraterga very narrowly rounded and not drawn behind the rear tergal margin (versus nearly pointed and produced behind the rear tergal margin), and gonopod process $\mathbf{h}$ small and pointed (versus absent).

\section{Etymology}

To emphasize gonopod process $\mathbf{h}$ being small and pointed; adjective.

\section{Material examined}

\section{Holotype}

MYANMAR: $\widehat{\partial}$, Mintaingbin Forest Camp, ca $35 \mathrm{~km}$ north of Aungban, Chan State, 20 $55^{\prime 2} 20^{\prime \prime} \mathrm{N}$, 96 33'60" E, ca 1300 m a.s.1., 11-23 Jun. 2004, leg. H. Schillhammer \& H.V. Shaverdo (NHMW$8248)$.

\section{Paratype}

MYANMAR: 1 , same data as for holotype (NHMW-8249).

\section{Description}

MEASUREMENTS AND COLOUR. Length $27.5\left({ }^{3}\right)$ or $29 \mathrm{~mm}(+)$, width of midbody pro- and metazonae 1.56 and $2.1 \mathrm{~mm} \mathrm{( \Im )}$ or 1.98 and $2.5 \mathrm{~mm}(q)$, respectively. Coloration of alcohol material upon long-term preservation rather uniformly light brown to brown, with light yellow paraterga, antennae, venter and legs (Fig. 21A-I).

HeAD. Clypeolabral region and vertex sparsely setose, epicranial suture distinct. Antennae rather short (Fig. 21B), reaching only in front of body segment $3(\hat{O},+$ ) when stretched dorsally. In width, segment $3<4<$ head $<$ collum $<$ segment $2<5-15$; thereafter body gently and gradually tapering. Collum with three transverse rows of setae: $4+4$ anterior, $2+2$ intermediate and $3+3$ posterior; an evident lateral incision at about anterior $1 / 3$; caudal corner of paraterga very broadly rounded, declined ventrad, not drawn behind rear tergal margin.

BoDy. Tegument smooth and shining, prozonae very finely shagreened, metaterga rather smooth and leathery, with posterior halves faintly rugulose, surface below paraterga finely microgranulate (Fig. 21A-F). Postcollum metaterga with two transverse rows of setae: $2+2$ in anterior (pre-sulcus) row, mostly abraded, and $2+2$ in posterior (post-sulcus) row, mostly traceable as insertion points, except 
for segments 18 and 19, each latter with $4+4$ setae in posterior row. Tergal setae simple, slender, about $1 / 3$ of metatergal length (Fig. 21A, F). Axial line visible both on pro- and metazonae. Paraterga welldeveloped (Fig. 21A-G), especially so in ${ }^{3}$, set high (at upper $1 / 4$ of body height), anterior edge rounded and narrowly bordered, fused to callus; caudal corner very narrowly rounded, segments 2 and 3 slightly extending behind rear tergal margin, thereafter not surpassing rear tergal margin until segment 15 (Fig. 21A-D). Paratega 2 broad, anterior edge angular, lateral edge with two small, but evident incisions in anterior half. Following paraterga with an evident incision in anterior $1 / 3$ of lateral edge (Fig. 21A, C, F). Calluses on paraterga delimited by a sulcus only dorsally, rather narrow, a little wider on porebearing segments. Ozopores distinct, lying at about $1 / 4$ of metatergal length in front of posterior edge of metaterga. Transverse sulcus usually distinct (Fig. 21 A, D, F), slightly incomplete on segment 19, complete on segments 5-18, narrow, line-shaped, rather deep, reaching bases of paraterga, beaded at bottom. Stricture between pro- and metazonae evident, rather wide and deep, beaded at bottom down to base of paraterga (Fig. 21A, C-F). Pleurosternal carinae complete crests with a sharp caudal tooth on segments 2 and 3 , thereafter increasingly reduced and remaining a sharp caudal tooth until segment $9(ð)$ or $6($ ( $)$, retained as a small caudal tooth and increasingly reduced until segment 17, absent from segment $18(ð)$ or 7 ( ( ). Epiproct (Fig. 21E-G) conical, flattened dorsoventrally, with two evident,

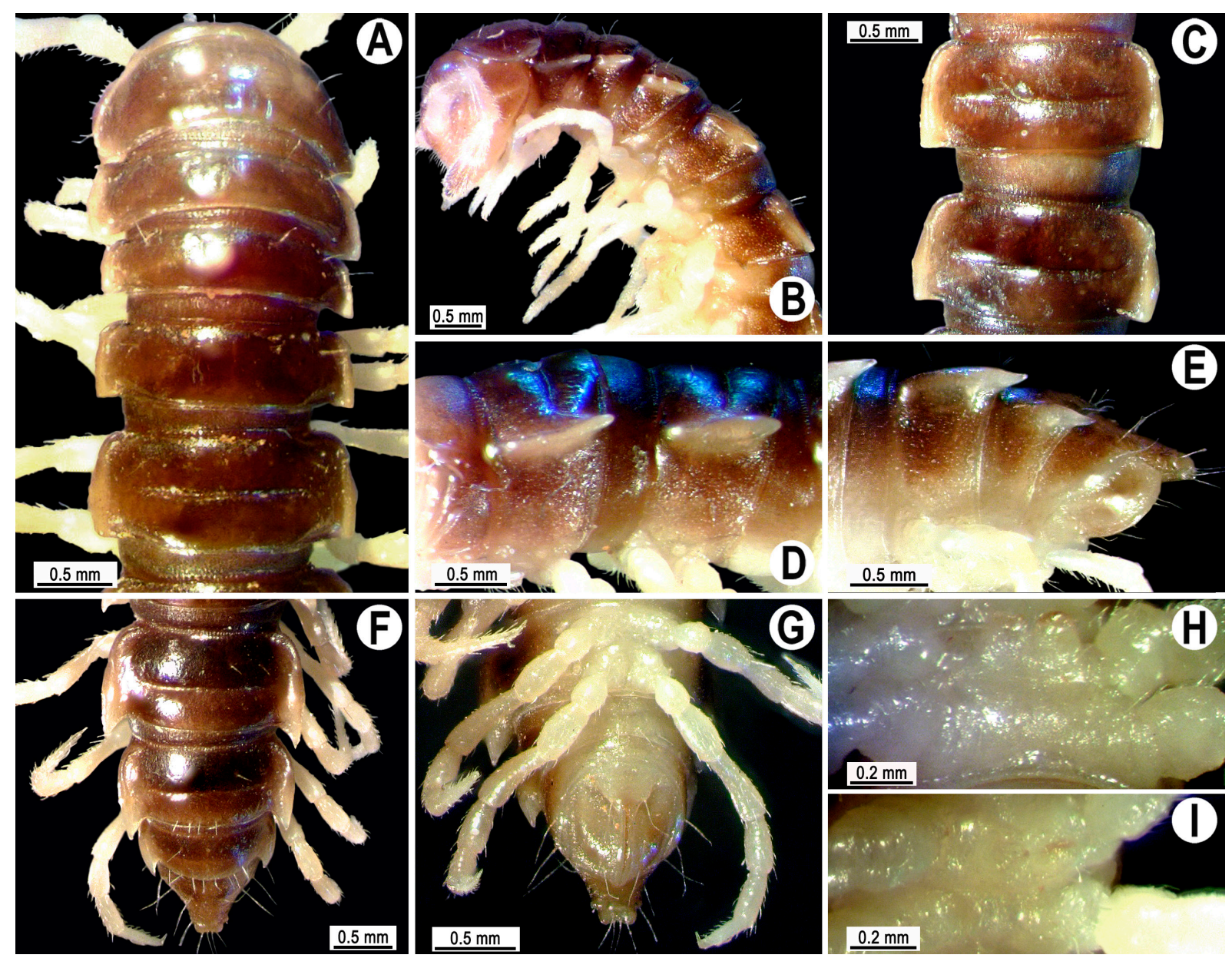

Fig. 21. Tylopus punctus sp. nov., holotype, ふૈ. A-B. Anterior part of body, dorsal and lateral views, respectively. C-D. Segments 11-12, dorsal and lateral views, respectively. E-G. Posterior part of body, lateral, subdorsal and subventral views, respectively. H-I. Sternal cones between coxae 4, subcaudal and sublateral views, respectively. 
rather large, rounded, apical papillae; tip subtruncate; lateral pre-apical papillae clear, lying close to tip. Hypoproct roundly subtriangular, setigerous knobs at caudal edge small and well-separated (Fig. 21G).

STERNA. Sparsely setose, without modifications, but with a pair of small, blunt, fully separated cones between $\sigma^{\lambda}$ coxae 4 (Fig. $\left.21 \mathrm{H}, \mathrm{I}\right)$. Legs rather short and slender, midbody ones ca 1.1-1.2 (ठ) or 0.8-0.9 (ㅇ) as long as body height, $\widehat{\delta}$ prefemora not swollen, $\widehat{\partial}$ tarsal brushes present only on legs 1 and 2.

GoNOPOD. Rather simple (Fig. 22); coxa slightly curved caudad, sparsely setose distoventrally. Prefemur sparsely setose, about $1 / 3$ as long as femorite + postfemoral part. Femorite curved and stout, with an evident mesal groove and a strong distolateral sulcus demarcating a postfemoral part; process $\mathbf{h}$ small, slender and pointed; solenophore (sph) clearly coiled, long and flattened.

\section{Remark}

Pocock (1895) described only T. doriae (Pocock, 1895) and T. silvestris from northern Myanmar, the above being a third species of this genus also occurring in northern Myanmar.

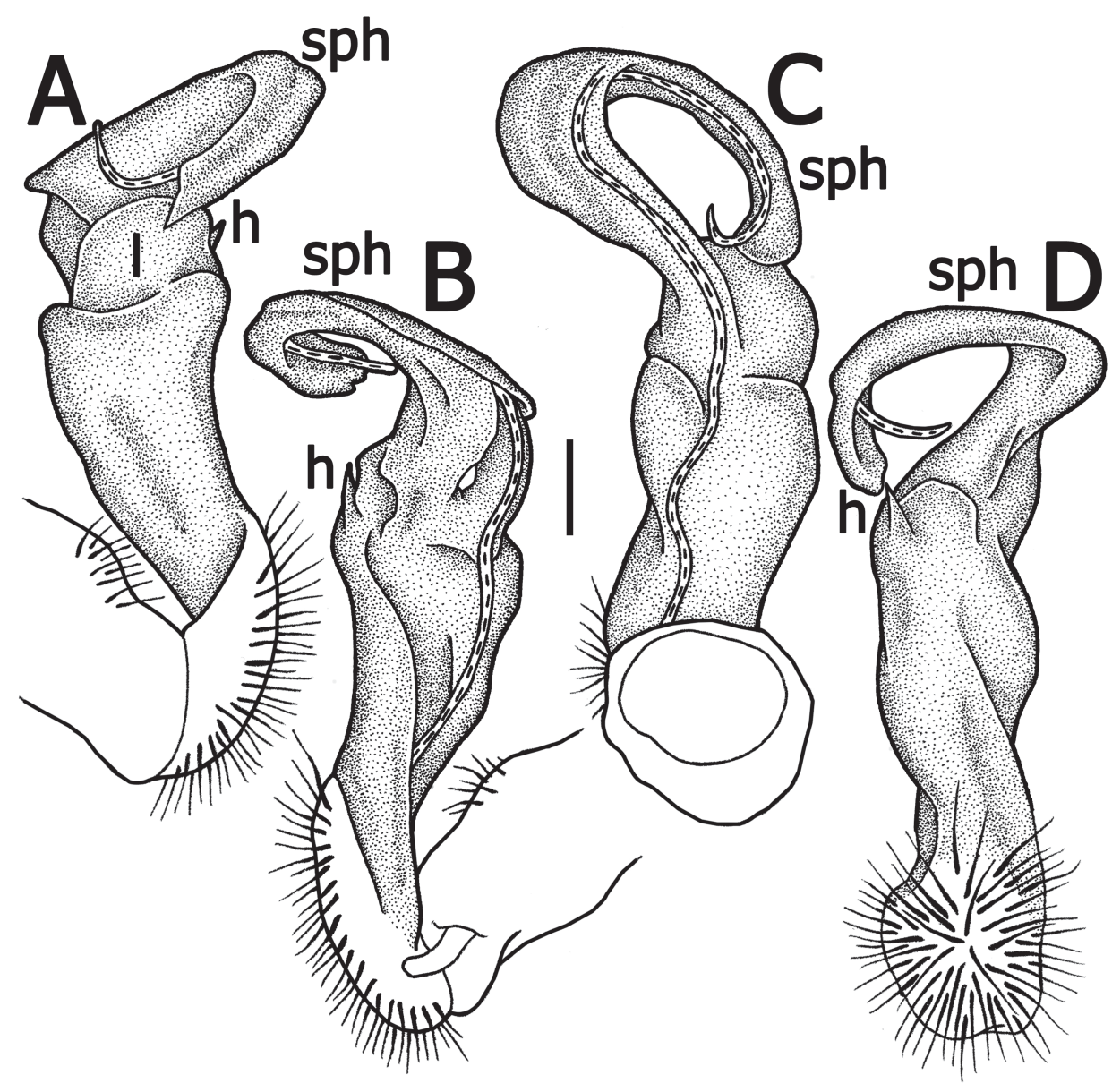

Fig. 22. Tylopus punctus sp. nov., holotype, $\widehat{\partial}$. A-D. Left gonopod, lateral, mesal, subcaudal and suboral views, respectively. Scale $b a r=0.2 \mathrm{~mm}$. Abbreviations are explained in the text. 


\section{New faunistic record}

Tylopus baenzigeri Golovatch \& Enghoff, 1993

Figs 23-26

Tylopus baenzigeri Golovatch \& Enghoff, 1993: 101, figs 50-51 (Type locality, Doi Suthep National Park).

Tylopus baenzigeri - Enghoff 2005: 99. — Likhitrakarn et al. 2010: 25; 2014a: 65.

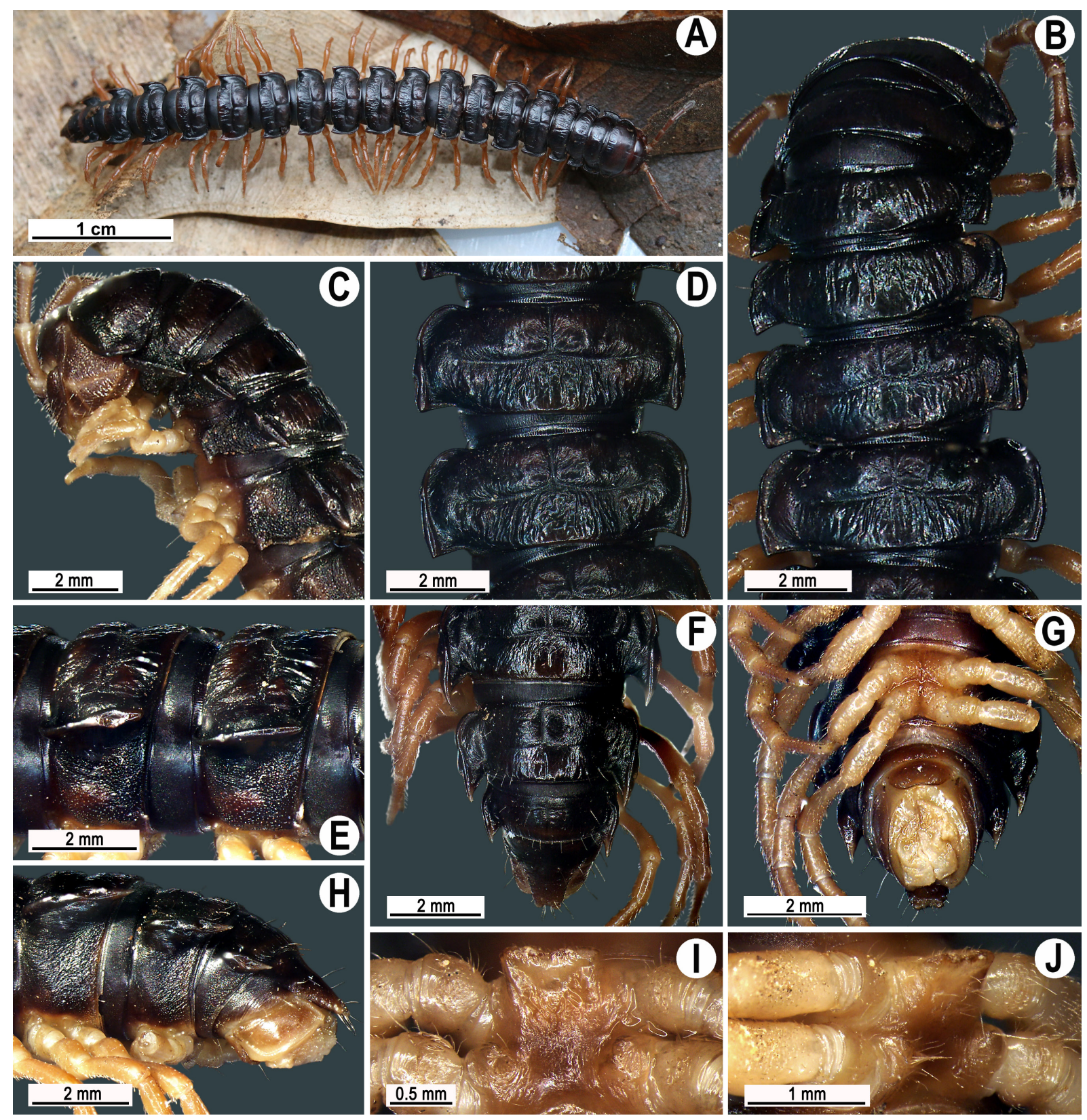

Fig. 23. Tylopus baenzigeri Golovatch \& Enghoff, 1993, §. A. A. Habitus, live coloration. B-C. Anterior part of body, dorsal and lateral views, respectively. D-E. Segments 10 and 11, dorsal and lateral views, respectively. F-H. Posterior part of body, dorsal, ventral and lateral views, respectively. I-J. Sternal cones between coxae 4 , subcaudal and sublateral views, respectively. 


\section{Material examined}

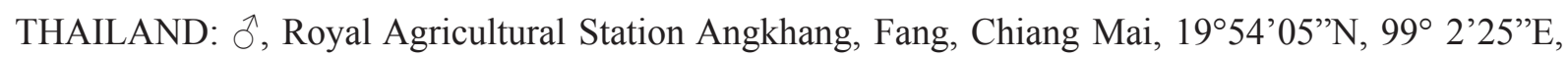
ca 1420 m a.s.l., 12 August 2014, leg. N. Likhitrakarn (CUMZ).

\section{Descriptive notes}

MEASUREMENTS AND COLOUR. Length $43.8 \mathrm{~mm}$, width of midbody pro- and metazonae 3.51 and $5.04 \mathrm{~mm}$, respectively. Coloration of live animal, as well as of alcohol material black-brown (Fig. 23A-G), head and venter dark to light brown, legs and antennae yellowish brown to light yellowish.

BoDy. Antennae rather short (Fig. 23B), extending behind body segment 3 ( $\left.\delta^{\Uparrow}\right)$ when stretched dorsally. In width, segment $3<4<5<$ collum $<$ segment $2<6-17$; thereafter body gently and gradually tapering. Collum with three transverse rows of setae: $4+4$ anterior, $1+1$ intermediate and $4+4$ posterior; a very faint incision laterally in posterior $1 \frac{1}{3}$; caudal corner of paraterga very broadly rounded, not drawn behind rear tergal margin (Fig. 23B-C). Paraterga 2 well-developed (Fig. 23B-C), horizontal, lateral edge with two minute incisions in anterior half, caudal corner very narrowly rounded. Paraterga 3 and 4 each nearly pointed, expanded laterally, with two minute incisions in the middle. Sterna densely setose and finely microtuberculate (Fig. 24D); with a large, subtrapeziform, ventrally slightly concave, sternal lobe between $\sigma^{\lambda}$ coxae 4 (Fig. 23I-J). Legs rather long and slender, midbody ones ca 1.2-1.3 ( $\sigma^{\lambda}$ ) as long as

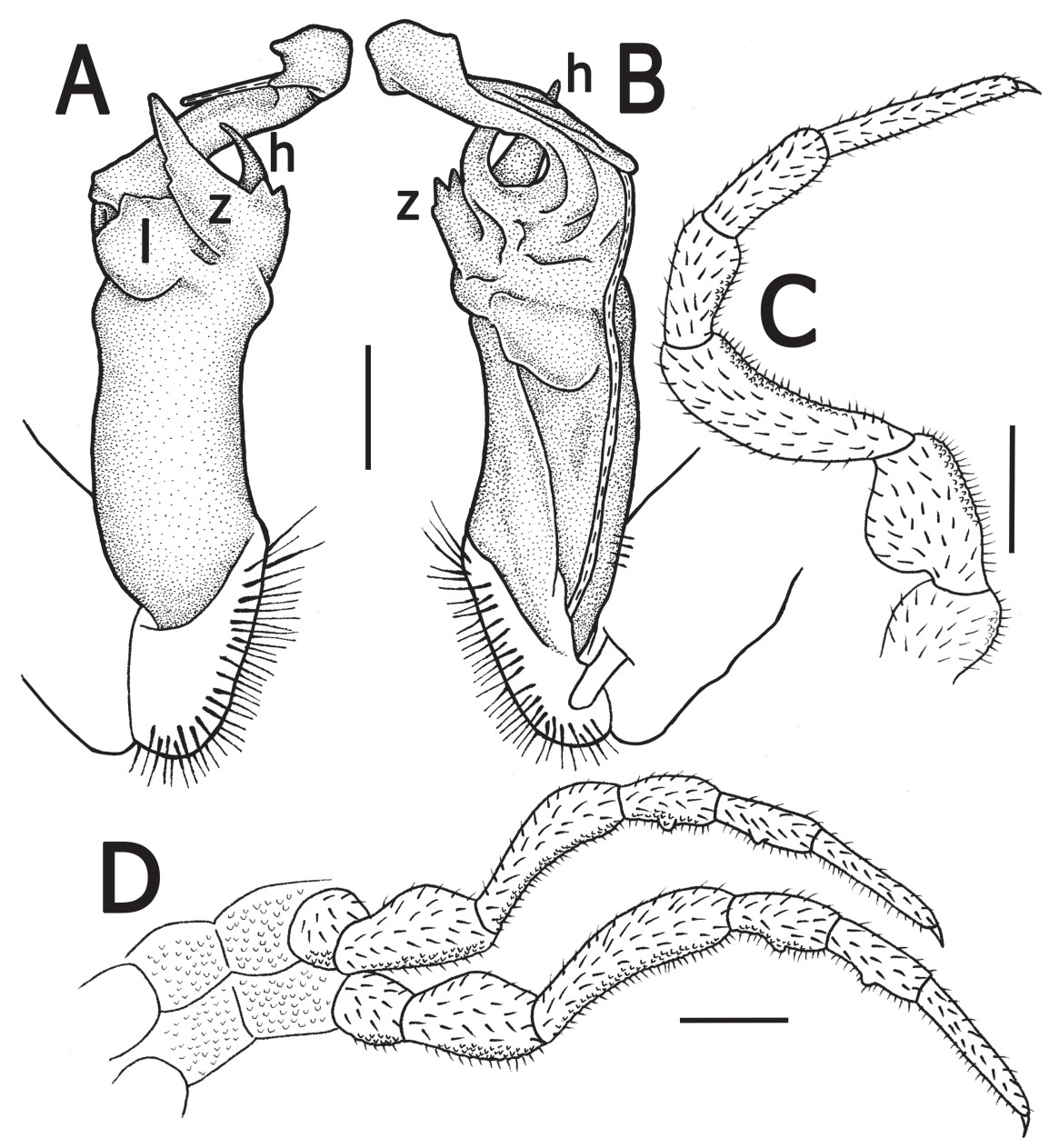

Fig. 24. Tylopus baenzigeri Golovatch \& Enghoff, 1993, đ. A-B. Right gonopod, lateral and mesal views, respectively. C. Leg 8 . D. Legs of segment 11 . Scale bars $=0.5 \mathrm{~mm}$. Abbreviations are explained in the text. 
body height; $\hat{\partial}$ legs without tarsal brushes; $\hat{\partial}$ postfemora and tibiae each with an adenostyle (tubercle) on segments 8-17; $\partial^{\lambda}$ coxae, prefemora, femora and postfemora microtuberculate ventrally (Fig. 24C-D).

\section{Remarks}

This new specimen agrees in most details with the original description (Golovatch \& Enghoff 1993), especially in gonopod structure which shows a huge spine $\mathbf{z}$ serrate on both sides (Figs 24A-B, 3), and in a large body. Thus, to document its identity the new specimen has been illustrated in detail for comparative purposes (Figs 23-25). The type locality of T. baenzigeri, Doi Suthep National Park, is located quite far away (about $120 \mathrm{~km}$ ) from this new place.

\section{Checklist}

Table 1 presents a checklist of the known or new Tylopus species, all arranged in alphabetic order. Data on their distribution are also provided.

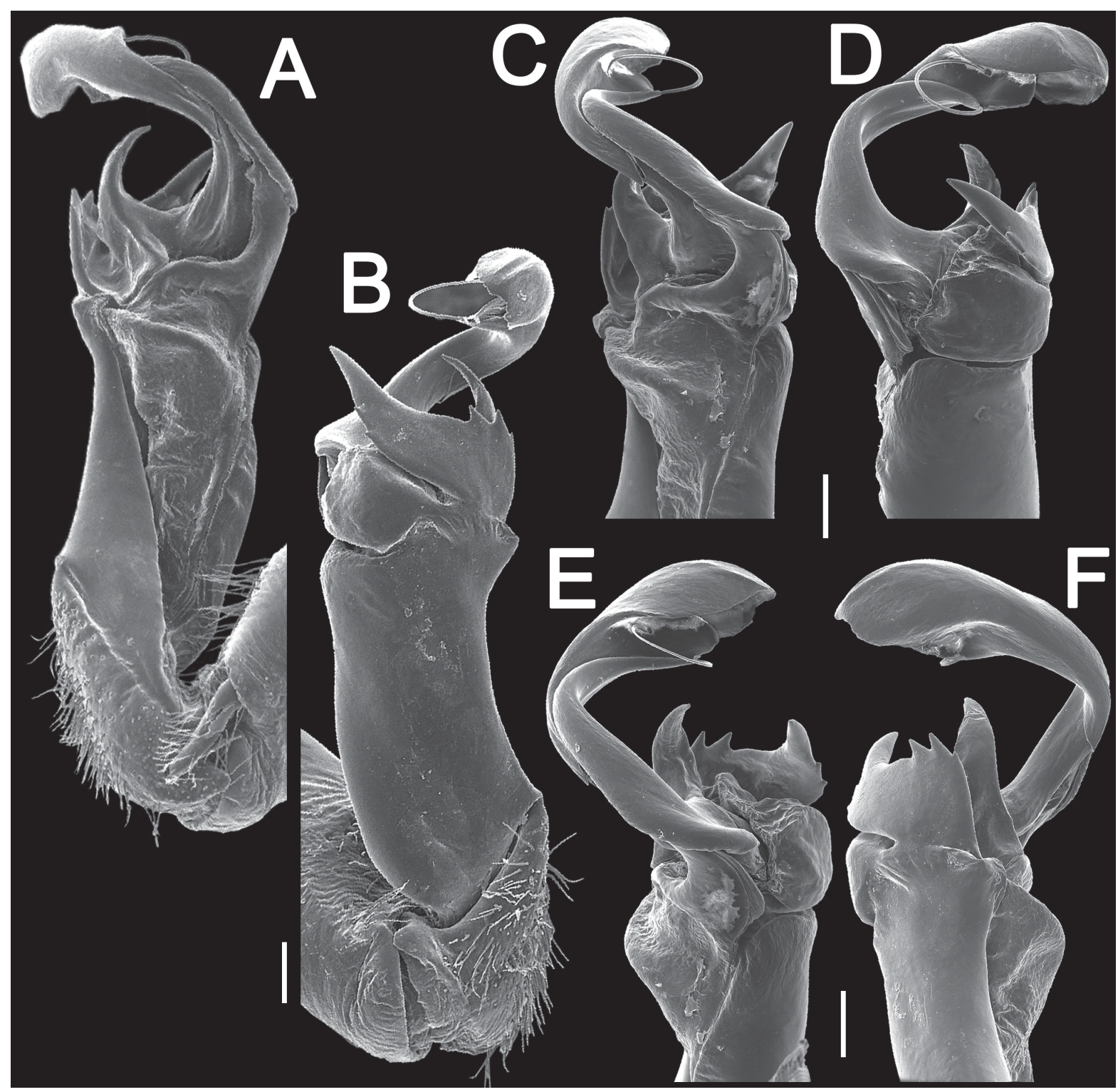

Fig. 25. Tylopus baenzigeri Golovatch \& Enghoff, 1993, ô, right gonopod. A-B. Mesal and lateral views, respectively. C-F. Distal part, submesal, sublateral, subcaudal and suboral views, respectively. Scale bar $=0.2 \mathrm{~mm}$. 
Table 1. Records of Tylopus species.

\begin{tabular}{|c|c|c|}
\hline No. & Species & Localities \\
\hline 1 & Tylopus acuminatus sp. nov. & $\begin{array}{l}\text { Ban Sin Chai; Phuthalang forest protected } \\
\text { area; Phufa; Ban Borkhun; Khoua; Ban Na } \\
\text { Thong, Phongsali Province, Phagneung } \\
\text { Phoukulom waterfall, Luang Namtha } \\
\text { Province, Laos (see details above). }\end{array}$ \\
\hline 2 & Tylopus affinis Golovatch \& Enghoff, 1993 & $\begin{array}{l}\text { Doi Suthep National Park (Golovatch \& } \\
\text { Enghoff 1993); Doi Inthanon National Park, } \\
\text { Chiang Mai Province, Thailand (Golovatch } \\
\text { \& Enghoff 1993; Enghoff 2005). }\end{array}$ \\
\hline 3 & Tylopus allorugosus Golovatch \& Enghoff, 1993 & $\begin{array}{l}\text { Doi Inthanon National Park; Doi Suthep } \\
\text { National Park, Chiang Mai Province, } \\
\text { Thailand (Golovatch \& Enghoff 1993; } \\
\text { Likhitrakarn et al. 2010). }\end{array}$ \\
\hline 4 & Tylopus amicus Golovatch \& Enghoff, 1993 & $\begin{array}{l}\text { Doi Pha Hom Pok National Park, Chiang } \\
\text { Mai Province, Thailand (Golovatch \& } \\
\text { Enghoff 1993). }\end{array}$ \\
\hline 5 & Tylopus asper Golovatch \& Enghoff, 1993 & $\begin{array}{l}\text { Doi Inthanon National Park, Chiang Mai } \\
\text { Province, Thailand (Golovatch \& Enghoff } \\
\text { 1993). }\end{array}$ \\
\hline 6 & Tylopus baenzigeri Golovatch \& Enghoff, 1993 & $\begin{array}{l}\text { Doi Suthep National Park (Golovatch \& } \\
\text { Enghoff 1993); Royal Agricultural Station, } \\
\text { Angkhang Chiang Mai Province, Thailand } \\
\text { (see above). }\end{array}$ \\
\hline 7 & $\begin{array}{l}\text { Tylopus bispinosus Likhitrakarn, Golovatch, } \\
\text { Prateepasen \& Panha, } 2010\end{array}$ & $\begin{array}{l}\text { Umphang, Tak Province, Thailand } \\
\text { (Likhitrakarn et al. 2010). }\end{array}$ \\
\hline 8 & Tylopus coriaceus Golovatch \& Enghoff, 1993 & $\begin{array}{l}\text { Phu Kheio, Chaiyapum Province, Thailand } \\
\text { (Golovatch \& Enghoff 1993). }\end{array}$ \\
\hline 9 & $\begin{array}{l}\text { Tylopus corrugatus Likhitrakarn, Golovatch \& } \\
\text { Panha, } 2014\end{array}$ & $\begin{array}{l}\text { Doi Inthanon National Park, Chiang Mai } \\
\text { Province, Thailand (Likhitrakarn et al. } \\
\text { 2014a). }\end{array}$ \\
\hline 10 & Tylopus crassipes Golovatch, 1984 & $\begin{array}{l}\text { Oquyho (Golovatch 1984); Nam Xay } \\
\text { commune; Hoang Lien National Park, Lao } \\
\text { cai Province, Vietnam (Nguyen 2012). }\end{array}$ \\
\hline 11 & Tylopus degerboelae Golovatch \& Enghoff, 1993 & $\begin{array}{l}\text { Doi Inthanon National Park; Doi Chiang } \\
\text { Dao National Park (Golovatch \& Enghoff } \\
\text { 1993); Doi Suthep National Park (Golovatch } \\
\text { \& Enghoff 1993, Likhitrakarn et al. 2010); } \\
\text { Doi Phatang, Chiang Mai Province, } \\
\text { Thailand (Likhitrakarn et al. 2010). } \\
\end{array}$ \\
\hline 12 & Tylopus deharvengi Liu \& Luo, 2013 & $\begin{array}{l}\text { Yaonan Dong, Guangxi, China (Liu \& Luo } \\
\text { 2013). }\end{array}$ \\
\hline 13 & Tylopus doriae (Pocock, 1895) & $\begin{array}{l}\text { Yado; Bia-po; Meteleo; Puepoli, Myanmar } \\
\text { (Pocock 1895); Doi Suthep National Park, } \\
\text { Chiang Mai Province, Thailand (Golovatch } \\
\text { \& Enghoff 1993). }\end{array}$ \\
\hline
\end{tabular}




\begin{tabular}{|c|c|c|}
\hline No. & Species & Localities \\
\hline 14 & Tylopus dorsalis sp. nov. & $\begin{array}{l}\text { Phuthalang forest protected area, Phongsali } \\
\text { Province, Laos (see above) }\end{array}$ \\
\hline 15 & $\begin{array}{l}\text { Tylopus extremus Likhitrakarn, Golovatch, } \\
\text { Prateepasen \& Panha, } 2010\end{array}$ & $\begin{array}{l}\text { Doi Phahom Pok National Park, Fang } \\
\text { District, Chiang Mai Province, Thailand } \\
\text { (Likhitrakarn et al. 2010). }\end{array}$ \\
\hline 16 & Tylopus flavolineatus sp. nov. & $\begin{array}{l}\text { Wat Tham Santisuk, Lopburi Province } \\
\text { Thailand (see above) }\end{array}$ \\
\hline 17 & Tylopus golovatchi Nguyen, 2012 & $\begin{array}{l}\text { Xuan Son National Park, Phu Tho Province, } \\
\text { Vietnam (Nguyen 2012). }\end{array}$ \\
\hline 18 & $\begin{array}{l}\text { Tylopus grandis Likhitrakarn, Golovatch, } \\
\text { Prateepasen \& Panha, } 2010\end{array}$ & $\begin{array}{l}\text { Pha Mon Cave; Mae Lana, Pangmapha } \\
\text { District, Mae Hong Son Province } \\
\text { (Likhitrakarn et al. 2010). }\end{array}$ \\
\hline 19 & Tylopus granulatus Golovatch, 1984 & $\begin{array}{l}\text { Cuc Phuong Nature Reserve, Ninh binh } \\
\text { Province, Vietnam (Golovatch 1984). }\end{array}$ \\
\hline 20 & $\begin{array}{l}\text { Tylopus haplorugosus Golovatch \& Enghoff, } \\
1993\end{array}$ & $\begin{array}{l}\text { Doi Inthanon National Park, Chiang Mai } \\
\text { Province, Thailand (Golovatch \& Enghoff } \\
\text { 1993, Likhitrakarn et al. 2010). }\end{array}$ \\
\hline 21 & Tylopus hilaris (Attems, 1937) & $\begin{array}{l}\text { Bana, Danang Province (Attems 1937); } \\
\text { Bach Ma National Park, Thua Thien Hue } \\
\text { Province; Ngoc Linh Mountain, Kon Tum } \\
\text { Province, Vietnam (Nguyen 2012). }\end{array}$ \\
\hline 22 & Tylopus hilaroides Golovatch, 1984 & $\begin{array}{l}\text { Cuc Phuong Nature Reserve Ninh binh } \\
\text { Province (Golovatch 1984); Cuc Phuong } \\
\text { National Park, Ninh Binh Province, } \\
\text { Vietnam (Nguyen 2012). }\end{array}$ \\
\hline 23 & Tylopus hoffmani Golovatch \& Enghoff, 1993 & $\begin{array}{l}\text { Doi Suthep National Park, Chiang Mai } \\
\text { Province, Thailand (Golovatch \& Enghoff } \\
\text { 1993). }\end{array}$ \\
\hline 24 & Tylopus hongkhraiensis sp. nov. & $\begin{array}{l}\text { Huai Hong Khrai Royal Development } \\
\text { Study Centre, Chiang Mai Province, } \\
\text { Thailand (see above) }\end{array}$ \\
\hline 25 & Tylopus jeekeli Golovatch \& Enghoff, 1993 & $\begin{array}{l}\text { Doi Inthanon National park (Golovatch \& } \\
\text { Enghoff 1993); Doi Suthep National Park, } \\
\text { Chiang Mai Province, Thailand (Golovatch } \\
\text { \& Enghoff 1993; Likhitrakarn et al. 2010). }\end{array}$ \\
\hline 26 & Tylopus kabaki Golovatch, 2014 & $\begin{array}{l}\text { Dêqên, Yunnan Province, China (Golovatch } \\
\text { 2014). }\end{array}$ \\
\hline 27 & Tylopus maculatus Golovatch, 1984 & $\begin{array}{l}\text { Oquyho, Lao cai Province, Vietnam } \\
\text { (Golovatch 1984). }\end{array}$ \\
\hline 28 & Tylopus magicus Golovatch, 1984 & $\begin{array}{l}\text { Oquyho, Lao cai Province, Vietnam } \\
\text { (Golovatch 1984). }\end{array}$ \\
\hline 29 & Tylopus moniliformis sp. nov. & $\begin{array}{l}\text { Tad Fane Waterfall, Champasak Province, } \\
\text { Laos (see above) }\end{array}$ \\
\hline 30 & Tylopus mutilatus (Attems, 1953) & $\begin{array}{l}\text { Langbiang mountain, Lam Dong Province, } \\
\text { Vietnam (Attems 1953). }\end{array}$ \\
\hline
\end{tabular}




\begin{tabular}{|c|c|c|}
\hline No. & Species & Localities \\
\hline 31 & Tylopus nodulipes (Attems, 1953) & $\begin{array}{l}\text { Luang Prabang, Laos; Mt Fan-Si-Pan } \\
\text { (Attems 1953); Nam Xay commune, Lao } \\
\text { Cai Province; Son Tay commune, Ha Tinh } \\
\text { Province; Pu Mat National Park, Nghe An } \\
\text { Province, Vietnam (Nguyen 2012). }\end{array}$ \\
\hline 32 & Tylopus pallidus Golovatch \& Enghoff, 1993 & $\begin{array}{l}\text { Doi Pha Hom Pok, Chiang Mai Province, } \\
\text { Thailand (Golovatch \& Enghoff 1993). }\end{array}$ \\
\hline 33 & $\begin{array}{l}\text { Tylopus parahilaroides Likhitrakarn, Golovatch } \\
\text { \& Panha, } 2014\end{array}$ & $\begin{array}{l}\text { Phuluang Wildlife Sanctuary, Phuluang } \\
\text { District, Loei Province, Thailand } \\
\text { (Likhitrakarn } \text { et al. 2014a). }\end{array}$ \\
\hline 34 & $\begin{array}{l}\text { Tylopus parajeekeli Likhitrakarn, Golovatch, } \\
\text { Prateepasen \& Panha, } 2010\end{array}$ & $\begin{array}{l}\text { Doi Inthanon National Park, Chiang Mai } \\
\text { Province, Thailand (Likhitrakarn et al. 2010). }\end{array}$ \\
\hline 35 & Tylopus perarmatus Hoffman, 1973 & $\begin{array}{l}\text { Doi Suthep National Park (Hoffman 1973; } \\
\text { Golovatch \& Enghoff 1993); Doi Inthanon } \\
\text { National Park (Golovatch \& Enghoff 1993; } \\
\text { Likhitrakarn et al. 2010); Doi Chiang Dao } \\
\text { (Golovatch \& Enghoff 1993); Doi Phatang, } \\
\text { Chiang Mai Province (Likhitrakarn et } \\
\text { al. 2010); Ban Huai Kaeo (Golovatch \& } \\
\text { Enghoff 1993); Thum Pha Thai, Lampang } \\
\text { Province; Ban Pang Rim Kon; Phucheefah; } \\
\text { Doi Pha Tang, Chiang Rai Province; Nam } \\
\text { Min Waterfall, Phayao Province; Tham } \\
\text { Pha Nang Khoi, Phrae Province;Ton } \\
\text { Tong Waterfall, Nan Province, Thailand } \\
\text { (Likhitrakarn et al. 2010). }\end{array}$ \\
\hline 36 & Tylopus perplexus Golovatch \& Enghoff, 1993 & $\begin{array}{l}\text { Doi Pha Hom Pok, Chiang Mai Province, } \\
\text { Thailand (Golovatch \& Enghoff 1993). }\end{array}$ \\
\hline 37 & Tylopus phanluongi Nguyen, 2012 & $\begin{array}{l}\text { Ngoc Linh Mountain, Kon Tun Province, } \\
\text { Vietnam (Nguyen 2012). }\end{array}$ \\
\hline 38 & $\begin{array}{l}\text { Tylopus poolpermorum Golovatch \& Enghoff, } \\
1993\end{array}$ & $\begin{array}{l}\text { Doi Pha Hom Pok, Chiang Mai Province, } \\
\text { Thailand (Golovatch \& Enghoff 1993). }\end{array}$ \\
\hline 39 & Tylopus procurvus Golovatch, 1984 & $\begin{array}{l}\text { Oquyho (Golovatch 1984); Hoang Lien } \\
\text { National Park, Lao cai Province, Vietnam } \\
\text { (Nguyen 2012). }\end{array}$ \\
\hline 40 & Tylopus prosperus Golovatch \& Enghoff, 1993 & $\begin{array}{l}\text { Doi Inthanon National Park, Chiang Mai } \\
\text { Province, Thailand (Golovatch \& Enghoff } \\
\text { 1993; Likhitrakarn et al. 2010). }\end{array}$ \\
\hline 41 & Tylopus pulvinipes Golovatch \& Enghoff, 1993 & $\begin{array}{l}\text { Phu Kheio, Chaiyaphum Province, Thailand } \\
\text { (Golovatch \& Enghoff 1993). }\end{array}$ \\
\hline 42 & Tylopus punctus sp. nov. & $\begin{array}{l}\text { Mintaingbin Forest Camp, Chan State, } \\
\text { Myanmar (see above). }\end{array}$ \\
\hline 43 & Tylopus reductus Golovatch, 2013 & $\begin{array}{l}\text { Gaoligong Shan Mountain, Yunnan } \\
\text { Province, China (Golovatch 2013). }\end{array}$ \\
\hline 44 & Tylopus retusus sp. nov. & $\begin{array}{l}\text { Xay city, Oudomxai Province, Laos (see } \\
\text { below). }\end{array}$ \\
\hline 45 & Tylopus roseiparaterga Nguyen, 2012 & $\begin{array}{l}\text { Tam Dao National Park, Vinh Phuc } \\
\text { Province, Vietnam (Nguyen 2012). }\end{array}$ \\
\hline
\end{tabular}




\begin{tabular}{|c|c|c|}
\hline No. & Species & Localities \\
\hline 46 & Tylopus rugosus Golovatch \& Enghoff, 1993 & $\begin{array}{l}\text { Chiang Dao (Golovatch \& Enghoff, 1993); } \\
\text { Buathong Waterfall forest park, Chiang } \\
\text { Mai Province, Thailand (Likhitrakarn et al. } \\
\text { 2010). }\end{array}$ \\
\hline 47 & Tylopus sapaensis Nguyen, 2012 & $\begin{array}{l}\text { Hoang Lien National Park, Lao Cai } \\
\text { Province, Vietnam (Nguyen 2012). }\end{array}$ \\
\hline 48 & Tylopus schawalleri Golovatch, 2013 & $\begin{array}{l}\text { Diancang Shan Mountain, Yunnan Province, } \\
\text { China (Golovatch 2013). } \\
\end{array}$ \\
\hline 49 & Tylopus semirugosus Golovatch \& Enghoff, 1993 & $\begin{array}{l}\text { Ban Mussoe, Mae Sot District, Tak } \\
\text { Province, Thailand (Golovatch \& Enghoff } \\
\text { 1993). }\end{array}$ \\
\hline 50 & Tylopus sigma (Attems, 1953) & $\begin{array}{l}\text { Sapa, Lao Cai Province, Vietnam (Attems } \\
\text { 1953). }\end{array}$ \\
\hline 51 & Tylopus silvestris (Pocock, 1895) & village of Thao, Myanmar (Pocock 1895). \\
\hline 52 & $\begin{array}{l}\text { Tylopus similirugosus Golovatch \& Enghoff, } \\
1993\end{array}$ & $\begin{array}{l}\text { Doi Suthep National Park, Chiang Mai } \\
\text { Province, Thailand (Golovatch \& Enghoff } \\
\text { 1993). }\end{array}$ \\
\hline 53 & Tylopus similis Golovatch, 2014 & $\begin{array}{l}\text { Between Lijiang and Shangrila, Yunnan } \\
\text { Province, China (Golovatch 2014). }\end{array}$ \\
\hline 54 & Tylopus sinensis Golovatch, 1995 & $\begin{array}{l}\text { Mengzi County, Yunnan Province, China } \\
\text { (Golovatch 1995). }\end{array}$ \\
\hline 55 & Tylopus spinisterna Nguyen, 2012 & $\begin{array}{l}\text { Bi Doup-Nui Ba National Park, Lam Dong } \\
\text { Province, Vietnam (Nguyen 2012). }\end{array}$ \\
\hline 56 & $\begin{array}{l}\text { Tylopus strongylosomoides (Korsós \& } \\
\text { Golovatch, 1989) }\end{array}$ & $\begin{array}{l}\text { Tam Dao National Park, Vinh Phu Province } \\
\text { (Korsós \& Golovatch 1989); Xuan Son } \\
\text { national Park, Phu Tho Province, Vietnam } \\
\text { (Nguyen 2012). }\end{array}$ \\
\hline 57 & $\begin{array}{l}\text { Tylopus subcoriaceus Golovatch \& Enghoff, } \\
1993\end{array}$ & $\begin{array}{l}\text { Doi Suthep National Park, Chiang Mai } \\
\text { Province, Thailand (Golovatch \& Enghoff } \\
\text { 1993). }\end{array}$ \\
\hline 58 & Tylopus tamdaoensis Korsós \& Golovatch, 1989 & $\begin{array}{l}\text { Tam Dao National Park, Vinh Phu Province, } \\
\text { Vietnam (Korsós \& Golovatch 1989; } \\
\text { Nguyen 2012). }\end{array}$ \\
\hline 59 & Tylopus thunghaihin sp. nov. & $\begin{array}{l}\text { Plain of Jars, Xieng Khouang Province, } \\
\text { Laos (see above). }\end{array}$ \\
\hline 60 & Tylopus topali Golovatch, 1984 & $\begin{array}{l}\text { Cuc Phuong Nature Reserve, Ninh binh } \\
\text { Province (Golovatch 1984; Nguyen 2012); } \\
\text { Xuan Son National Park, Phu Tho Province, } \\
\text { Vietnam (Nguyen 2012). }\end{array}$ \\
\hline 61 & $\begin{array}{l}\text { Tylopus trigonum Likhitrakarn, Golovatch \& } \\
\text { Panha, } 2014\end{array}$ & $\begin{array}{l}\text { Pa Wai waterfall, Tak Province, Thailand } \\
\text { (Likhitrakarn et al. 2014a). }\end{array}$ \\
\hline 62 & $\begin{array}{l}\text { Tylopus veliger Likhitrakarn, Golovatch, } \\
\text { Prateepasen \& Panha, } 2010\end{array}$ & $\begin{array}{l}\text { Ton Tong Waterfall, Nan Province, Thailand } \\
\text { (Likhitrakarn et al. 2010). }\end{array}$ \\
\hline
\end{tabular}


Key to the known species of Tylopus (based chiefly on ${ }^{\Uparrow}$ ), modified after Likhitrakarn et al. (2010):

1. Most of $\hat{\delta}$ prefemora evidently swollen laterally (Figs $13 \mathrm{C}, 24 \mathrm{C}$ ) ..........................

- All $\delta$ prefemora normal, not bulged laterally (Figs 2G, 11F, G, 17E-G, 19C) ..........29

2. Surface of metaterga virtually smooth, at best extremely faintly rugulose in certain places and/ or with a few barely traceable (setigerous) tubercles near caudal margin (setae mostly broken off) (Figs 7B, D, 12A-B, D, 21A, C) ........................................................

- Surface of metaterga mostly rugulose to coarsely rugose/tuberculate (Figs 18A-B, D, 23B, D)

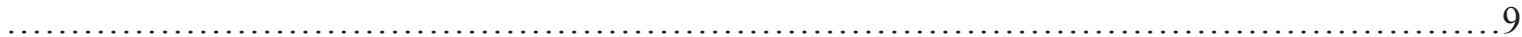

3. Paraterga moderately developed (Figs $1 \mathrm{~A}, \mathrm{C}, 21 \mathrm{~A}, \mathrm{C}$ ), ratio of $\hat{\mathrm{O}}$ midbody prozonite to metazonite width below 1:1.2

- Paraterga relatively well-developed (Figs 10B, D, 11B, D, 18B, D), radio of $\sigma^{\lambda}$ midbody prozonite to metazonite width over $1: 1.2$

4. Transverse sulcus on metaterga starting with segment 5. Calluses without incisions. Gonopod with process hsmallanddentiform. Thailand ..................... prosperusGolovatch\&Enghoff, 1993

- Transverse sulcus on metaterga starting with segment 4. Calluses with faint one or two denticles on poreless and poriferous paraterga, respectively. Gonopod very simple, without processes. Southern China ....................................................T. reductus Golovatch, 2013

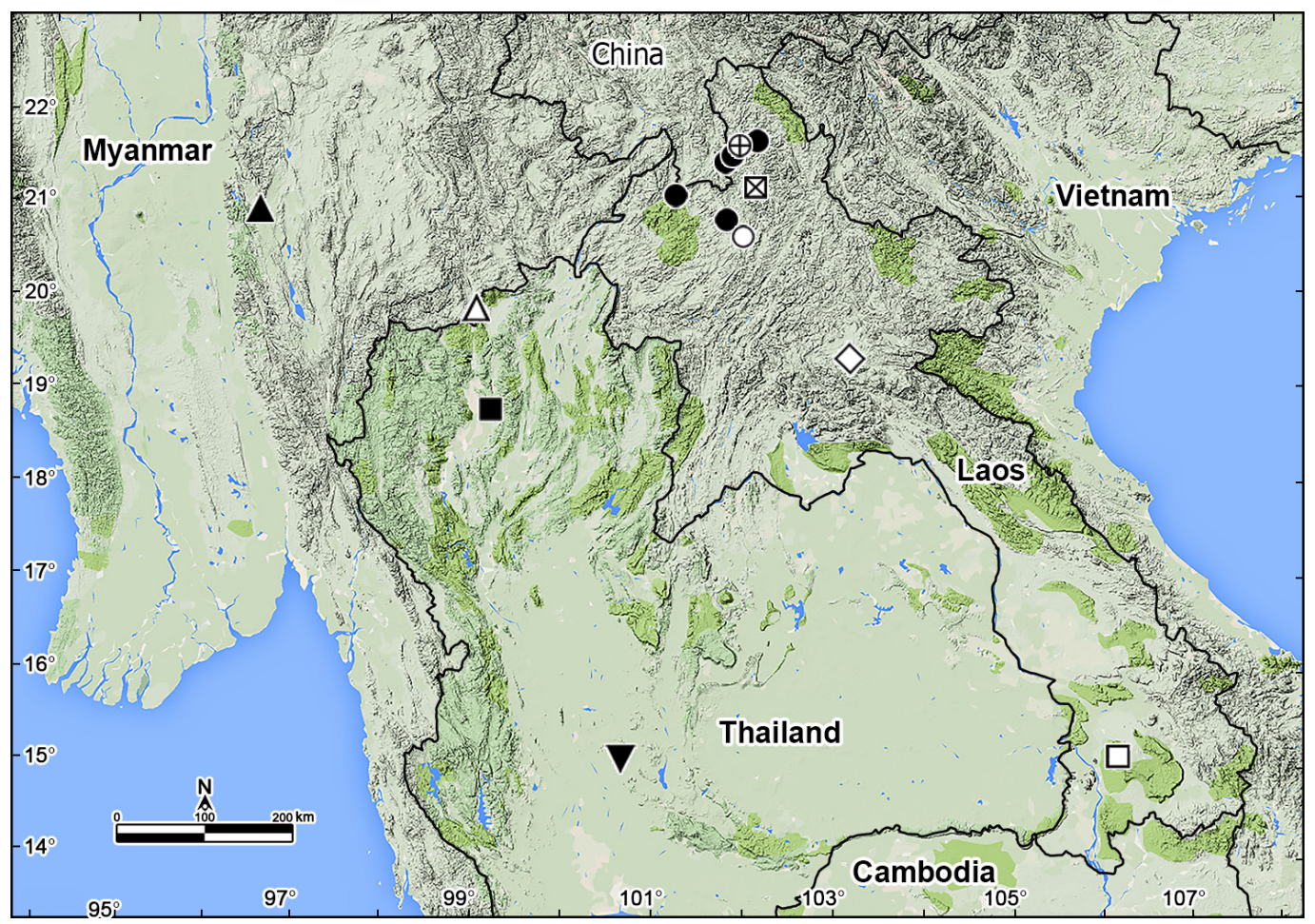

Fig. 26. Distribution of the new eight species of Tylopus. Filled triangle. T. punctus sp. nov. Filled circle. T. acuminatus sp. nov. Crossed circle. T. acuminatus sp. nov., T. dorsalis sp. nov. Crossed square. T. acuminatus sp. nov. T. retusus sp. nov. Open circle. T. retusus sp. nov. Open triangle. T. baenzigeri Golovatch \& Enghoff, 1993. Filled square. T. hongkhraiensis sp. nov. Open diamond. T. thunghaihin sp. nov. Inverted filled triangle. T. flavolineatus sp. nov. Open square. T. moniliformis sp. nov. 
5. Calluses without incisions. Gonopod postfemoral lobe $\mathbf{I}$ much broader than long; area basal to $\mathbf{I}$ delimited by a distinct cingulum ...................................................... 6

- Calluses mostly with 1-2 incisions. Gonopod postfemoral lobe $\mathbf{I}$ either as long as broad or longer; no cingulum basal to $\mathbf{I}$

6. Body smaller: length up to ca $19-30 \mathrm{~mm}$. Gonopod with a broadly coiled solenophore and a small finger-shaped process on lobe $\mathbf{l}$. China

T. kabaki Golovatch, 2014

- Body larger: length ca 33-35 mm. Gonopod with a slender and coiled solenophore, but without processes on lobe $\mathbf{l}$. Vietnam ....

T. magicus Golovatch, 1984

7. Metaterga at best only very faintly rugulose near stricture, near sulcus and/or at base of paraterga, with 2-3 weak, oblong tubercles near rear margin. ô postfemora and tibiae tuberculiferous. Gonopods with process $\mathbf{z}$ serrate, with 3 spines. Thailand . T. similirugosus Golovatch \& Enghoff, 1993

- Metatergal surface entirely smooth, polished, without tubercles. $\widehat{\partial}$ legs without adenostyles (= tubercles). Gonopods with process $\mathbf{z}$ pointed, without spines .8

8. Midline wanting. Gonopods with process $\mathbf{h}$ without additional tooth, while process $\mathbf{z}$ very high. Vietnam .................................................T. mutilatus (Attems, 1953)

- Midline mostly traceable on prozonae and anterior halves of metaterga. Gonopods with process $\mathbf{h}$ higher with an evident dorsal tooth, while process $\mathbf{z}$ small (Figs 13A-B, 14-15). Laos

T. acuminatus sp. nov.

9. Body larger: $37-42 \mathrm{~mm}$ long, $2.8-3.8$ and $4.1-5.0 \mathrm{~mm}$ wide on pro- and metaterga, respectively ......

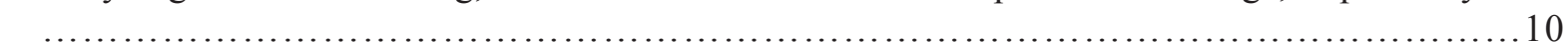

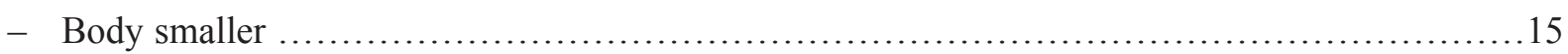

10. Sterna between $\hat{\sigma}$ coxae 4 with a pair of separated cones. Gonopod with a short spiniform process $\mathbf{h}$, a basally only poorly delimited lobe $\mathbf{I}$ and a small lobe-shaped process $\mathbf{z}$. Thailand T. grandis Likhitrakarn, Golovatch, Prateepasen \& Panha, 2010

- Sterna between ${ }^{\lambda}$ coxae 4 with a slightly notched sternal lobe. Gonopod with a rather long process $\mathbf{h}$ carrying two branches, plus a basally evidently delimited lobe $\mathbf{I}$ and a large, serrated process $\mathbf{z}$. Vietnam

T. phanluongi Nguyen, 2012

11. Both processes $\mathbf{h}$ and $\mathbf{z}$ of gonopod spiniform. Thailand

T. bispinosus Likhitrakarn, Golovatch, Prateepasen \& Panha, 2010

- Gonopod otherwise

12. Gonopod process $\mathbf{h}$ subflagelliform, process $\mathbf{m}$ extremely long and prominent. Thailand

T. extremus Likhitrakarn, Golovatch, Prateepasen \& Panha, 2010

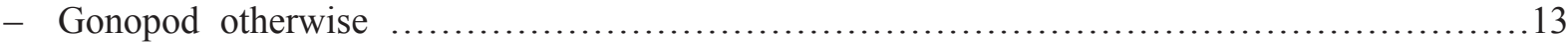

13. Gonopod process $\mathbf{h}$ prominent, spine $\mathbf{s}$ high, rather slender, curved, nearly pointed. Vietnam (Gopaensis Nguyen, 2012

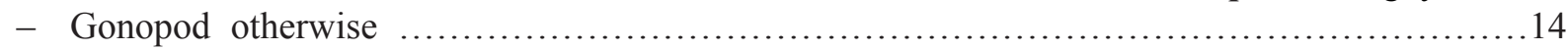

14. $\delta$ legs shorter, ca 1.2-1.3 times as long as midbody height. Gonopod lobe $\mathbf{I}$ velum-shaped and supplied with two denticles; spine $\mathbf{z}$ short and knife-shaped, while spine $\mathbf{h}$ rudimentary. Thailand

T. veliger Likhitrakarn, Golovatch, Prateepasen \& Panha, 2010

- ô legs longer, ca 1.6-1.7 times as long as midbody height. Gonopod spine z small, placed closer to base of spine h. Thailand ............ T. parajeekeli Likhitrakarn, Golovatch, Prateepasen \& Panha, 2010 
15. Most of metaterga with a pattern of $2+2$ and $2+2$ setigerous tubercles in two rows, rear row somewhat less strongly developed than fore one. Myanmar and Thailand ...T. doriae (Pocock, 1895)

- Most of metaterga with rear row of setigerous tubercles or wrinkles more strongly developed than

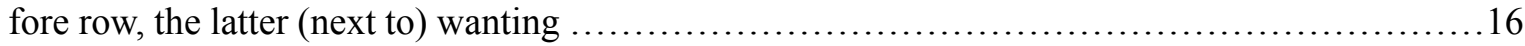

16. Transverse sulcus on metaterga starting with segment 4, either fully or almost fully developed there,

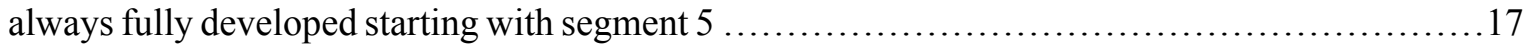

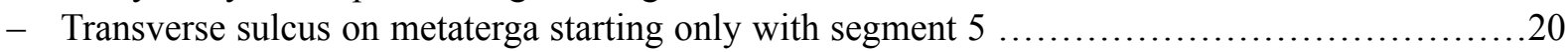

17. Transverse sulcus fully developed and reaching base of paraterga already starting with segment 4 . Gonopod tooth $\mathbf{z}$ at base of lobe $\mathbf{I}$ coarsely serrate along proximal margin. Vietnam

T. hilaris (Attems, 1937)

- Transverse sulcus fully developed only starting with segment 5. Gonopod tooth $\mathbf{z}$ either devoid of serration or serrate along distal margin ................................................... 18

18. Paraterga 2 rather broadly rounded caudolaterally. Gonopod relatively simple, process $\mathbf{h}$ poorly developed, no additional outgrowths near base. Thailand

T. affinis Golovatch \& Enghoff, 1993

- Paraterga 2 pointed caudally. Gonopods more complex

19. Coloration dark brown, without a cingulate pattern. Sternal lamina between $\hat{\sigma}$ coxae 4 low and distinctly bimodal. Gonopod tooth $\mathbf{z}$ prominent and serrate along distal margin. Thailand

T. rugosus Golovatch \& Enghoff, 1993

- Coloration pale, with a cingulate pattern. Sternal lamina between $\widehat{\jmath}$ coxae 4 high, subquadrate. Gonopod tooth $\mathrm{z}$ smaller and spiniform. Thailand .........T. semirugosus Golovatch \& Enghoff, 1993

20. Paratergal corner protruding caudad behind rear margin only starting with segment 15 , being obtuse-angled or subrectangular and lying more or less within the margin until segment 14 . Vietnam

T. hilaroides Golovatch, 1984

- Paratergal corner protruding caudad behind rear margin before segment 14 , mostly pointed ...21

21. Pattern of tergal setation on segments 18 and/or 19: $2+2$ and $5+5$ in two rows .............22

- Pattern of tergal setation at least on segments $5-19: 2+2$ and $4+4$ in two rows ..............25

22. Pattern of tergal setation $2+2$ and $5+5$ on both segments 18 and 19. Paraterga 2 pointed caudally. Epiproct with pre-apical incisions very close to apical knobs. Sternal lamina between $\partial$ coxae 4 an unusually low and even ridge. Adenostyles on midbody $\delta$ postfemora and, to a lesser extent, tibiae exceptionally prominent. Thailand ......T. poolpermorum Golovatch \& Enghoff, 1993

- Pattern of tergal setation $2+2$ and 5+5 on segment 19. Paraterga 2 more or less narrowly rounded. Pre-apical incisions on epiproct more strongly removed from tip. Sternal lamina between $\delta^{\lambda}$

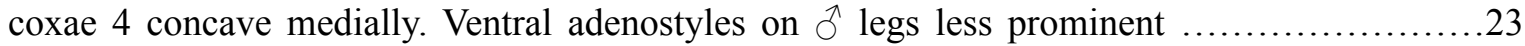

23. Body smaller: width ca $2.0 \mathrm{~mm}$. Sternal lamina between $\delta$ coxae 4 a pair of separated setigerous tubercles. Ventral adenostyles on $\overbrace{}^{\Uparrow}$ legs almost missing. Gonopods without any outgrowths near base of process $\mathbf{h}$. Thailand ............................ T. haplorugosus Golovatch \& Enghoff, 1993

- Body larger: width over $3.0 \mathrm{~mm}$. Sternal lamina between $\hat{\sigma}$ coxae 4 single. Ventral adenostyles on $\hat{\delta}$ legs more prominent. Gonopod with a spine near base of process $\mathbf{h}$

24. Sternal lamina between $\widehat{\partial}$ coxae 4 high, emarginated. Adenostyles on $\widehat{\delta}$ postfemora and tibiae well-developed. Gonopods rather simple, spine $\mathbf{z}$ inconspicuous. Thailand 
- Sternal lamina between $\widehat{\partial}$ coxae lower, slightly concave. Adenostyles on $\widehat{\partial}$ postfemora and tibiae less strongly developed. Gonopods more complex, spine z long and large. Thailand T. perarmatus Hoffman, 1973

25. Paraterga 2 pointed caudally. Sternal lamina between $\widehat{\jmath}$ coxae 4 exceptionally densely setose, low and concave ventrally. Gonopods with a medium-sized process $\mathbf{h}$ and a smaller lobular $\mathbf{z}$ at base of $\mathbf{h}$. Thailand

T. jeekeli Golovatch \& Enghoff, 1993

- Paraterga 2 more or less narrowly rounded caudally. Sternal lamina between $\sigma^{\lambda}$ coxae 4 higher and less strongly setose. Gonopod outgrowths $\mathbf{h}$ and $\mathbf{z}$ either almost wanting or very large ...26

26. Sternal lamina between $\delta$ coxae 4 with a straight ventral margin. Pleurosternal carinae poorly developed, in $\widehat{\partial}$ slightly drawn behind rear margin only until segments $8-10 \ldots \ldots \ldots \ldots \ldots \ldots . \ldots 27$

- Sternal lamina between $\hat{\sigma}$ coxae 4 slightly concave ventrally. Pleurosternal carinae better developed, in $\delta$ slightly drawn behind rear margin at least until segment $15 \ldots \ldots \ldots \ldots \ldots \ldots . \ldots 28$

27. Body smaller: width up to 3.1-3.2 mm. Mid-dorsal line very clear on both halves of metaterga. Gonopods relatively simple, with both $\mathbf{h}$ and $\mathbf{z}$ almost wanting. Thailand

T. hoffmani Golovatch \& Enghoff, 1993

- Body larger: width 4.0-5.3 mm. Mid-dorsal line not so well-developed at least on rear halves of metaterga. Gonopods more complex, with both $\mathbf{h}$ and $\mathbf{z}$ very conspicuous (Figs 24A-B, 25). Thailand T. baenzigeri Golovatch \& Enghoff, 1993

28. Metatergum 19 slightly rugulose posteriorly. Calluses on segment 2 with three, on following paraterga with two, incisions. Gonopods extremely complex, with numerous spiniform outgrowths. Thailand T. perplexus Golovatch \& Enghoff, 1993

- Metatergum 19 entirely smooth. Calluses with two or three incisions on poreless and poriferous paraterga, respectively. Gonopod less strongly differentiated. Thailand

T. amicus Golovatch \& Enghoff, 1993

29. Either most of $\widehat{\delta}$ sterna with an oblique tubercle or spine, or only anterior sterna with a small cone, near coxae

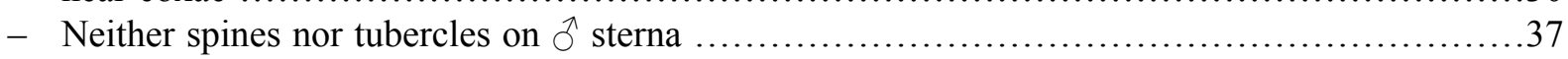

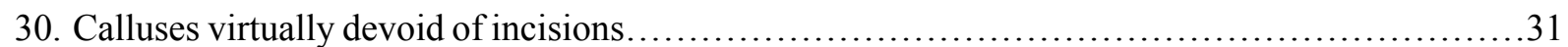

- Calluses always at least with one lateral incision .......................................... 32

31. $\widehat{\sigma}$ coxae 4 with a pair of separated cones. Gonopod process $\mathbf{h}$ small, while solenophore slender and short. China .................................................... sinensis Golovatch, 1995

- $\delta$ coxae 4 with an entire, subtrapeziform, sternal lobe. Gonopod process $\mathbf{h}$ larger, while solenophore stout and long. Vietnam

T. golovatchi Nguyen, 2012

32. A pair of small, fully separated, setose cones between $\delta$ coxae 4 (Fig. 10I-J). Gonopod with process $\mathbf{h}$ rather short, slightly flattened, blunt (Fig. 11A-D). Laos ........... T. retusus sp. nov.

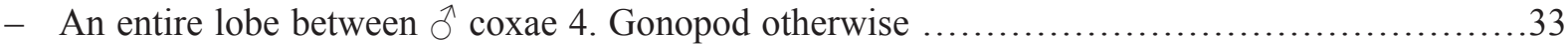

33. Metaterga strongly rugose/tuberculate/granulate (Fig. 18A-F, H) ............................

- Metaterga entirely smooth and polished, devoid of evident tubercles, at best extremely faintly rugulose near transverse sulcus (Fig. 1A-F) 
34. Calluses mostly with one lateral, clear incision. Pleurosternal carinae missing after segment 17. Gonopod processes $\mathbf{h}, \mathbf{z}, \mathbf{m}$ and spine $\mathbf{x}$ present (Fig. 19A-B). Laos ...T. thunghaihin sp. nov.

- Calluses with two lateral setigerous incisions. Pleurosternal carinae missing after segment 12. Only gonopod process $\mathbf{h}$ present. Vietnam ........................T. spinisterna Nguyen, 2012

35. Only rear sternum on most of $\hat{\partial}$ segments with a pair of small spines. Metaterga mostly with $2+2$ and $3+3$ setigerous tubercles in two transverse rows. Pleurosternal carinae missing after segment 9. Myanmar

T. silvestris (Pocock, 1895)

- Fore and rear sterna of most of $\widehat{\partial}$ segments with a pair of small tubercles and spines, respectively. Pleurosternal carinae present until segment 18 ....

36. Metaterga with four transverse rows of very small setigerous tubercles or setae. $\widehat{\delta}$ tarsal brushes present until leg 6 . 0 femora 5 with a very strong, distoventral, densely pilose adenostyle (Fig. 2F). Gonopod process $\mathbf{h}$ higher and pointed (Fig. 2A-D). (Fig. 26). Thailand ...... T. flavolineatus sp. nov.

- Metaterga with two transverse rows of small tubercles or spines, respevtively 0 tarsal brushes missing. $\delta$ legs normal. Gonopod process $\mathbf{h}$ very small. Vietnam ..............T. maculatus Golovatch, 1984

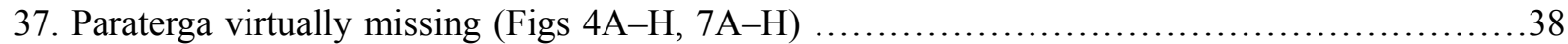

- Paraterga well- or strongly developed (Figs 1A, C, 10B, D, 12B, D, 16B, D, 18B, D, 23B, D) ...39

38. Antennae shorter (Fig. 4A), drawn behind only body segment 2 when stretched dorsally. A small, rounded, densely setose, sternal cone between $\widehat{\partial}$ coxae 4 (Fig. 4I-J). Goponod process $\mathbf{h}$ prominent, while process $\mathbf{z}$ long and rather slender (Figs 5-6). Thailand .........T. hongkhraiensis sp. nov.

- Antennae longer (Fig. 7A), reaching behind body segment 3. An entire, high, inverted funnel-shaped, sternal lobe between each of $\widehat{\partial}$ coxae 3 and 4 (Fig. 7I-J). Goponod without processes (Figs 8-9). Laos

T. moniliformis sp. nov.

39. Metaterga entirely smooth and polished, devoid of evident tubercles, at best extremely faintly rugulose near transverse sulcus

- Metaterga rather clearly rugose/tuberculate/granulate, posterior row of setae at least partly borne on tubercles

40. Transverse sulcus on metaterga starting with segment 3 or 4 , but fully developed and reaching bases of paraterga starting with segment 4 or 5 . Gonopod process $\mathbf{h}$ large (Fig. 17A-D) ........41

- Transverse sulcus on metaterga starting only with segment 5. Gonopod process $\mathbf{h}$ small (Fig. 22) ...44

41. Gonopod with a distinct sharp process on lobe I. Ventral adenostyles on $\widehat{\partial}$ legs absent. Southern China T. similis Golovatch, 2014

- Gonopod without processes on lobe $\mathbf{1}$. Ventral adenostyles on $\widehat{\delta}$ legs: a distal knob on femur, a distomedial knob on postfemur, and a parabasal knob on both tibia and tarsus .42

42. Head wider than collum and subequal in width to segment 3. Gonopod process $\mathbf{h}$ at about midlength with a strong ventral outgrowth, while solenophore without processes. Vietnam .........

T. procurvus Golovatch, 1984

- Head narrower than collum. Gonopod process $\mathbf{h}$ without outgrowths, while process $\mathbf{x}$ present on solenophore

43. Antennae shorter (Fig. 16A), extending only behind body segment 2 when stretched dorsally. 0 tarsal brushes present until segment 6 . Gonopod process $\mathbf{x}$ longer, the latter's tip rounded dorsally (Fig. 17A-D). Laos

T. dorsalis sp. nov. 
- Antennae longer, reaching until body segment 5. ô tarsal brushes present on all segments. Gonopod process $\mathbf{x}$ shorter, its tip pointed. Vietnam ........................T. crassipes Golovatch, 1984

44. Small species: width $1.6 \mathrm{~mm}$. Only a single row of $2+2$ tergal setae. Metaterga entirely smooth. Adenostyles on $\delta$ legs present. Vietnam ............................... T. sigma (Attems, 1953)

- Body wider than $2.0 \mathrm{~mm}$. Metaterga with two transverse rows of setae or traceable insertion points. Metaterga very finely rugulose only near transverse sulcus. Adenostyles on $\widehat{\delta}$ legs absent or represented by pads in their stead

45. Paraterga broader: $3.1 \mathrm{~mm}$ wide. Pleurosternal carinae present until segment 13 or 14. Pads present on $\delta$ femora, postfemora, tibiae (all distally) and tarsi (almost entirely). Thailand

T. pulvinipes Golovatch \& Enghoff, 1993

- Paraterga narrower: 2.1-2.5 mm wide. Pleurosternal carinae present until segment 17. $\delta$ legs without pads. Myanmar

T. punctus sp. nov.

46. Metatergal surface polished and smooth except for two rows of conspicuous tubercles .47

- Metaterga at least partly rugulose/rugose to granular; at most one row of tubercles

47. $\widehat{\gamma}$ legs without adenostyles (= tubercles). Gonopods with process $\mathbf{h}$ higher than solenophore, strongly twisted, pointed apically. Southern China ................T. schawalleri Golovatch, 2013

- $\widehat{\partial}$ legs with adenostyles (= tubercles) at least on segment 6 . Gonopods otherwise. Vietnam ...48

48. Paraterga very poorly developed, rounded, low, projecting slightly behind rear margin like small knobs only on segments 18 and 19. Calluses virtually devoid of incisions. Transverse sulcus on metaterga poorly developed, starting already with segment 2 , although fully developed only starting with segment 5 . A paramedian pair of denticles between $\widehat{\partial}$ coxae 5 behind a prominent, subquadrate lamina between $\hat{\sigma}$ coxae 4 . Gonopod process $\mathbf{h}$ entirely missing. Thailand T. strongylosomoides (Korsós \& Golovatch, 1989)

- Paraterga better developed, protruding behind rear margin at least starting with segment 5. Calluses always at least with one lateral incision. Transverse sulcus starting only with segments 3-5. Dentiform tubercles between $\hat{\sigma}$ coxae 5 missing. Gonopod process $\mathbf{h}$ invariably present

49. Body larger: more than $25 \mathrm{~mm}$ long. $\widehat{\partial}$ tarsal brushes not present on all legs. Gonopod lobe Inormal ...50

- Body smaller: less than $18 \mathrm{~mm}$ long. $\widehat{\sigma}$ tarsal brushes present on all legs. Gonopod lobe $\mathbf{I}$ with a spine apically .

50. $\delta$ tarsal brushes present on legs 1-15. Pleurosternal carinae present until segment 9. Gonopod process $\mathbf{h}$ larger, finger-shaped. Vietnam .....................T. roseiparaterga Nguyen, 2012

- $\hat{o}$ tarsal brushes present on legs 5-30. Pleurosternal carinae present until segment 17. Gonopod process $\mathbf{h}$ small, slender and pointed. Southern China T. deharvengi Liu \& Luo, 2013

51. Paraterga acutangular caudally and pointed beak-like already starting with collum. Tergal setigerous tubercles: $3+3$ and $5+5$ on segments 16-19. Adenostyle pattern on $\widehat{\jmath}$ legs: a distal knob on femora and a parabasal knob on most of postfemora, tibiae and tarsi. Gonopod process $\mathbf{h}$ large, lamellar and sigmoid. Vietnam ......................................... granulatus Golovatch, 1984

- Paraterga acutangular caudally and pointed beak-like only starting with segment $4.2+2$ and 4+4 tergal setigerous tubercles on segments 16-19. Adenostyle pattern on $\widehat{\sigma}$ legs: a proximal fingershaped tubercle crowned with a bunch of setae only on femora 6,8 and 9 . Gonopod process $\mathbf{h}$ smaller, spiniform. Vietnam

T. topali Golovatch, 1984 
52. Transverse sulcus on metaterga starting and fully developed only with segment 5. Ventral adenostyles present on all $\hat{\delta}$ podomeres except coxa. Vietnam and/or Laos .............53

- Transverse sulcus on metaterga starting with segment 4, but fully developed only starting with segment 5. Ventral tubercles only on some of $\delta$ telopoditomeres. Thailand .................54

53. Metaterga rugulose also in front of transverse sulcus, at rear margin with several oblong tubercles. Sternal lamina between $\widehat{O}$ coxae 4 a pair of setigerous knobs. Neither gonopod lobe $\mathbf{m}$ nor lobe $\mathbf{I}$ spinigerous. Vietnam ..................................T. tamdaoensis Korsós \& Golovatch, 1989

- Metaterga rugose only behind transverse sulcus, without evident tubercles at rear margin. Sternal lamina between $\hat{o}$ coxae 4 single. Both gonopod lobe $\mathbf{m}$ and lobe $\mathbf{I}$ crowned with a spine. Laos and Vietnam

T. nodulipes (Attems, 1953)

54. Metaterga modestly rugulose only near transverse sulcus, posteriorly neither granular nor microtuberculate. Calluses broad. Gonopod process $\mathbf{h}$ simple, high, never particularly coiled; lobe $\mathbf{I}$

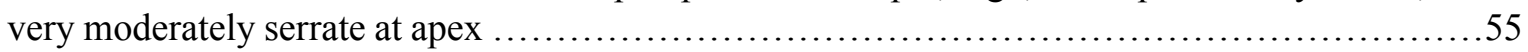

- Metaterga distinctly rugose-granular/microtuberculate even on fore halves. Calluses narrow. Gonopod process $\mathbf{h}$ better developed and more strongly coiled; lobe $\mathbf{I}$ apically either bare or with

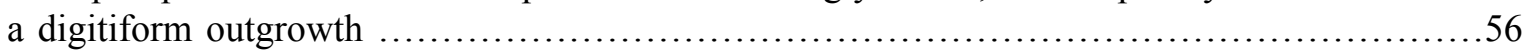

55. Caudal corner of paraterga pointed starting with segment 3. Pleurosternal carinae particularly well-developed, drawn behind rear margin until segment 16 or 17. Adenostyles often present on ot prefemora ..................................... degerboelae Golovatch \& Enghoff, 1993

- Caudal corners of paraterga mainly narrowly rounded, pointed only starting with segment 15 . Pleurosternal carinae less strongly developed ..................... T. pallidus Golovatch \& Enghoff, 1993

56. Coloration dark, brown. Sternal lamina between $\delta$ coxae 4 a pair of separated setigerous tubercles preceded by another pair of very small tubercles between coxae 3. Gonopod lobe $\mathbf{I}$ devoid of an apical process ........................................ asper Golovatch \& Enghoff, 1993

- Coloration uniformly pale. Sternal lamina between $\widehat{\gamma}$ coxae 4 single, not accompanied by additional tubercles in front or behind. Gonopod lobe $\mathbf{I}$ with a strong, apical, finger-shaped process ......57

57. Mostly $3+3$ tubercles at rear margin of metaterga. Sternal lamina between $\hat{\delta}$ coxae 4 distinctly emarginate. Larger adenostyles close to midlength on $\widehat{\delta}$ postfemora and tibiae, femora with a distal knob. Gonopod process $\mathbf{h}$ slenderer and shorter, apex of lobule $\mathbf{m}$ not developed into a spine T. subcoriaceus Golovatch \& Enghoff, 1993

- Mostly 4+4 tubercles at rear margin of metaterga. Sternal lamina between $\delta^{\lambda}$ coxae trapeziform. Larger adenostyles on both postfemora and tibiae more distal, femoral knob missing. Gonopod process $\mathbf{h}$ unusually prominent, with a hook at base; apex of lobule $\mathbf{m}$ spiniform ....

T. coriaceus Golovatch \& Enghoff, 1993

\section{Discussion}

At the moment, a total of 62 species of Tylopus are known from Indochina and the adjacent parts of southern China and Myanmar, including eight new species described above. Most of the species (31, or $>50 \%$ ) come from Thailand, followed by Vietnam (18), Laos (6), southern China (6) and Myanmar (3). Country endemism is close to $100 \%$, as only T. doriae and T. nodulipes have been recorded from two of the countries at once. There is little doubt, however, that the above outlined picture is still far from final.

Having collected millipedes throughout Thailand and Laos, we can state that most of the Tylopus species are quite rare and restricted in distribution, even though many occur sympatrically if not syntopically. 
Thus, the Doi Inthanon and Doi Suthep mountains, both in northern Thailand, support at least 10 congeners each (Likhitrakarn et al. 2014a). It seems that such sympatric assemblages are represented by a number of phenofaunas separated by certain time periods rather than a geographic distance. As a result, the adults of most of the known species have only been collected once and from a single locality, with repeated collecting success being rather an exception than a rule.

An additional factor to be considered, the one that only makes the picture even more complicated, lies in the fact that the bulk of Tylopus diversity appears to be confined to montane woodlands exceeding $500 \mathrm{~m}$ in elevation. This only exacerbates the situation as too many of such places are difficult to access and thus only contribute to the abundant lacunae to be covered by future collecting efforts. Given the highly mosaic, often relictual distribution of mountainous forests in the regions concerned, against the background of too numerous undercollected to completely unsampled mountainous areas across most of Indochina, as well as southern China and the East Indies, the real diversity of Tylopus can still be very generously termed as highly underestimated. Thus, during the past two decades, since the first large review of Tylopus which focused on the fauna of Thailand alone (see Golovatch \& Enghoff 1993), the number of described congeners known to occur in that country has nearly doubled, whereas the whole generic diversity tripled. Yet Cambodia remains a complete terra incognita in this respect (Likhitrakarn et al. 2015).

\section{Acknowledgements}

This project was partly funded through grants received from the Office of the Royal Development Projects Board (RDPB), while most of the financial support was obtained from The Thailand Research Fund, The TRF Senior Research Scholar RTA 5880002 (2015-2018) to SP. We thank the members of the Animal Systematics Research Unit for their invaluable assistance in the field.

\section{References}

Attems C. 1937. Myriopoda 3. Polydesmoidea I. Fam. Strongylosomidae. Das Tierreich 68: 1-300.

Attems C. 1953. Myriopoden von Indochina. Expedition von Dr. C. Dawydoff (1938-1939). Mémoires du Muséum national d'Histoire naturelle, N.S. 5A: 133-230.

Enghoff H. 2005. The millipedes of Thailand (Diplopoda). Steenstrupia 29 (1): 87-103.

Golovatch S.I. 1984. Contributions to the millipede fauna of Vietnam (Diplopoda) II. Acta Zoologica Hungarica 30: 53-77.

Golovatch S.I. 1995. On several new or poorly-known Oriental Paradoxosomatidae (Diplopoda Polydesmida), III. Arthropoda Selecta 4 (2): 89-97.

Golovatch S.I. 2013. On several new or poorly-known Oriental Paradoxosomatidae (Diplopoda: Polydesmida), XIII. Arthropoda Selecta 22 (1): 1-31.

Golovatch S.I. 2014. On several new or poorly-known Oriental Paradoxosomatidae (Diplopoda: Polydesmida), XV. Arthropoda Selecta 23 (1): 1-19.

Golovatch S.I. \& Enghoff H. 1993. Review of the millipede genus Tylopus, with descriptions of new species from Thailand (Diplopoda, Polydesmida, Paradoxosomatidae). Steenstrupia 19 (3): 85-125.

Hoffman R.L. 1973. Descriptions and allocations of new or poorly known genera and species of Paradoxosomatidae from south-eastern Asia (Diplopoda: Polydesmida). Journal of Natural History 7 (4): 361-389. http://dx.doi.org/10.1080/00222937300770281

Jeekel C.A.W. 1965. A revision of the Burmese Paradoxosomatidae (Diplopoda, Polydesmida) in the Museo Civico di Storia Naturale at Genoa (Part I). Tijdschrift voor Entomologie 108: 95-144. 
Jeekel C.A.W. 1968. On the classification and geographical distribution of the family Paradoxosomatidae (Diplopoda, Polydesmida). Academisch Proefschrift, Rotterdam.

Korsós Z. \& Golovatch S.I. 1989. Addenda to the millipede fauna of Vietnam (Diplopoda). Acta Zoologica Hungarica 35: 211-220.

Likhitrakarn N., Golovatch S.I. \& Panha S. 2014a. Three new species of the millipede genus Tylopus Jeekel, 1968 from Thailand, with additional notes on the species described by Attems (Diplopoda, Polydesmida, Paradoxosomatidae). ZooKeys 435: 63-91. http://dx.doi.org/10.3897/zookeys.435.8286

Likhitrakarn N., Golovatch S.I. \& Panha S. 2014b. Two new species of dragon millipedes, genus Desmoxytes Chamnerlin, 1923, from Laos (Diplopoda: Polydesmida: Paradoxosomatidae), with redescriptions of all four species of Attems from Vietnam. Zootaxa 3931 (4): 483-504. http://dx.doi. org/10.11646/zootaxa.3931.4.2

Likhitrakarn N., Golovatch S.I. \& Panha S. 2015. A checklist of the millipedes (Diplopoda) of Cambodia. Zootaxa 3973 (1): 175-184. http://dx.doi.org/10.11646/zootaxa.3973.1.7

Likhitrakarn N., Golovatch S.I., Prateepasen R. \& Panha S. 2010. Review of the genus Tylopus Jeekel, 1968, with descriptions of five new species from Thailand (Diplopoda, Polydesmida, Paradoxosomatidae). ZooKeys 72: 23-68. http://dx.doi.org/10.3897/zookeys.72.744

Liu W.X. \& Luo X.Z. 2013. A new species of the millipede genus Tylopus Jeekel from southern China (Diplopoda, Polydesmida, Paradoxosomatidae). Acta Zootaxonomica Sinica 38 (1): 50-52.

Nguyen A.D. 2012. Tylopus millipedes in Vietnam (Diplopoda: Polydesmida: Paradoxosomatidae: Sulciferini), with descriptions of five new species. Raffles Bulletin of Zoology 60 (2): 289-311.

Pocock R.I. 1895. Report upon the Chilopoda and Diplopoda obtained by P.W. Bassett-Smith, Esq., Surgeon R.N., and J.J. Walker, Esq., R.N., during the cruise in the Chinese Seas of H.M.S.'Penguin', Commander W. U. Moore commanding. Annals and Magazine of Natural History series 6, 15:346-368. http://biodiversitylibrary.org/page/19265532

Manuscript received: 30 November 2015

Manuscript accepted: 11 January 2016

Published on: 10 May 2016

Topic editor: Rudy Jocqué

Desk editor: Kristiaan Hoedemakers

Printed versions of all papers are also deposited in the libraries of the institutes that are members of the EJT consortium: Muséum national d'Histoire naturelle, Paris, France; Botanic Garden Meise, Belgium; Royal Museum for Central Africa, Tervuren, Belgium; Natural History Museum, London, United Kingdom; Royal Belgian Institute of Natural Sciences, Brussels, Belgium; Natural History Museum of Denmark, Copenhagen, Denmark. 